\title{
The development of spontaneous hypertension in rats
}

Citation for published version (APA):

Evenwel, R. T. (1982). The development of spontaneous hypertension in rats. [Doctoral Thesis, Maastricht University]. Rijksuniversiteit Limburg. https://doi.org/10.26481/dis.19820528re

Document status and date:

Published: 01/01/1982

DOI:

10.26481/dis.19820528re

Document Version:

Publisher's PDF, also known as Version of record

\section{Please check the document version of this publication:}

- A submitted manuscript is the version of the article upon submission and before peer-review. There can be important differences between the submitted version and the official published version of record.

People interested in the research are advised to contact the author for the final version of the publication, or visit the DOI to the publisher's website.

- The final author version and the galley proof are versions of the publication after peer review.

- The final published version features the final layout of the paper including the volume, issue and page numbers.

Link to publication

\footnotetext{
General rights rights.

- You may freely distribute the URL identifying the publication in the public portal. please follow below link for the End User Agreement:

www.umlib.nl/taverne-license

Take down policy

If you believe that this document breaches copyright please contact us at:

repository@maastrichtuniversity.nl

providing details and we will investigate your claim.
}

Copyright and moral rights for the publications made accessible in the public portal are retained by the authors and/or other copyright owners and it is a condition of accessing publications that users recognise and abide by the legal requirements associated with these

- Users may download and print one copy of any publication from the public portal for the purpose of private study or research.

- You may not further distribute the material or use it for any profit-making activity or commercial gain

If the publication is distributed under the terms of Article $25 \mathrm{fa}$ of the Dutch Copyright Act, indicated by the "Taverne" license above, 


\section{The development of spontaneous hypertension in rats}


Promotor: $\quad$ Prof.Dr. H.A.J. Struyker Boudier

Referenten: Prof.Dr.M.A.D.H. Schalekamp

Prof.Dr. K.H. Rahn 


\section{The development of spontaneous hypertension in rats}

Proefschrift ter verkrijging van de graad van doctor in de geneeskunde aan de Rijksuniversiteit Limburg te Maastricht op gezag van de rector magnificus Prot.Dr. H.C. Hemker.

Volgens besluit van het college van Dekanen in het openbaar te verdedigen op vrijdag 28 mei 1982, des namiddags te 16.00 uur in de aula van de universiteit.

door

Robert Tom Evenwel

geboren te Rotterdam 
Voor Cisca 


\section{Dankwoord (Acknowledgements)}

Geen proefschrift is compleet zonder een dankwoord aan ledereen die er aan meegewerkt heeft. Evenals vele andere proefschriften is ook dit proefschrift geenszins het werk van éen persoon.

Op de eerste plaats wil ik een speciaal woord van dank richten tot mijn promotor Prof. Dr. H.A.J. Struyker Boudier.

Beste Harry, zonder jouw niet aflatende steun en stimulatie zou dit proefschrift nooit tot stand gekomen zijn. Ondanks je drukke activiteiten, wist je altijd tijd vrij te maken om met mij van gedachten te wisselen en de verkregen resultaten in goede banen te leiden. Wat $\mathrm{ik}$ bijzonder in je waardeer, is, dat je op zeer kritieke momenten zelfs aan de practische uitwoering van de experimenten hebt meegedaan.

De beide referenten Prof. Dr. M.A.D.H. Schalekamp en Prof. Dr. K.H. Rahn wil ik bedanken voor de wijze, waarop zij belangstelling voor mijn proefschrift hebben getoond en het kritisch lezen van het manuscript.

Op het moment waarop de tijdsdruk zo groot geworden was, dat ik er aan twijfelde, of ik mijn proefschrift ooit af zou krijgen, heb ik de niet aflatende steun van Barbara Geers en mijn vrouw Cisca gehad, die tijdens de kerstvakantie hun vrije tijd hebben opgeofferd om het grootste gedeelte van dit manuscript uit te typen.

In die periode heb ik ook de steun ondervonden van Wim Buurman, die vele avonden heeft opgeofferd bij de voorbereiding van dit manuscript. Nelly Baltussen en Mia Hogenboom wil ik speciaal bedanken voor het geduld dat zij hebben opgebracht voor de vele malen dat het manuscript moest worden aangepast na het ontdekken van onvolledigheden.

Een aantal bepalingen in dit proefschrift zijn opgezet door Jos Smits, die ook altijd bereid was om bij technische moeilijkheden de helpende hand te bieden. De door Jos opgezette noradrenaline bepaling in dit proefschrift is volledig uitgevoerd door Lily Vervoort. Carina Kasbergen en Hellma van Essen hebben de vele operaties uitgevoerd die in dit proefschrift beschreven staan. Helma en Carina, ik wil jullie speciaal bedanken voor de overuren, die jullie gemaakt hebben.

Monique Fuss en Riet Damen hebben de meeste tekeningen gemaakt, die in dit proefschrift staan. Monique de Haes heeft de literatuurlijst van het eerste hoofdstuk verzorgd. Daarnaast heeft zij er samen met Marijke Berger voor gezorgd, dat de literatuuraanvragen met spoed behandeld werden.

Ook mensen van andere capaciteitsgroepen thebben aan dit proefschrift meegewerkt. Frits Prinzen heeft mij met microspheren leren werken en Wim Hermens en George Willems hebben mij vele goede ideeën aan de hand gedaan omtrent de extravasatie van eiwitten.

Tenslotte will ik nog een speciaal woord van dank tot Cisca richten. Cisca, ook jij hebt een zware periode achter de rug na het schrijven van dit proefschrift. Om mij de gelegenheid te geven in Maastricht te promoveren, heb iij vele zaken in Rotterdam moeten achterlaten. De vele dagen die je alleen 
gezeten hebt, kan Ik niet teruggeven, wel kan $1 k$ beloven, dat ik in de toekomst wat meer IIjd voor je zal vrijmaken. 



\section{Contents.}

\section{Chapter I}

Introduction

A. General introduction 14

B. Comparison of mechanisms involved in spontaneous

hypertension in the rat and essential hypertension in humans.

a. Genetic influences

b. Blood pressure development in the SHR

c. Hemodynamics

d. Fluid volumes

e. Renal factors

f. Baroreceptor reflex control 24

g. Hormonal factors 25

h. The sympathetic nervous system 25

1. The regulation of peripheral resistance 27

1. Relation of transcapillary escape rate (TER) to increased postarteriolar resistance and blood overperfusion in the microcirculation (an hypothesis)

k. The present thesis

\section{Chapter II}

Development of high blood pressure and its variability in rats with spontaneous hypertension.

Introduction $\quad 42$

Methods

Results

44

Discussion

\section{Chapter III}

Baroreflex sensitivity during the development of spontaneous hypertension in rats.

Methods

Results

Discussion

\section{Chapter IV}

Systemic and peripheral hemodynamics during the development of spontaneous hypertension in rats.

Materials and methods

Results 


\section{Chapter V}

Total plasma volume and its regional distribution

during the development of spontaneous hypertension in rats.

Introduction

Materials and methods

Results

Discussion

\section{Chapter VI}

Transcapillary escape rate and organ clearance of albumin

during the development of spontaneous hypertension in rats.

88

Introduction

88

Materials and methods

89

Results

90

Discussion

\section{Chapter VII}

Extracellular fluid volume in young and adult spontaneously

hypertensive rats.

102

Introduction

102

Materials and methods

103

Results

Discussion

\section{Chapter VIII}

Sympathetic activity in young and adult SHR and WKY.

Materials and methods

Results

Discussion

\section{Chapter IX}

Adaptations of the sympathetic nervous system and cardiovascular system to physical exercise during the development

of spontaneous hypertension in rats.

Introduction

Materials and methods

Results

Discussion

\section{Chapter X}

General discussion and summary.

Samenvatting (Summary) 


\section{Chapter I}

\section{Introduction}

\section{A. General introduction}

The history of the investigation of hypertension goes back to 1827 when Bright (17) described a patient with an enlarged left ventricle and atrophic kidneys. The link between these phenomena and the occurrence of high blood pressure was not made until the introduction of spygmomanometric measurement of blood pressure into clinical practice (112).

In the present time a considerable amount of research has led to the recognition of a large number of possible etiologic forms of hypertension (Table 1). In spite of this, a definite cause cannot be established in the majority of patients with hypertension; these cases are therefore designated as essential hypertension. The prevalence of essential hypertension has recently been reviewed by Danielson and Dammström (31). In their large group of 1000 patients with hypertension only $5 \%$ had secondary hypertension, whereas the remaining $95 \%$ were designated as having essential hypertension. In previous studies percentages varied from 70-95.

Investigation into the causes of essential hypertension is hampered by factors such as: the long time course in which hypertension develops and stabilizes, the variability between the patients and technical problems in the measurement of underlying hemodynamic and other mechanisms.

Animal models have been developed to facilitate the investigation of causes of hypertension.

One of the first attempts to develop such animal models was that of Tigerstedt (158) who injected kidney extract (renin) into a rabbit and observed increased blood pressure. These attempts were followed by others (e.g. Goldblatt with renal artery clipping (60), Hering (76) with sinoaortic denervation). Table 2 summarizes the major developments in this respect. An important disadvantage of these early, and of several later developed animal models, is the hormonal, toxic, surgical or psychological intervention to create hypertension, which limits their usage as models for essential hypertension.

This imperfection has led to the introduction of several genetic forms of hypertension in rats (Table 3). Nowadays the spontaneously hypertensive rat (121) of the Kyoto strain (SHR) has become generally available and is therefore the most widely used genetic rat model for human essential hypertension.

Despite the fact that some authors consider the SHR not as a suitable model for human studies (108), and though there are some differences between the SHR and humans with essential hypertension (e.g. the resistance of the SHR to atherosclerosis and their susceptibility to pulmonary diseases), the value of this animal model is now generally recognized on the basis of the manifold similarities between the hypertension of the SHR and human essential hypertension (159). 


\section{Table 1}

Chassiffication of hyportension by wology

A. Essenthal hypertunsion

E. Rienal

1. Parenchymal

Acute glomerulionephritis

Chronic nephrit is glomerulonephritis

pyetomephritis; heredity; lupus enythematosus

irradi:atton:

Polycystic kidney diserse

Hydronephrosis

Reiryin producing tumor

Diabet lic nephropathy (KKinmeil stiel-

Wilsony

2. Renovascular

Fibromtuscular arterial stenosis

Atherosiclerotic arterial stenosis

Renal infarctions

Polyarteritiss

3. Trauma

Peririental hematoma

Renal arter hal thrombosis

Renal arterial dissection

C. Endoctime

1. Thyrota

Hyperthyoidism

Hypothyroldism

2. Adrenial

Pheochromocyloma

Prilmary aldosteronism

Adenoma

Hyperpilasila

Glucocorticold suppressible

thyperaldosteronism

Congenitial adrenal hyperplasia

11. A Hydroxylation deficiency

17- Hydroxylation deticiancy

Cushing's diserase

3. Parathyroid

Hyperparathyroidism
D. Naurogentic

Respiratory acidosis (ciabon dioxyce retenton)

Brain tumor

Encophallts

Bulbar poliomyelitis

Familial dysintonomia

Acute porphyta

Quadriplegia "micurtitonal crisis"

Extraadrenal chromaffin tumors

Paragangliomas

Yon Rocklinghausen "s disuaso

E. Mechanical interterencie whith flow

AV fistulas (Paget's disease, patent ductus arteriosusid Aortic insulficiency

Coarctation of the aort

Atheroselerotic systolic hypertension

F. Exogenous

1. Poisoning

Lead

Thallium

2. Medication

Sympathetic amines

MAO Inhlbitor combined with ophedrine or tyramitne (including tyraminerich foods, cheese, red wine)

Birth control pills

Prednisone hiligh doses

3. Foond

Licorice Ingestion

4. latroganlo

Volume overioad in marginal renal insulficioncy

G. Toxemla of pregnancy

H. Miscellaneous

Polycythemla

Rubra vera

"Stress," Gaisbooks's syndrome

Burns

Carcinoid syndroming

After Julius: In hypertension: Physlopathology and treatment, E. Genest and O. Kuchel

Mc Graw Hill New York 1977 p.10. 


\section{Table 2}

\section{Experimental forms of hypertension}

Madel

A. Renall

B. Endocrine

C. Neurogenic author

Goldblatt (1934)

Goldblatt (1939)

Grollmann (1944)

Loomis (1946)

Tigerstedt (1898)

Selye (1943)

Kumar (1957)

Dickinson (1963)

Hering (1927)

Shipley (1945)

Forsyth (1971)

Reis (1973)

Borg (1978)
Induction factor

Reduction of renal flow by clipping the renal artery (60)

Partial occlusion of the aorta above the kidney (59)

Deformation of the normal shape of the kidney (ligature) (66)

Reduction of renal tissue (infarction) (101)

Injection of kidney extract (renin) (158)

Deoxy corticosterone + salt in drinking water (145)

Injection of aldosterone (92)

Injection of angiotensin (38)

Sino aortic denervation (76)

Stimulation of stellate ganglia and cardiac nerves (147)

Operant conditioning (50)

Brain stem lesion (n.tractus solitarii (39)

Life-Long exposure to noise (15) 


\section{Table 3}

\section{Experimental genetic hypertension in rats}

\begin{tabular}{|c|c|c|}
\hline Author & year of introduction & Accepted nomenclature * \\
\hline Smirk (150) & 1958 & $\begin{array}{l}\text { GH: Genetically hypertensive } \\
\text { strain }\end{array}$ \\
\hline \multirow[t]{2}{*}{$\operatorname{Dahl}(29,30)$} & 1962 & DR: Dahl Salt-resistant strain \\
\hline & & DS: Dahl Salt-sensitive strain \\
\hline \multirow[t]{2}{*}{ Okamoto (121) } & 1963 & $\begin{array}{l}\text { SHR: Spontaneously } \\
\text { hypertensive rat strain }\end{array}$ \\
\hline & & WKY: Wistar-Kyoto strain \\
\hline Yamori (168) & 1972 & $\begin{array}{l}\text { SHRSP: SHR-stroke prone } \\
\text { strain (Kyoto) }\end{array}$ \\
\hline \multirow[t]{2}{*}{ Bianchi (9) } & 1974 & $\begin{array}{l}\text { MHS: Milan hypertensive } \\
\text { strain }\end{array}$ \\
\hline & & $\begin{array}{l}\text { MNS: Milan normotensive } \\
\text { strain }\end{array}$ \\
\hline \multirow[t]{2}{*}{ Zamir $(170)$} & 1978 & $\begin{array}{l}\text { SBH: Sabra hypertensive } \\
\text { strain }\end{array}$ \\
\hline & & $\begin{array}{l}\text { SBN: Sabra normotensive } \\
\text { strain }\end{array}$ \\
\hline Denoroy (36) & & LH: Lyon hypertensive strain \\
\hline Vincent (163) & 1978 & LN: Lyon normotensive strain \\
\hline Renaud (129) & & $\begin{array}{l}\text { LL: Lyon Low blood pressure } \\
\text { strain }\end{array}$ \\
\hline
\end{tabular}

* Report of the nomenclature committee on hypertensive rat strains of the International Society of Hypertension after the Third International Symposium on Spontaneously Hypertensive Rat and related studies (Kyoto, Japan 13-15 september 1978) 
B. Comparison of mechanisms Involved in spontaneous hypertension in the rand assentlal hypertension in humans

\section{a. Genetlc Influences}

Essential hypertension is supposed to be a result of both environmental and genetic influences (110):

The latter influences have provoked a great deal of interest. In a recent symposium on genetic markers in essential hypertension an altered membrane transport of cations has been proposed as a general specific genetic marker for both SHR and patients with essential hypertension (110). Losse (101) was the first author who described an increased sodium concentration in the erythrocytes of patients with essential hypertension.

Several other studies have shown alterations in membrane ionic transport and related enzyme activity (Na-K-ATPase) both in rats with spontaneous hypertension $(53,54,127)$ and in individuals with essential hypertension $(57,58,128)$. Disturbances in $\mathrm{Na}^{+}$and $\mathrm{K}+$ fluxes have been found in individuals with essential hypertension, relatives of individuals with essential hypertension, but not in individuals with hypertension of renal origin or in normotensive individuals, which indicates that these membrane alterations are genetically transmitted and specific for essential hypertension (58). The similarity in the genetically determined membrane alterations in SHR and human essential hypertension strongly supports the usefullness of the SHR as an animal model for essential hypertension.

\section{b. Blood pressure development in the SHR}

In 1960 Okamoto started with selective brother-sister inbreeding of Wistar-rats with an elevated blood pressure. In 1969 this resulted in a strain of SHR (26th generation) in which the development of the hypertension occurred earllier and resulted in higher blood pressure values than in the first generations (120). In this strain the blood pressure was elevated in animals as young as 5 weeks. From 5-12 weeks blood pressure rose rapidly and systolic blood pressure stabilized at $12-15$ weeks $( \pm 200 \mathrm{mmHg}$ ). Similar results as to the development and stabilization of systolic blood pressure in the SHR are presented in chapter II of this thesis.

The exact onset of elevation of blood pressure in the SHR is a subject of controversy. Some authors belleve that the SHR is never normotensive in its life, since an increase in blood pressure has been reported at birth (19). Others reported a normal blood pressure in the first 3 weeks after birth and a rise in blood pressure thereafter (95). This discrepancy can be explained by differences in substrains of the SHR or differences in the techniques of blood pressure measurements in those studies (108). Similarly as in the SHR the onset of blood pressure rise is not known in patients with essential hypertension. Although primary hypertension has been reported in children $(80,137)$ no detailed long-term follow up-studies from onset of hypertension in children to stabilization of the hypertension in adulthood are as yet avallable (159). In adults it may take years before borderli18 
ne hypertension develops into essential hypertension (87).

Since in the SHR the development and stabilization of hypertension takes weeks rather than years, the usefullness of this genetic animal model in the investigation of primary hypertension is obvilous.

\section{c. Hemodynamics}

The mean arterial pressure is determined by cardiac output and total peripheral resistance (69). In an early phase of essential hypertension (borderline phase) the increase in arterial pressure is associated with an increased cardiac index $(85,87,157,167)$, while in the established phase of the hypertension the cardiac index has returned to normal and the perip. heral resistance is increased $(87,157,167)$. Similarly, in the SHR an increased peripheral resistance has been found in the established phase of hypertension $(46,151)$. Data on the cardiac index in the young SHR are more conflicting. In the 8-12 weeks old anaesthetized SHR a normal cardiac in. dex has been reported by Frohlich (55) on the basis of measurement of cardiac output acutely with an electromagnetic flow-probe on the ascending aorta. In conscious 4-5 weeks old SHR Smith and Hutchins (151) reported an increased cardiac index with the flow-probe technique. Lundin and Hallbäck-Nordlander (105) confirmed this latter observation in 6 weeks old SHR with a dye dilution technique. It seems that the discrepancies between Frohlich's work and the latter two groups can be explained by the use of anaesthetics as well as the selection of groups of different ages.

These observations have lead to two questions:

1) What is the cause of the increased cardiac output?

2) Is the increased cardiac output of importance for the later development and stabilization of the hypertension?

With respect to the first question it should be noted that the increased cardiac output is accompanied by an increased heart rate, both in humans with borderline hypertension and in young SHR $(85,105)$. After pharmacological blockade of the autonomic nervous system influences to the heart (atropine + B-blockade) cardiac output became normal in both humans with borderline hypertension (85) and in young spontaneously hypertensive rats during the hyperkinetic circulatory state (105). These data suggest that the increased cardiac output in the SHR is induced by the autonomic nervous system.

Another factor which can lead to an increased cardiac output is an increased preload to the heart (69). In borderline hypertension in young human subjects a range of relatively low to high plasma and blood volume values has been found $(51,86,109,167)$. The positive correllation between total blood volume and cardiac output in these patients would support the role of intravascular volumes in maintaining cardiac output during the deve- 
lopment of hypertension $(109,167)$. Safar et al. (139) have suggested that from a hemodynamic point of view the distribution of vascular fluid vollume within the vascular system should be considered in addition to the total volume. It is of interest that centralization of the blood volume to the cardiopulmonary region has been found in borderline hypertensive patients and that the cardiopulmonary blood volume has a higher correlation with the cardiac index than the total blood volume in those patients (110). Similarly, an increased central blood volume has been observed during the hyperkinetic circulatory phase of the SHR (104) and an increased left atrial pressure has also been discribed (132).

An increased preload of the heart may cause an increased stroke volume rather than an increased heart rate, according to the Frank-Starling law of the heart, which implies that an increased filling of the ventricles enhances the strength of cardiac contraction within the limits of the heart's abilitity (69). On the other hand in conscious dogs an increased heart rate combined with a normal stroke volume was observed after a volume load, which indicates that an increased volume load would not necessarily lead to an increased stroke volume, but can also lead to an increased heart rate (12). In other words, an increased volume load to the heart caused by an increased central blood volume may be a suitable alternative explanation for an Increased cardiac output and heart rate in the young SHR and in patients with borderline hypertension.

With respect to the second question, regarding the importance of the increased cardlac output for the induction of hypertension, the "autoregulation" theory of Borst and Borst-de Geus (16) modified by Ledingham and Cohen (96) and Guyton et al. $(69,70)$ could be an important concept. Before further discussing the role of autoregulation in hypertension it is appropriate to define the term as applied in this thesils. Autoregulation refers to local tissue mechanisms which act intrinsically to control vascular resistan$c e$ and thereby flow through a particular tissue.

The underlying mechanisms in this process are poorly understood but by definition occur independently of the central nervous systems or circulating hormones and appear to differ in different organs (27).

In the original theory of Borst-de Geus the chain of events was started with retention of water and salt by the kidneys, which resulted in an in. creased intravascular volume, an increased output and an overperfusion of several tissues. This unwarranted overperfusion was opposed by local autoregulatory mechanisms, which prevented these tissues from a further overperfusion by increasing the peripheral resistance $(16,24,27)$. This sequence of events was confirmed in the salt loaded dog, after partial removal of the kidney mass (27).

Recently it was reported by Liard (99) that retention of water and salt by the kidney is not a necessary step in the "autoregulation" concept of hypertension and that an increase in peripheral resistance as a result of an increased cardiac output can also occur after a volume-indepent increase in cardlac output, e.g. by chronic intracoronary infusion of the beta- 
adrenergic receptor stimulant dobutamine. In these experiments the cardiac output fell below normal values, and the peripheral resistance returned to normal values when the infusion was ended, which indicates that a persistent cardiagenic stimulus must be present to maintain the increased peripheral resistance. In the SHR arguments have been put forward against the autoregulation theory. Life-long beta-adrenoreceptor blocka. de reduced the cardiac output by $30 \%$ but did not prevent the rise in blood pressure (126). In these experiments however, many factors apart from cardiac beta-blockade can influence the blood pressure in a different way (fluid volume, sympathetic activity, $\alpha$-adrenoreceptor sensitivity and the use of anaesthetics were not taken into account).

As was already indicated "autoregulation" is a local tissue mechanism. It is believed that some tissues (e.g. skin) react relatively passively to a change in flow whereas other tissues (e.q. brain and kidney) are highly autoregulated (27). If autoregulation is a mechanism involved in the genesis of spontaneous and essential hypertension, an abnormal distribution of blood fllow may therefore be expected during the hyperkinetic circulatory phase. During the borderline phase of essential hypertension in man, an increased cardiac output correlates significantly with an increased hepatic and renal flow, which suggests an overperfusion in those organs (10). In this study the borderline hypertensive patients were not compared to normotensive controls. In another study an increased lower limb flow, and a normal renal and hepatic flow was reported when borderline hypertensives were compared with normotensive controls (157). This study suggests that the increased cardiac output is mainly transmitted to skeletal mus. cle, which implies either that autoregulation is not a dominant mechanism in skeletal muscle, when compared to other organs (kidney and liver), or that autoregulation is dominated by an other regulative mechanism.

With respect to the hyperkinetic circulatory state of the SHR (4-6 weeks after birth) no data on flow distribution are yet avallable. Considering the importance of the concept of autoregulation in spontaneous and essential hypertension, such studies are clearly indicated.

\section{d. Fluid volumes}

Retention of fluid is observed in renovascular hypertenslon, renoprival hypertension $(69,94)$, and hypertension associated with primary hyperaldosteronism (143). In spontaneous or essential hypertension definite fluid retention could not be measured $(10,143,160)$. The extracellular fluid volu. me has been reported either increased or normal in essentlal hypertension depending on the method used $(43,155)$. It has been reported to be normal in young SHR (inuline space) (160) and in older SHR with an established hypertension (ferrocyanide space) (10). 
Essentlal hypertension is generally associated with a decreased or normal plasma volume $(109,123)$. In the SHR data on plasma volumes are more conflicting. In young SHA (UII 6 weeks after birth) a normal plasma and blood volume has been reported (160). After that age either an increased (116), normal (146) or decreased plasma volume $(10,134)$ has been described. This discrepancy can be explained by the use of inappropriate normotensive control animals (normotensive Wistar rats) by the first two au. thors and therefore a reduced plasma volume seems more likely in the adult SHR. The explanation of a reduction in plasma volume in both essential and spontaneous hypertension remains unclear. Although a role of the kidney in the fluid volume balance cannot be denied, its roie in the reduction of plasma volume in the SHR is doubtfull, since the blood vessel system in the SHR is relatively overfilled, as has been demonstrated by an increased mean circulatory filling pressure in the SHR (140) (i.e. the blood pressure when circulation stops). Since most blood is on the venous side of the circulation (69) functional or structural changes of veins and venules could provide a suitable explanation for a decreased plasma volume in both spontaneous and essential hypertension. The decreased venous distensibility described in the SHR (149) as well as in humans with essential hypertension $(139,154)$ could explain the decreased plasma volume in both types of hypertension. In addition there are observations on the venous side of the circulation that point to other factors which might be responsible for a decreased plasma volume in the SHR: 1) A reduced number of venules $(75)$; 2) an increase in venous wall thickness, which may compress the lumen (64); 3) a decreased unstressed volume (46). It would be of interest to investigate whether the plasma volume changes are equally distributed over all organs of the body in the SHR or restricted to specific organs. A more detailed discussion is given in chapter $V$.

\section{Renal factors}

Since the introduction of Goldblatt's kidney model of hypertension (60) special attention has been paid to the kidney in several forms of hypertension including essential hypertension. The kidney has at least two important generally accepted mechanisms which contribute to the regulation of blood pressure:

1. The renin-anglotensin system.

Renin is a proteolytic enzyme which is secreted by the juxtaglomerular cells in the kidney; it catalyzes the conversion of one of the plasma pro. teins, called renin substrate, into the peptide angiotensin I.

When anglotensin $I$, which is a decapeptide passes through the lungs it is further split to the octapeptide anglotensin II under the influence of converting enzyme located in the lung tissue.

Angiotensin 11 is a very powerful vasoconstrictor agent (69). The activity of the renin-anglotensin system has been reported to vary from high to depressed in both spontaneous $(6,33,52)$ and essential hypertension $(11,40)$. 
In a recent detailed study where proper attention has been given to several potentially interfering factors (e.g. the conscious state of the animals, the appropriate normotensive control group etc.) a normal reninangiotensin system was found during the development of the hypertension in the SHR, but its activity was increased after the development. This implies that the renin-angiotensin system has no obvious role in the induction of spontaneous hypertension (6).

2. The renal control of fluid volumes.

According to Guyton the kidney plays an important role in long-term blood pressure regulation by controlling the fluid balance $(69,70)$. In normotensive individuals the fluid balance is in equilibrium under normal physiological conditions; a sudden rise in blood pressure leads to increased diuresis (pressure diuresis), and conversely a decrease in blood pressure leads to decreased diuresis and retention of fluid. This mechanism operates at a higher blood pressure level in hypertensive man and animals (e.g. when hypertension is brought to normotension in a hypertensive animal without affecting the kidney function, water and salt are retained).

Dysregulation of the kidney in hypertension can be demonstrated in a new genetic model for hypertension: the "Milan Hypertensive Rat Strain" (MHS) introduced bij Bianchi (9). In this animal model the kidney plays an important role in the induction of hypertension. At an early age (5 weeks after birth) this form of hypertension is accompanied by suppression of the reninangiotensin system and retention of fluid, resulting in an increa. sed plasma volume (7) and a normal extracellular fluid volume (Br space) (8), which leads to a stable form of hypertension at a later age.

In another model of kidney induced hypertension, the one clip one kidney Goldblatt hypertensive rat (94), fluid retention can be demonstrated more explicitly by both an increase in plasma volume and in extracellular fluid volume (ferrocyanide space).

In other forms of hypertension (e.g. DOCA salt hypertension) salt intake is associated with a aggravated fluid retention in an early phase (67). In essential hypertension and spontaneous hypertension salt intake has been reported to have a unquestionable influence (113). However, its role in the fluid balance and kidney function is not clearly defined and therefore indicated by some authors as a dangerous minefield in hypertension Investi. gations $(22,88,113)$. Although retention of fluid has not been demonstrated in the SHR (10), and abnormalities in the renin-angiotensin system are not clearly present, arguments have been put forward for an inductive role of the kidney in the SHR.

In young SHR (5-6 weeks after birth) an increased sympathetic tone to the renal artery has been demonstrated (25). Renal sympathetic denervation before the development of hypertension in the SHR leads to an attenuation of the hypertension $(91,99)$. These observations are suggestive for an increased preglomerular resistance to blood flow in the kidney (a similar mechanism is inwolved in the induction of Goldblatt hypertension). In adult SHR with established hypertension, an increased renal resistance 
has been reported $(3,4)$, resulting in a normal blood flow $(46,116)$. In patients with essential hypertention similar an increased resistance was lound resulting elther in a decreased blood flow $(130,157)$ or a normal blood flow through the kidneys (23).

The observation of an increased resistance to flow in the established phase of spontaneous hypertension in rats and essential hypertension in individuals may Indicate two possibilities:

1) the hypertension started with an increased resistance in the kidney (a mechanism which is similar to Goldblatt hypertension).

2) the increased resistance is an adaptation of the kidney to the increased pressure and protects the kidney from overperfusion (autoregulation). Both considerations lead to the conclusion that the possible "prohypertensive" role of the kidney in both spontaneous and essential hypertension can only be studied in the very early phase of spontaneous and essential hypertension.

\section{f. Baroreceptor reflex control}

An important factor wich is involved in the disturbed regulation of blood pressure in hypertension is the baroreflex. It has been shown that the range of control exerted by baroreceptors adapts to maintained high pressure both in hypertensive man $(18,65,90)$ and in several forms of experimental hypertension in animals $(1,2,84,118,141)$. The adaptation of baroreceptors to a maintained high pressure has been associated with a decrease of the overall baroreflex sensitivity (BRS). Cumulative evidence over the last decade supports reduced a BRS in borderline $(43,153)$ and essential human hypertension $(18,65,148)$. In animal studies a reduced BRS was shown In renal (84) as well as spontaneously hypertensive rats $(98,142)$. Experimentally the baroreflex can be rendered unfunctional by denervation. One of the earliest observations in which denervation of the baroreceptor control led to chronic hypertension was that of Nowak (119).

Studies on blood pressure after denervation of the baroreflex are hampered by the great variability of blood pressure $(69,78)$ and the ineffectiveness of the denervation (82), which have led to conflicting results whether or not denervation of the baroreflex can produce hypertension $(4 \pi, 83,119)$. It has to be noted, however, that if an effect of baroreflex denervation in the studles mentioned above was observed, its effect over a long period of the was only small, which suggests that the baroreflex has no great influ. ence on the mean arterlal pressure over a longer time.

On the other hand an increased variability in blood pressure is seen both in rats with aortic baroreceptor deafferentiation (47) and in spontaneously hypertensive rats (56) and in patients with essential hypertension (56). In patients with essential hypertension a direct correlation exists between a decrease in baroreflex sensitivity and an increase in blood pressure labll. ty $(165)$.

It can be concluded that although the baroreflex sensitivity is depressed in both people with essential hypertension and in spontaneously hyper- 
tensive rats, its function in the induction of hypertension is not established.

\section{g. Hormonal factors}

Strong evidence for hormonal causes directlly linked to the pathogenesis of spontaneous hypertension is currently lacking (159). Especially important is the experiment with parabiotic animals (WKY and SHR) of Ebihara (42) in which potential humoral substances are free to exchange between the partners. Arterial pressure did not change in the parabiotic SHR and WKY, which provides basic evidence against any circulating factor responsible for the hypertension in the SHR. Aldosterone is a hormone that has attracted considerable attention as a potential factor in the pathogenesis of spontaneous hypertension in rats. Freeman reported a depressed aldosterone level in SHR of different ages (52), whereas Kenyon (89) could demonstrate that adrenalectomy -and thus the absent aldosterone secretion- inhibits the development of hypertension in SHR. This latter effect was abolished by continuous infusion of aldosterone in the SHR. In patients with essential hypertension no strong evidence exists that plasma aldosterone, or aldosterone secretion, differs from normotensive individuals, although the ranges have been reported to be much wider (11).

Recently vasopressin has drawn attention as a potent vasoconstrictor. In SHR of different ages increased urine excretion and plasma levels have been found (28). However, the magnitude of this elevation is not sufficient to account for the rise in blood pressure.

Although spontaneous hypertension does not clearly seem to be related to the actions of a circulating hormone, endocrine substances acting more locally could be relevant. In this regard the recent finding of a reduction of the depressor substance kallikreine in the urine of humans with essential hypertension and in SHR seems of special interest (159).

\section{h. The sympathetic nervous system}

Perhaps the most intensively studied system in the SHR is the sympathetic nervous system. Both for the SHR and for humans with essential hypertension an increased activity of this system has been implied in the genesis and maintance of hypertension. The plasma noradrenaline concentration is frequently used as a parameter of sympathetic activity. In patients with essential hypertension plasma noradrenaline levels have been reported to be normal $(61)$ or increased $(34,44,103)$ under resting conditions. In a recent extensive review of 32 studies comparing plasma noradrenaline concentrations in groups of patients with essentlal hypertension and normotensive control individuals, Goldstein (61) showed that $88 \%$ of the studies reported higher levels in essential hypertension, whereas in only $41 \%$ statistical significance was reached, partly as a consequence of improper selection of control individuals. This review concludes that there is fair evidence for an increased sympathetic activity in patients with essential 
hypertension. Stress, (e.g. exercise) results in a more pronounced difference in plasma noradrenaline concentration between groups of normotensive and essential hypertensive individuals (62). Interestingly, this increased response of the sympathetic nervous system to stress seems genetically linked, since it is present in children of hypertensive parents as well (45). In the SHR data on plasma noradrenaline concentration have led to conflicting conclusions. Under resting conditions either increased (21) or normal $(32,106)$ values have been reported. A clear difference in plasma noradrenaline concentration between SHR and WKY was demonstrated when stressfull stimull were applied $(21,106)$. The role of the sympathetic nerve activity was further evaluated in the SHR with other techniques. An Increased turnover of noradrenaline was found in the heart and kidney of the SHA $(124,169)$; direct nerve recordings also provide arguments for increased sympathetic nerve activity (144).

From these experiments one could conclude to a possible involvement of the sympathetic nervous system in both types of hypertension. However, an important question remains: is the sympathetic nervous system involved in the initiation of hypertension or does it merely adapt to high blood pressure? (e.g. as a mechanism to maintain flow to different tissues in the hypertensive state). Plasma noradrenaline concentrations were found to be normal in borderline hypertensives in resting conditions and during exercise stress (74). Similarly, resting plasma noradrenaline levels were found to be normal in young SHR (106). These resuits do not support an initiating role of the sympathetic nervous system in spontaneous and in essential hypertension. On the other hand chemical or immunological destruction of the sympathetic nervous system was reported to abolish or reduce spontaneous hypertension in rats, especially when started at an early age $(68,162)$. A great disadvantage of these methods, however, is the rather unspecific interference with the sympathetic nervous system. A method which reduces the increased sympathetic nervous activity to normal levels in spontaneous hypertension will be of great help in the investigation of this type of hypertension. In this regard the observation of Östman (122) that sympathetic activity to the heart is decreased during swim tralining over a longer period in normotensive rats is of interest. Such a physiological method of reducing sympathetic activity could provide an attractive method for the study of the role of sympathetic activity in the development and maintenance of spontaneous hypertension. 


\section{The regulation of peripherall resistance}

Beyond doubt the increase in peripheral resistance is the major long-term hemodynamic change in essential hypertension. The microvessels and especially the arterioles are mainly responsible for the peripheral re. sistance under normal conditions. In a single vessel the resistance can be calculated from Poiseuille's Law:

$$
\mathrm{R}=\frac{8 \rho \mathrm{L}}{\pi r^{4}}
$$

The resistance $(R)$ is directly proportional to the blood viscosity ( )and the length (L) but inversely proportional to the fourth power of the radius $\left(r^{4}\right)$. If there are more parallel vessels involved the resistance can be calculated with the formula

$$
R=\left(\frac{1}{R_{1}}+\frac{1}{R_{2}}+\frac{1}{R_{3}}\right)^{-1}
$$

where $R_{1}, R_{2}$ and $R_{3} \ldots .$. are each the resistance of individual vessels. Little is known about the viscosity of the blood in hypertension. An increase of $7 \%$ has been reported in humans with essential hypertension (156) and an increase of $20 \%$ in the blood of the SHR (35). This magnitude of increase can only partly explain the increased blood pressure. A decrease in length has been reported in the arterioles of the SHR rather than a increase in length (75).

From Poiseuille's Law it must be concluded, that the most important factor which contributes to the resistance is the radius of the vessel, and it can be easily calculated that a decrease of $10 \%$ in radius leads to an increase of $52 \%$ in resistance.

Thus many investigations have focussed on a possible decreased lumen of the arterioles in experimental hypertension. These studles investigated both functional differences (e.g. increased sensitivity to noradrenaline or other pressor agents; alterations in cell membrane properties related to for instance sodium-calcium exchange or vascular nucleotides, etc. re. cent review: 166) and structural differences. With respect to this latter possibility Folkow's theory of long-term structural wascular design in hypertension is an important one (48).

From dose-response curves of noradrenaline in isolated hindquarters of SHR and WKY Folkow concluded that even in the maximally dilated state an increased vascuiar resistance is still present in the SHR (cf figure 1.1). He explained this structural change by a generalized wall hypertrophy and a decreased lumen of the precapillary resistance vessels (increased wall/lumen ratio). A decreased lumen was indeed found by Mulvany (114) in the mesentery of 6 month old SHR when compared to WKY. Bohien (13) 


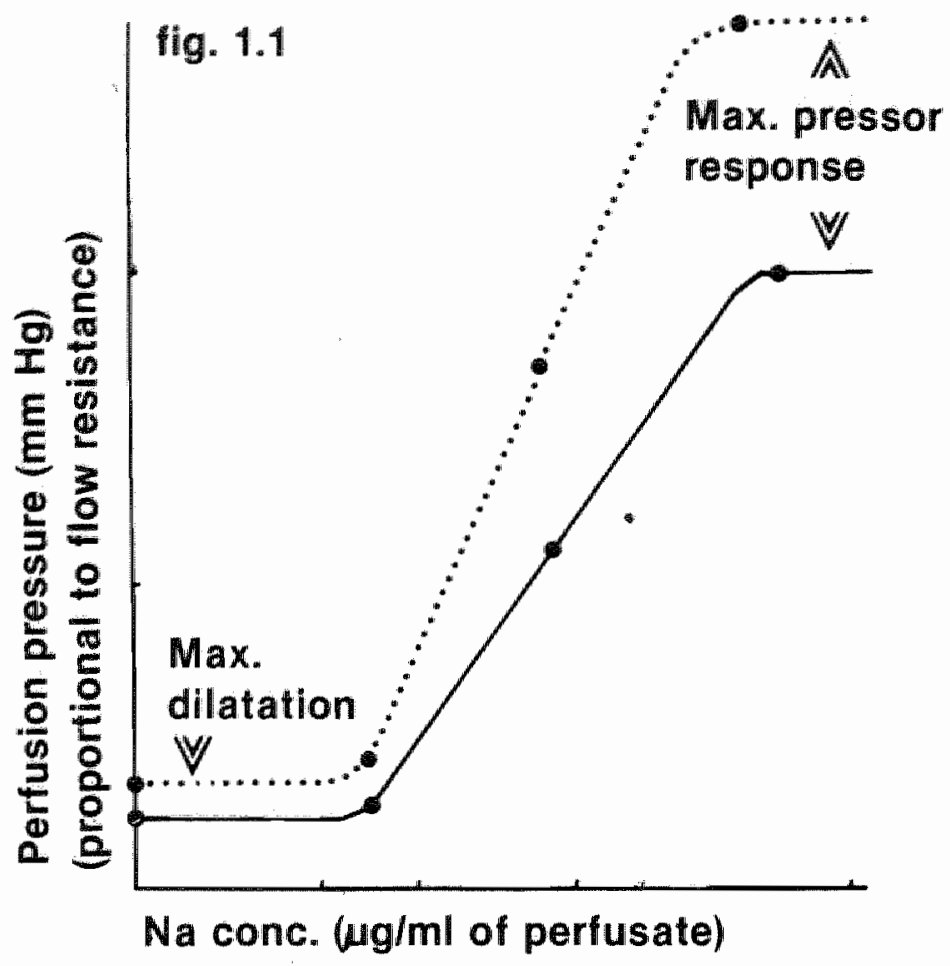

Fig. 1.1 This figure represents the influence of increasing concentrations of noradrenaline on the perfusion pressure of isolated hindquarters of SHR... and WKY-

Since the flow rate of perfusion was held constant in these experiments the perfusion pressure was proportional to the flow resistance. (After Folkow; 48,49).

could not establish a decrease in lumen in the cremaster muscle of younger rats (5-7 and 16-18 weeks old SHR). He even found an increase in vessel lumen rather than a decrease.

Another attractive explanation for an increase in resistance in several tissues in the SHR is a decreased number of arterioles. This was observed for skeletal muscle $(20,41)$, skin (71) and gut (75). Henrich (75) described not only a reduced number of arterioles but also a reduced number of capillaries and venules.

If this is a general phenomenon some other hemodynamic observations made in spontaneous and essential hypertension can be explained e.g. the decreased plasma volume and the increased transcapillary escape rate of plasma proteins which will be discussed in the next paragraph.

Hallbäck et al. (72) stated that rarification of microvessels cannol be an important mechanism in the increased resistance in the SHR. They com- 
pared dose-response curves of noradrenaline in the isolated hindquarters of the SHR to dose-response curves in the isolated hindquarters of normo. tensive rats in which the microvessels were rarified by microplugging. The dose-response curve was still steeper in the SHR and the maximal pressure response was elevated in the SHR when compared to the animals in which the microvessels were rarified, which indicates an increased sens:tivity to noradrenaline in the isolated hindquarters of the SHR, but not in the isolated hindquarters of the microplugged normotensive rat.

From these data they concluded that the mechanism which increases the peripheral resistance in the SHR is not related to rarification of microvessels. In our opinion this conclusion is not allowed. The increased response to noradrenaline in the SHR can still be an adaptation to the long-term rise in blood pressure and therefore experiments in which microplugging is performed over a longer time in conscious normotensive animals, will be of more value for conclusions and suggestions about the possibility of elevated peripheral resistance by rarification of microvessels in the SHR and other forms of hypertension.

\section{Relation of transcapillary escape rate (TER) to increased postarteriolar re:} sistance and blood overperfusion in the microcirculation (an hypothesis)

When albumin is injected into the bloodstream of man or experimental animals the plasma disappearance consists of different phases, with different half-lives $(138,152)$. The first phase represents mainly the extravasation (tissue distribution) of albumin and its slope is called transcapillary escape rate (TER). Although the albumin TER has been reported to be elevated both in the SHR (135) and in patients with essential hypertension (123) the mechanism involved in this elevation remains unclear.

The expression transcapillary escape rate suggests that escape of albumin occurs only through the capillaries; however, since an escape of albumin through venules has been reported in the cat mesentery (115), and moreover since substances of a lower molecular weight escape through the arterioles in the SHR (77), escape through venules and arterioles must also be taken into account. In the isolated hindquarters of the rat it has been shown that the clearance of albumin (disappearance of albumin to the extravascular space) is determined by filtration processes rather than diffusion (134). Filtration is determined by three important factors:

1. The size of the surface through which the albumin escapes.

2. The difference in hydrostatlic pressure (inside and outside the vessel wall).

3. The permeability of the surface area for albumin.

Rippe and Folkow (133) showed that the capillary permeability for albumin is similar in the isolated hindquarters of SHR and in WKY. A larger effective exchange surface area does not seem likely in the light of the reduced number of all kinds of microvessels (arterioles, capillaries and venules) in different tissues of the SHR as discussed earlier. This leaves the increa. sed hydrostatic pressure difference as the most obvious possibility for an 
increased TER.

An increased pressure has been measured in the arterioles, capillaries and venules of the young SHR (13) and in the capillaries of patients with essential hypertension (96). The factors which can lead to an increased pressure in arterloles and capillaries venules can be simply converted from the formula's given in figure 1.2. The pressure at the proximal end of the arterloles is given by:

$P_{\text {art }}=Q\left(R_{\text {art }}+R_{\text {cap }}+R_{\text {ven }}\right)+P_{v}$

in which $P_{\text {art }}$ is the pressure at the proximal end of the arterioles; $R_{a r t}$ is the arteriolar resistance, $R_{c a p}$ is the resistance in the capillaries and $R_{\text {ven }}$ is the resistance in the venules, whereas $P_{W}$ is the central venous pressure and $Q$ is the blood flow through the tissue. Since $R_{\text {art }}$ is larger than $R_{c a p}+R_{\text {ven }}$ the arterial pressure is mainly determined by $R_{\text {art }}$. With respect to the influence of $R_{\text {art }}$ it must be kept in mind that if the resistance to flow through the organ or tissue contributes only to a small degree to the peripheral resistance, an increase or decrease of $R_{\text {art }}$ will not influence $P_{\text {art }}$, since $\mathrm{P}_{\text {art }}$ is determined by the "pressure head" of the whole body. A decrease or increase of $\mathrm{R}_{\text {art }}$ will then result only in a decrease or increase of flow in that particular organ or tissue.

In the same way as in formula (3) capillary pressure and venular pressure can be calculated (cf. figure 1.2):

$$
\begin{aligned}
& P_{\text {cap }}=Q\left(R_{\text {cap }}+R_{\text {ven }}\right)+P_{v} \\
& P_{\text {ven }}=Q\left(R_{\text {ven }}\right)+P_{v}
\end{aligned}
$$

It is evident from these formula's what factors can lead to an increased pressure in arterioles, capillaries and venules:

a. An increased central venous pressure can lead to an increase in pressure in capillaries and venules.

b. When the blood flow increases the arteriolar, capillary and venular pressure will rise.

c. An Increased resistance in the capillary or venular system can lead to an increased pressure in those systems (e.g. by a decreased number of capillaries and/or venules or by a constriction of venules).

Arguments have been put forward for a direct correlation between an increased microvascular pressure and an enhanced transvascular escape of albumin: (1) in cardiac failure a direct correlation has been reported between the right atrial pressure and the TER (78), which can be explained by an Increased pressure in venules and caplllaries according to possibility (a); (2) in the isolated hindquarters of the rat the bloodflow was directly proportional to the extravasation of albumin (134), which can be explained by possibllity (b). 


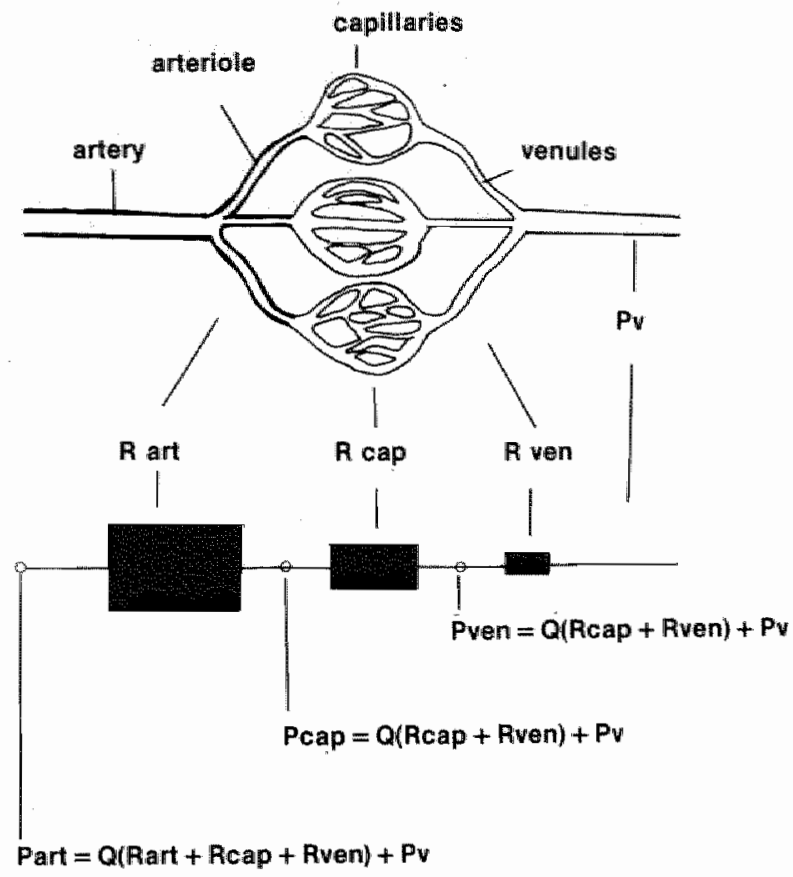

Fig. 1.2 Relation between flow $(Q)$ and resistances of arterioles $\left(R_{a r t}\right)$, capillaries $\left(R_{\text {cap }}\right)$ and venules $\left(\mathbb{R}_{\text {ven }}\right)$ in the microcirculation.

Let us go back to the situation in SHR and individuals with essential hypertension. During the early phase both types of hypertension are characterized by an increased cardiac index and a normal peripheral resistance (167). In borderline hypertension with an increased cardiac index an unequal flow distribution has been reported (157).

Although data on blood flow distribution are as yet unavallable during the hyperkinetic circulatory phase of the SHR some important speculations can be made:

1. The increased flow will lead to an increased extravasation of albumin only in those organs to which the increased flow is transmitted.

2. The increased vascular escape of albumin is present in all the organs independent of an overperfusion of blood.

According to possibility 1. an increased escape of albumin would be more ilkely due to an increased transcapillary or transvenular transport than to an increased transarteriolar transport. If possibility 2 . is true then in the young SHR an increased transarteriolar transport seems more likely, sin. ce the same pressure is present at the beginning of all arterioles (assuming that the resistance in the large arteries is (low). 
In the established phase of spontaneous hypertension and human essen. tial hypertension the situation is different. This phase is characterized by a normal cardiac output and a normal flow through the individual tissues and overperfusion cannot explain an increased albumin escape. Thus only two obvious possibilities remain for an increase in albumin clearance:

1. An increased escape of albumin which passes through the arterial wallis as a consequence of an increased arteriolar pressure.

2. An increased escape of albumin as a consequence of an increased venular and/or capillary resistance.

According to the first possibility an increase of albumin escape must be present in all organs, whereas when possibility 2 occurs extra transvascular albumin escape may be restricted to a few organs. Finally, it must be noticed that an additional increase in transvascular escape of albumin occurs when the caplliary pressure surpasses $45 \mathrm{~mm} \mathrm{Hg}$ (134) probably due to overstretching of the capillary wall (stretched pore phenomenon).

In conclusion: Transvascular escape of albumin is enhanced in both es. sential and spontaneous hypertension probably as a consequence of an increased microvascular pressure, either due to an overflow of blood or an increased resistance downstream. The explanation of the latter could be a decreased number of vessels or a constriction of venules. The extravasation of albumin during the different phases of spontaneous hypertension and the distribution to several organs can give information about the mechanism of an enhanced TER in hypertension (e.g. in the gut of the adult SHR the number of capillaries has been reported to be decreased when compared to WKY (76); however, no difference in flow was observed between the gut of SHR and of WKY, which leads to the conclusion of an increased capillary pressure and an increased transvascular escape of albumin in the gut). Our hypothesis is that during the hyperkinetic circulatory state of the hypertension, extravasation of albumin is present only in those organs to which the increased bloodflow is transmitted, whereas after the hyperkinetic circulatory state an increased albumin extravasation is seen in those organs in which an increased postarteriolar resistance exists. In the present thesis this hypothesis will be investigated on the basis of the measurement of regional flows and albumin clearances in different tissues.

\section{k. The present thesis}

The aim of the present thesis is to perform a dynamic study of several mechanisms involved in the development and stabilization of spontaneous hypertension in rats.

Although blood pressure measurements are included in almost every study on the SHR, the variability of blood pressure has been largely neglected. In the adult SHR with established hypertension a significant positive correlation between blood pressure and its variability has been reported (56). 
No data are avallable on the variability of blood pressure of the SHR all younger age. Therefore, in chapter II not only the mean arterial blood pressure (M.A.P.) was investigated in large groups of SHR and WKY of different ages (at 4-7, 7-9, 9-12 and 12-20 weeks after birth) but also the variability of M.A.P. at different ages of the SHR $(5,7-8$ and 14 weeks after birth). An important mechanism in the regulation of blood pressure and its variability is the baroreceptor reflex. Adaptation of the barorellex to higher blood pressure levels is generally associated with a decrease of its sensitivity.

Although a decrease of its sensitivity has been reported both in borderline hypertension $(43,153)$ and in essential hypertension (148) its possible role in the induction of spontaneous hypertension in rats still needs to be investigated. In chapter III the baroreflex sensitivity was measured during the development and stabilization of spontaneous hypertension in rats. A very important concept which attempts to explain the induction of both spontaneous hypertention, essential hypertension and other forms of hy. pertension is the autoregulation theory $(16,70,97)$. In this theory it is suggested that an increased cardiac index leads to an increased peripheral resistance in a attempt to reduce an overperfusion of blood in the microcirculation. With respect to this theory it must be noted that the timing of autoregulation may be different in different tissues (27). To evaluate the role of different organs with respect to the speed of autoregulation and the induction of an increase in peripheral resistance as a consequence of overperfusion, the flow distribution over several tissues was investigated in the SHR during the hyperkinetic circulatory state and shortly after it in chapter IV.

Another important recently described phenomenon involved in the induction and maintenance of spontaneous hypertension is a reduction of microvessels (arterioles, capillaries and venules) (75). This phenomenon could not only contribute to the increased peripheral resistance in spontaneous hypertension but also to increased transcapillary escape rate of plasma proteins and decreased plasma volume. Therefore in chapter $V$ total plama volume and plasma volumes in several organs were measured during the development and stabilization of spontaneous hypertension, whereas albumin clearances of several tissues were measured during the development and stabilization of spontaneous hypertension in chapter VI. Again, these studies were performed in groups of SHR and WKY of different ages during the development and stabilization of hypertension.

A third important concept in hypertention is dysregulation of kidney func. tion. The kidney can influence the blood pressure elther by the reninangiotensin system or by retention of fluid (69).

The renin-anglotensin system has been reported to be normal or reduced in spontaneous hypertension during its development $(6,52)$, whereas extracellular fluid volume (as a parameter for flluid retention) has been reported to be normal in young SHR (inuline space, 160) and in older SHR (ferrocyanide space (10). A difficulty in the determination of extracellular fluid volu- 
me is that different agents give different results; therefore the exact extracellular fluid volume is not known (69).

Consequently only extracellular fluid volumes obtained by the same method should be compared (143). In chapter VII the extracellular fluid volume $\left({ }^{51} \mathrm{Cr}\right.$ EDTA space) was measured in young SHR in the hyperkinetic circulatory state and in old SHR with established hypertension.

The activity of the sympathetic nervous system has been reported to be normal $(21,32)$ or increased (124) in the adult SHR with established hypertension and normal in young SHR when the hypertension is still developing (105) if plasma noradrenaline is used as a parameter for sympathetic activity. If, on the other hand other parameters are used for the activity of the sympathetic nervous system (e.g. direct nerve recordings, turnover of noradrenaline) the sympathetic system has been reported to have an increased activity in the SHR $(124,144,169)$. The role of the sympathetic nervous system was further evaluated in the SHR by destroying it with nerve growth factor antiserum, which leads to normotension in the SHR $(68,162)$. A major disadvantage, however, of this substance is its toxicity; therefore the recent observation that physical training reduces sympathetic activity in rats is of great interest. In the present study the role of the sympathetic nervous system in the induction and maintenance of spontaneous hypertension was established in 5 and 15 weeks old SHR and WKY by measuring plasma noradrenallne level as an index of sympathetic activity (VIII), while in the next chapter (IX) the effects of general adaptation to training and the effect of training on the sympathetic nervous system was evalua. ted. 


\section{References}

1. Aars, H.: Acta Physiol. Scand. 72, 298 (1968).

2. Angell-James, J.E.: Circ. Res. 32, 149 (1973).

3. Arendshorst, W.J.: Circ. Res. 44, 344 (1979).

4. Arendshorst, W.J. and Beierwaltes, W.H.: Am. J. Physiol. 236, F246 (1979).

5. Azar, S., Johnson, M.A., Scheinman, J., Bruno, L. and Tobian, L.: Clin. Sci. 56, 203 (1979).

6. Bagby, S.P., McDonald, W.J. and Mass, R.D.: Hypertension 1, 347 (1979).

7. Bianchi, G., Baer, P.G., Fox, U., Duzzi, L., Caravaggi, A.M., Möhring, J. and Cusi, D.: In: The kidney in arterial hypertension (G. Bianchi and G. Bazzato, Eds) Bunge Scientific Publishers, Utrecht, 1979.

8. Bianchi, G., Baer, P.G., Fox, U., Duzzi, L., Pagetti, D. and Giovannetti, A.M.: Circ. Res. 36 and 37, suppl. 1, 1 (1975).

9. Bianchi, G., Fox, U. and Imbasciati, E.: Life Sci. 14, 339 (1974).

10. Bianchi, M., Bellini, G., Hessan, H., Kim, K.E., Schwartz, G. and Fernandez, M.: Clin. Sci. 61, 685 (1981).

11. Birkenhäger, W.H. and Schalekamp, M.A.D.H.: Control mechanisms in essential hypertension, Elsevier, Amsterdam (1976), p95.

12. Bishop, V.S. and Peterson, D.F.: Am. J. Physiol. 231, 854 (1976).

13. Bohlen, H.G. and Lobach, D.: Bloodvessels 15, 322 (1978).

14. Bohlen, H.G., Gore, R.W. and Hutchins, P.M.: Microvasc. Res. 13, 125 (1977).

15. Borg, E. and Moller, A.R.: Acta Physiol. Scand. 103, 340 (1978).

16. Borst, J.G.G. and Borst-de Geus, A.: Lancet 1, 677 (1963).

17. Bright, R.: Band 1 Longman, Rees Orme, Brown and Green, London, (1827).

18. Bristow, J.D., Honour, A.J., Pickering, G.W., Sleight, P. and Smyth, H.S.: Circulation 39, 48 (1969).

19. Bruno, L., Azar, S., and Weller, D.: Jap.Heart J. 20, suppl.1, 90 (1979).

20. Chen, I.I.H., Prewitt, R.L. and Dowel, R.F.: Am. J. Physiol. 241, H306 (1981).

21. Chiueh, C.C. and Kopin, I.J.: Am. J. Physiol. 234, H690 (1978).

22. Chrysant, S.G., Walsh, G.M., Kem, D.C. and Frohlich, E.D.: Kidney Int. 15, 33 (1979).

23. Coleman, T.C., Guyton, A.C., Young, D.B., de Clue, J.W., Norman, R.A. and Manning, R.D.: Clin. Exp. Pharmacol. Physiol. 2, 571 (1975). 24. Coleman, T.G., Samar, R.E. and Murphy, W.R.: Hypertension 1, 324 (1979).

25. Collis, M.G., DeMey, C. and Vanhoutte, P.M.: Hypertension 2, 45 (1980). 
26. Cowley, A.W.: In: Regulation of blood pressure by the central nervous system, G. Onestl, M. Fernandez, Kim., K.E. Eds. New York, 1976.

27. Cowley, A.W.: Am. J. Med. 68, 906 (1980).

28. Crofton, J.T., Share, L., Shade, R.F., Allen, C. and Tarnowski, D.: Am. J. Physiol. 235, 361 (1978).

29. Dahl, L.K., Heine, M. and Tassinari, L.: J. Exp. Med. 115, 1173 (1962).

30. Dahl, L.K., Heine, M. and Tassinari, L.: Nature 194, 480 (1962).

31. Danielson, M. and Dammström, B.: Acta Med. Scand. 209, 451 (1981).

32. Da-Prada, M. Picotti, G.B., Carruba, M.O. and Ravazzani, C.: Proc. of Eighth International Congress of Pharmacol. 331, 1981.

33. Day, M.D., Husain, A. and Jones, C.W.: British J. Pharmacol. 64, 392 (1978).

34. De-Champlain, J.: Clin. Endocrinol. Metabol. 6, 633 (1977).

35. De-Clerck, F., Beerens, M., Van Gorp, L. and Xhonneux, R.: Thromb. Res. 18, 291 (1980).

36. Denoroy, L., Fourniere, S., Vincent, M., Renaud, B., Pujol, J.F. and Sassard, J.: Brain Res. 162, 184 (1979).

37. De-Quatro, V. and Chan, S.: Lancet I, 806 (1972).

38. Dickinson, C.J. and Lawrence, J.R.: Lancet II, 1354 (1963).

39. Doba, N. and Reis, D.J.: Circ. Res. 32, 584 (1973).

40. Doyle, A.E.: Hypertension. Physiopathology and Treatment. Genest, E., Kuchel, O., McGraw Hill, New York, (1977), p.709.

41. Dusseau, J.W. and Hutchins, P.M.: Am. J. Physiol 236, H134 (1979).

42. Ebihara, A.: Spontaneous hypertension. K. Okamoto, Igaku Shoin LTD, Tokyo, (1972), p.214.

43. Eckberg, D.L.: Circulation 59, 632 (1979).

44. Engelman, K., Portnoy, B. and Sjoerdsma, A.: Circ. Res. 26 and 27, suppl. 1, 141 (1970).

45. Falkner, B., Onesti, G., Angelakos, E.T., Fernandez, M. and Langman, C.: Hypertension 1, 23 (1979).

46. Ferrone, R.A., Walsh, G.M., Tsuchiya, M. and Frohlich, E.D.: Am. J. Physiol. 236, 403 (1979).

47. Fink, G.D., Bryan, W.J., Mann, M., Osborn, J. and Werber, A.: Am. J. Physiol. 241, H268 (1981).

48. Folkow, B." Clin. Sci. Mol. Med. 55, suppl.4, 3 (1978).

49. Folkow, B.: Clln. Sci. 57, suppl.5, 83 (1979).

50. Forsyth, R.: Science 173, 546 (1971).

51. Fouad, F.M., Tarazi, R.C., Dustan, H.P. and Bravo, E.L.: Am. Heart J. $96,646(1978)$.

52. Freeman, R.H., Davis, J.O., Varsano Aharon, N., Ulick, S. and Weinberger, M.H.: Circ. Res. 37, 66 (1975).

53. Friedman, S.M., Nakashima, M., Mclndoe, R.A. and Friedman, C.L.: Experientia 32, 476 (1976). 
54. Friedman, S.M., Nakashima, M., Molndoe, A.A.: J. Physiol.

Pharmacol. 55, 1303 (1977).

55. Frohlich, E.D.: Hypertension. Physiopathology and Treatment:

Genest, E., Kuchel, O., McGraw Hill, New York, 1977, p.15.

56. Frohlich, E.D., Pfeffer, M.A., Weiss, A.K. and Brecher, G.A.: P. Soc. Exp. M. 140, 145 (1972).

57. Garay, R.P., Elyghozi, J.L., Dagher, G. and Meyer, P.: New Engl. J. Med. 302, 769 (1980).

58. Garay, R.P. and Meyer, P.: Lancet 11,349 (1979).

59. Goldblatt, H., Kahn, H., Hanzal, R.F.: J. Exp. Med. 69, 649 (1939).

60. Goldblatt, H., Lynch, J., Hanzal, R.F. and Summerville, W.W.: Exp.

Med. 59, 347 (1934).

61. Goldstein, D.S.: Hypertension 3, 48 (1981).

62. Goldstein, D.S.: Hypertension 3, 551 (1981).

63. Greenberg, S. and Bohr, D.R.: Circ. Res. 36 and 37, suppl.1, 208 (1976).

64. Greenberg, S., Palmer, E.C. and Wilborn, W.M.: Clin. Sci. Mol. Med. 55, suppl.4, 31 (1978).

65. Gribbin, B., Plickering, T.G., Sleight, P. and Peto, R.: Circ. Res. 29, 424 (1971).

66. Grollman, A.: Proc. Soc. Exp. Blol. 57, 102 (1944).

67. Grollman, A.: Handbook of Experimental Pharmacology, 16,

Springer, Berlin, Heidelberg, New York, p.71 (1975).

68. Gutilleta, A.F. and Oparil, S.: Hypertension 2, 304 (1980).

69. Guyton, A.C.: Textbook of Medical Physiology fifth edition, W.B. Saunder Company New York, (1976).

70. Guyton, A.C., Coleman, T.G., and Granger, H.J.: Ann. Rev. Physiol. 34, 13 (1972).

71. Haack, D.W., Schaffer, J.J. and Simpson, J.G., Proc. Exp, Biol. Med. 164, 453 (1980).

72. Hallbäck, M.G., Gothberg, G., Lundin, S., Ricksten, S.E. and Folkow B.: Acta Physiol. Scand. 97, 233 (1976).

73. Harper, R.N., Moore, M.A., Marr, M.C., Watts, L.E. and Hutchins, P.M.: Microvasc. Res. 16, 369 (1978).

74. Henquet, J.W., Kho, T., Schols, M., Thijssen, H. and Pahn, K.H.: Clin. Sci. 60, 25 (1981).

75. Henrich, H., Hertel, R. and Assmann, R.: Pflüg.Arch. 375, 153 (1978).

76. Hering, H.E.: Die Karotissinus reflexe auf Herz und Gefässe vom normal-physiologischen, pathologisch-physiologischen und klinischen Standpunkt: Th. Steinkopf, Dresden (1927).

77. Hertel, R. and Henrich, H.: Bibl.Anat. 18, 180 (1979).

78. Hesse, B., Parving, H.H., Lund-Jacobsen, $H$. and Noer, I.: Circ Res. $39,358(1976)$.

79. Heymans, C. and Neil, E.: Reflexogenic Areas of the Cardiovascular System, Little, Brown and Co, Boston (1958) p.89. 
B0. Hofman, A., Roelandt, J.T.C.R., Boomsma, F., Schalekamp,

M.A.D.H. and Valkenburg, H.A.: Clin. Scl. 61, (1981).

81. Holleberg, N.K. and Adams, D.F.: Am. J. Med. 60, 773 (1976).

82. Hutchins, P.M. and DarnelI, A.E.: Circ. Res. 34 and 35, suppl. 1, 161 (1974).

83. Ito, C.S. and Scher, M.A.: Circ. Res. 48, 576 (1981).

84. Jones, J.V. and Floras, J.S.: Clin. Scl. 59, 347 (1980).

85. Julius, S.: Schweiz. Med. W. Schr. 106, 1698 (1976).

86. Jullus, S., Pascual, A.V., Reilly "K. and London, R.: Arch. Int. Med.

127, 116 (1971).

87. Julius, S. and Schork, M.A.: J. Chron. Dis. 23, 723 (1971).

88. Karr-Dullien, V. and Bloomquist, E.: Proc.Soc.Exp.Biol.Med. 160, 421 (1979).

89. Kenyon, C.J., DeConti, G.A., Cupulo, N.A. and Morris, D.J.: J. Endocrinol. 109, 1841 (1981).

90. Kezdi, P.: Arch.Int.Med. 91, 26 (1953).

91. Kline, R.L., Kelton, P.M. and Mercer, P.F.: Can.J.Physiol.Pharmacol. $56,818(1978)$.

92. Kopin, I.J., McCarty, R. and Yamaguchi, I.: Clin.Exp.Hypertens. 2, $379(1980)$.

93. Kumar, D., Hall, A.E.D. Nakashima, R. and Gornall, A.G.:

Can.J.Biochem. Physiol. 35, 113 (1957).

94. Kunes, J. and Jelinek, J.: Clin. Exp. Pharmacol. Physiol. 6, 507 (1979).

95. Lais, L.T., Rios, L.L., Boutelle, S., DiBona, G.F. and Brody, M.J.: Blood Vessels 14, 277 (1977).

96. Landau, J. and Davis, J.: Lancet 1, 1327 (1957).

97. Ledingham, J.M. and Cohen, R.D.: Lancet II, 887 (1963).

98. Lee, J.Y., Walsh, G.W., Mokler, C.M. and Tobia, A.J.: Res. Commun.

Pharmacol. 29, 27 (1980).

99. Liard, J.F.: Experientia 33, 339 (1977).

100. Liard, J.F.: Clin. Sci. Mol. Med. 54, suppl.6 153 (1978).

101. Loomis, D.: Arch. Path. 41, 231 (1946).

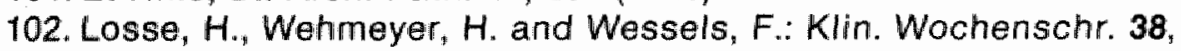
$393(1960)$.

103. Louis, W.J., Doyle, A.E. and Anavekar, S.: New Engl. J. Med. 288, 599 (1973).

104. Lundin, S.A., Folkow, B. and Rippe, B.: Acta Physiol. Scand. 112, 257 (1981).

105. Lundin, S.A., and Hallbäck-Nordlander, M.G.: Cardiovasc. Res. 14, 561 (1980).

106. McCarty, R. and Kopin, I.J.: Life Sci. 22, 997 (1978).

107. McCubbin, J.W., Green, J.H. and Page, I.H.: Circ. Res. 4, 205 (1956).

108. McGiff, J.C. and Quilley, P.C.: Circ. Res. 48, 455 (1981). 
109. Messerli, F.H., Christie B. DeCarvalho, J.G.R., Aristumo, G.G., Suarez, D.H., Dreslinski, G.R. and Frohlich, E.D.: Arch. Int. Med. $141,81(1981)$.

110. Messerli, M.D., DeCarvalho, J.G.R., Christie, B. and Frohlich, E.D.: Circulation 58, 441 (1978).

111. Meyer, P. and Garay, P.R.: (editors) "Proceedings of the Symposium Genetic Markers in Essential Hypertension". Clin. Exp.

Hypertension 3, 569 (1981).

112. Mohamed, F.: Med. Chir. Trans. 2nd Series 39, (1874).

113. Morgan, T., Carney, S. and Myers, J.: Pharmac. Ther. 9, 395 (1980).

114. Mulvany, M.J., Hansen, P.K., Aalkjaer, C.: Circ. Res. 43, 854 (1977).

115. Nakamura, Y. and Wayland, H.: Microvasc. Res. 9, 1 (1975).

116. Nikodijević, B., Dolgova-Korubin, V. and Tadžar. I.S.: Acta Med. lug. 26, 251 (1972).

117. Nishiyama, K., Nishiyama, A. and Frohlich, E.D.: Am.J.Physiol. 230, 691 (1976).

118. Nosaka, S. and Wang, S.C.: Am.J.Physiol. 222, 1079 (1972).

119. Nowak, S.J.G.: Ann.Surg. 111, 102 (1940).

120. Okamoto, K.: Spontaneous Hypertension, Igaku Shoin L.T.D., Tokyo, 1972 , p.1.

121. Okamoto, K., and Aoki, K.: Jap. Circ. J. 27, 282 (1963).

122. Östman, I. and Nybäck, K.: Neuroscience 1, 41 (1976).

123. Parving, $H$. and Gyntelberg, F.: Circ. Res. 32, 643 (1973).

124. Patel, K.P., Kline, R.L. and Mercer, P.F.: Hypertension 3, 682 (1981).

125. Pfeffer, M.A., Frohlich, E.D., Pfeffer, J.M. and Weiss, A.K.: Circ. Res. 34 and 35, suppl.1 (1974).

126. Pfeffer, M.A., Pfeffer, J.M., Weiss, A.K. and Frohlich, E.D.: Am.J.Physiol. 232, H639 (1977).

127. Postnov, Y.V., Orlov, S.N., Gulak, P. and Shevchenko, A.: Pflüg. Arch. 365, 257 (1976).

128. Postnov, Y.V. Orlov, S.N., Shevchenko, A. and Adler, AM.: Pflüg. Arch. 371, 263 (1977).

129. Renauld, B., Fourniere, S., Denoroy, L., Vincent, M., Pujol, J.F. and Sassard, J.: Brain Res. 159, 149 (1978).

130. Reubi, F.C. and Weidmann, P.: Clin.Exp.Hypertension 2, 593 (1980).

131. Ricksten, S.E., Yao, T. and Thoren, P.: Acta Physiol.Scand. 112, 169 (1981).

132. Ricksten, S.E.: Function of cardiac mechanoreceptors in primary hypertension: Ph.D. Thesis Götenborg (1980).

133. Rippe, B. and Folkow, B.: Acta Physiol.Scand. 101, 72 (1977).

134. Rippe, B.: Relationship between diffusion and convection across capillary walls. Ph.D. Thesis Gotenborg, 1978.

135. Rippe, B., Lundin, S. and Folkow, B.: Clin. Exp. Hypertension 1, 39 (1978).

136. Rippe, B., Kamiya, A. and Folkow, B.: Acta Physiol.Scand. 105, 171 (1979). 
137. Rossi, E.: Hypertension Physiopathology and Treatment; Genest, E., Kuchel, O., McGraw HIII, New York (1977), p692.

138. Rossing, N.: Clin. Sci. 33, 593 (1967).

139. Safar, M.E., London, G.M., Levenson, G.A., Simon, A.Ch. and Chau, N.P.: Hypertension 1, 615 (1979).

140. Samar, R.E. and Coleman, T.G.: Am.J.Physiol. 237, 584 (1979).

141. Sapru, H.N. and Krieger, A.J.: Am.J.Physiol. 236, H174 (1979).

142. Sapru, H.N. and Wang, S.C.: Am.J.Physiol. 230, 664 (1976).

143. Schalekamp, M.A.D.H.: Hypertension Physiopathology and Treatment; Genest, E., Kuchel, O. New York McGraw Hill, (1977), p.49.

144. Schramm, L.P. and Barton, G.N.: Am.J.Physiol. 236, R147 (1979).

145. Selye, H., Hall, C.E. and Rowley, E.M.: Can.Med.Assoc.J. 49, 88 (1943).

146. Sen, S.y Hoffman, G.C., Stowe, N.T., Smeby, R.R. and Bumpus, F.M.: J. Clin. Invest. 51, 710 (1972).

147. Shipley, R.E. and Gregg, D.E.: Am.J.Physiol. 143, 396 (1945).

148. Simon, A.Ch., Safar, M.E., Weiss, Y.A., London, G.M. and Milliez, P.L.: Brit.Heart.J. 39, 799 (1977).

149. Simon, G.: Circ.Res. 38, 412 (1976).

150. Smirk, F.H. and Hall, W.H.: Nature 182, 727 (1958).

151. Smith, T.L. and Hutchins, P.M.: Hypertension I, 508 (1979).

152. Studer, R.K. and Potchen, J.: Microvasc. Res. 3, 35 (1971).

153. Takashita, A., Tanaka, S., Kuroiwa, A. and Nakamura, M.: Circulation 51, 738 (1975.)

154. Takashita, A. and Mark, A.L.: Hypertension 1, 202 (1979).

155. Tarazl, R.C.: Circ. Res. 38, suppl. 2, 73 (1976).

156. Tibblin, G., Bergentz, S.E., Bjure, J., Wilhelmsen, L.: Am. Heart J. 72 , 165 (1966).

157. Temmar, M.M., Safar, M.E., Levenson, J.A. Totomoukouo, J.M. and Simon, A.: Clin. Sci. 60, 653 (1981).

158. Tigerstedt, R. and Bergman, P.G.: Skand. Arch. Physiol. 8, 223 (1898).

159. Trippodo, N.C. and Frohlich, E.D.: Circ. Res. 48, 309 (1981).

160. Trippodo, N.C., Walsh, G.M. and Frohlich, E.D.: Am. J. Physiol. 235, $52(1978)$.

161. Uirych, $M_{\text {: }}$ : Angiology 30, 104 (1979).

162. Vapaatalo, H., Hackman, R., Anttila, P., Vainionpaä, V. and Neuvonen, P.J... Naunyn-Schmied, Arch. Pharmacol. 284, 1(1974).

163. Vincent, $M_{*}$, Bornet, $H_{\text {, }}$ Berthezene, F., Dupont, d. and Sassard, J.: Clin. Scl. Mol. Med. 54, 391 (1978).

164. Wambach, G., Helber, A., Bonner, C. and Hummerick, W.: Klin. Wochenschr. 57, 169 (1979).

165. Watson, R.D.S., Stallard, T.J., Flinn, R.M. and Littler, W.A.:

Hypertension 2, 333 (1980).

166. Webb, R.C. and Bohr, D.F.: Am. Heart J. 102, 251 (1981). 
167. Weiss, Y.A. Safar, M.E., London, G.M., Simon, A.C.. Levenson, J.A. and Milliez, P.M.: Am. J. Med. 64, 382 (1978).

168. Yamori, Y., Nagaoka, A. and Okamoto, K.: Jap. Circ. J. 38, 1095 (1974).

169. Yamori, Y, Ooshima, A. and Okamoto, K.: Jap. Circ. J. 37, 1235 (1973).

170. Zamir, N., Gutman, Y. and Ben-Ishay, D.: Clin. Sci. Mol. Med. 55, suppl. 4, 105 (1978). 


\section{Chapter II}

\section{Development of high blood pressure and its variability in rats with spontaneous hyper- tension}

\section{Introduction}

Hypertension can be considered as a result of a dysfunction of mechanisms which keep the blood pressure within normal ranges in normotensive subjects. The minute-to-minute variability of mean arterial pressure is controlled primarily by the baroreceptor reflex (16). Surgical removal of baroreflex control leads to an extremely labile blood pressure $(4,8,16)$ in experimental animals. The long-term effects on mean arterial pressure are conflicting: both an increased $(6,8)$ and normal mean arterial pressure $(4,16)$ have been reported after removal of baroreflex control. Interestingly an increase in bload pressure variability has been observed in the SHR (7) and in subjects with essential hypertension $(2,9,12,13,20,21)$.

Both in borderline hypertensive subjects $(5,13)$ and in subjects with essential hypertension (14) a decrease in baroreflex sensitivity has been reported. Similar observations were achieved in the SHR $(3,17)$ (cf. also chapter III).

The combination of increased lability of blood pressure and decreased baroreflex sensitivity in the SHR suggests a similarity between the mechanisms involved in the induction of hypertension in animals with baroreflex deafferentiation and in the induction of hypertension in the SHR.

In the present study we investigated the mean arterial pressure (MAP) and its variability during the development of hypertension in the SHR.

\section{Methods}

\section{Animals}

Male pneumonia free spontaneously hypertensive rats (SHR) and genetically related Wistar Kyoto rats (WHY) were used in this study. These animals were born in our laboratory facilities and were selected from parents of which the blood pressure has previously been checked for the hypertensive and normotensive state in resp. SHR and WKY.

At an age of three weeks after birth the rats were separated from their mothers and housed at a temperature of $24 \pm 1^{\circ} \mathrm{C}$ in cages with $4-6$ animals per cage. They were given standard laboratory diet and water ad libitum. Different groups of animals were used at 5, 7-8 and 14 weeks after birth for the measurement of blood pressure and its variability. Moreover, different groups of SHR and WKY of 4-6 weeks, 7-9 weeks, 9-12 weeks and 12-20 weeks were used for a number of the remaining experiments; the mean arterial pressures of these animals are summarized in figure 2.1. 


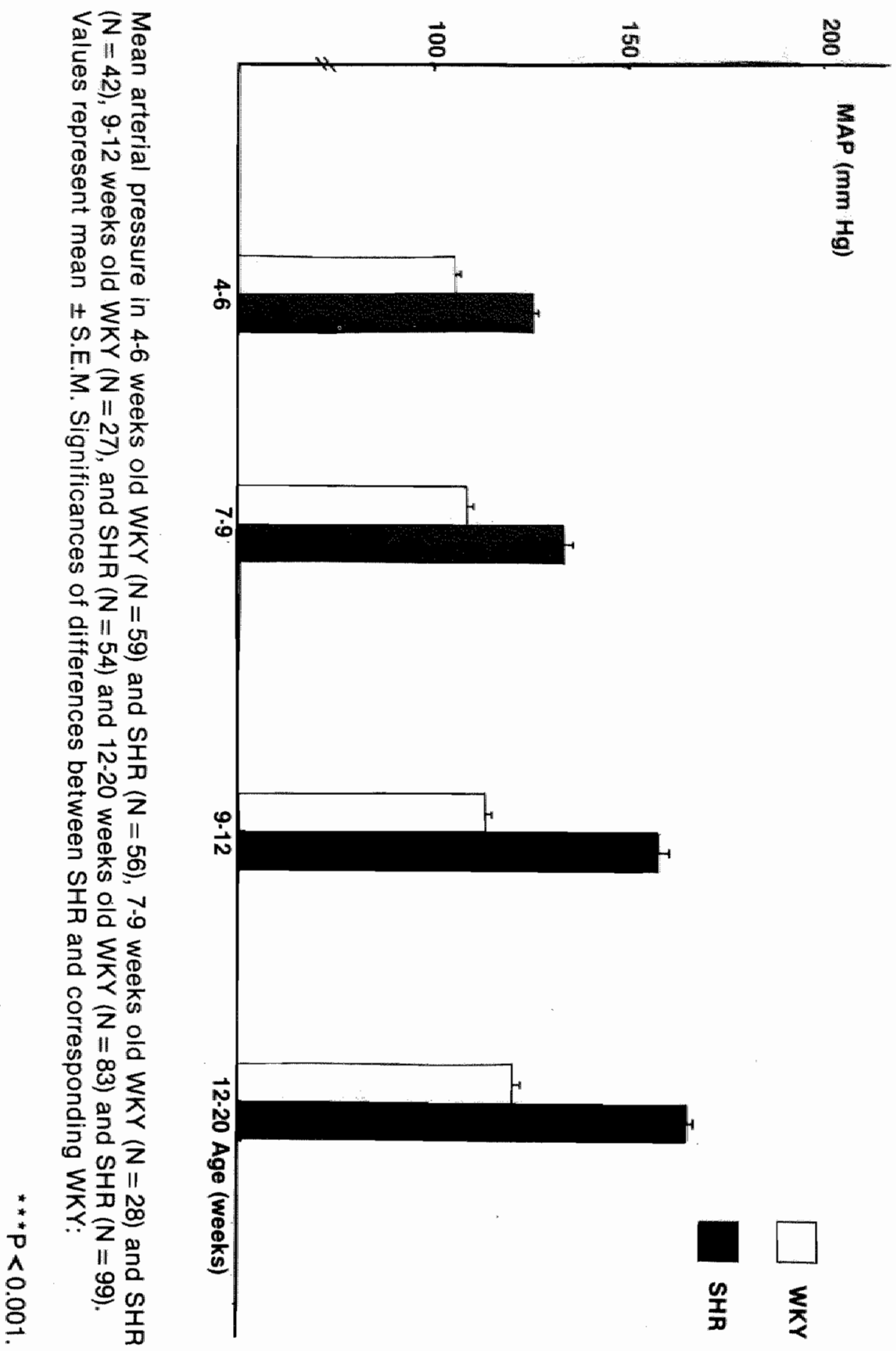


Blood pressure, heart rate and variability of blood pressure

For the direct, recording of blood pressure and heart rate a PE 50 or PE 10 catheter (depending on the size of the animal) was inserted into the right femoral artery under ether-anaesthesia. The catheter was exteriorized to the neck of the animals. Five hours after recovery from the anaesthesia blood pressure and heart rate were recorded in freely moving undisturbed animals.

Arterial blood pressure was measured with a Statham P 23 Db strain gauge and was recorded continuously on a Grass 7 P Polygraph.

The signal was electronically filtered $(0.5 \mathrm{~Hz})$ to obtain mean arterial pressure (MAP).

Thirty-sixty minutes after habituation of these animals a stable MAP and heart rate was observed. Following this period MAP and heart rate were determined every minute during one hour.

The standard deviation of the 60 consecutive blood pressure values was used to describe the variability in MAP (15).

The variation coefficient was calculated by dividing the standard deviation of the mean arterial pressure by the average mean arterial pressure and was expressed as percentage.

\section{Statistics}

Values indicated represent means \pm S.E.M. unless stated otherwise. Student's t-test was used for statistical comparison of mean arterial pressure, heart rate, variability and variation coefficient. Differences were considered statistically significant at the $P<0.05$ level.

A linear regression analysis (method of the least'squares) was used to test the correlation between MAP and variability at different ages in the SHR and WKY.

\section{Results}

Mean arterial pressure

The mean arterial pressure of large groups of animals used in this thesis are summarized in fig.2.1. In 4-6 weeks, 7-9 weeks, 9-12 weeks and 12-20 weeks old animals a significant increase in MAP of SHR was observed of resp. $15 \%, 17 \%, 31 \%$ and $40 \%$.

A similar pattern was seen in the specific groups used for the determination of variability of blood pressure (Table I). In 5 weeks, 7-8 weeks and 14 weeks old SHR significant increases in MAP were observed of resp. 15\%, $21 \%$ and $40 \%$.

\section{Heart rates}

Heart rates of 5 weeks, 7-8 weeks and 14 weeks old SHR were significantly Increased with resp. $9 \%, 7 \%$ and $10 \%$. 

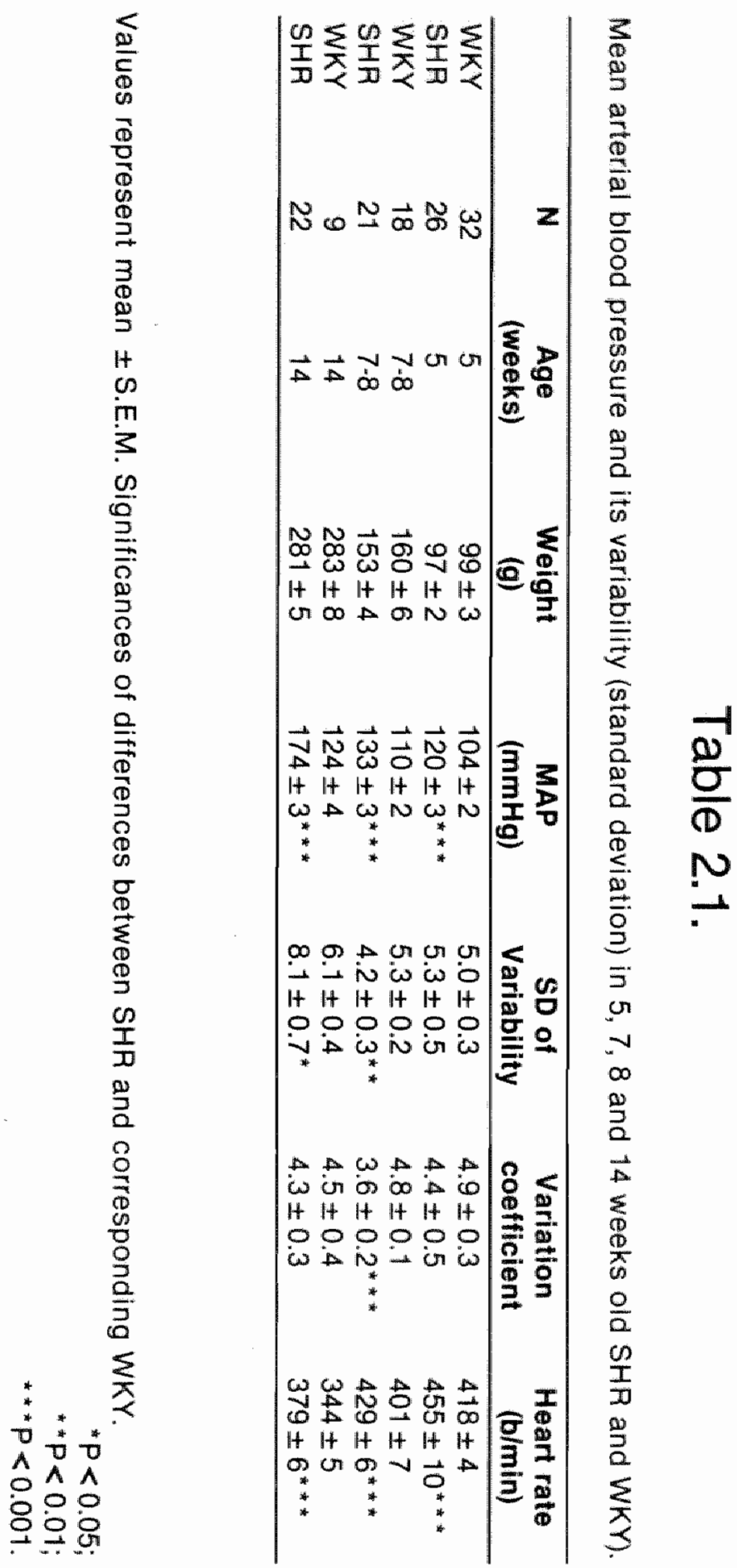
Variabllity in mean arterial blood pressure (SD) is summarized in table I. A significant decrease in variability was observed in the 7.8 weeks old SHR when compared to WKY, whereas variability was significantly increased in 14 weeks old SHR.

Within different groups of animals the standard deviation was correlated with MAP. In 5 weeks, 7-8 weeks and 14 weeks old WKY and SHR a correlation coefficient $\left(r^{2}\right)$ of resp. $0.005,0.01,0.005,0.17,0.05,0.07$ and 0.13 was observed. For none of the groups a significant correlation was observed, in other words the standard deviation is independent of the level of blood pressure. The varlation coefficient $\left(\frac{S D}{x} \times 100 \%\right)$ was only significantly depressed in
the 7.8 weeks old SHR.

\section{Discussion}

In this study we investigated the development of hypertension in the relation to the variability of the blood pressure. An increasing difference in mean arterial pressure was found in large groups of 4-6, 7-9, 9-12 and 12-20 weeks old SHR when compared to age matched WKY. Already at an age of 4-6 weeks blood pressure is significantly elevated in the SHR.

In a number of these animals the variability in mean arterial pressure was also measured. Within each group of animals the absolute MAP was not related to its variability, since no significant correlation was found between these two parameters. The lack of correlation between blood pressure and its variability is at variance with Frohlich"s work, who reported a positive significant correlation between blood pressure and its variability in the adult SHR using restraining cages for the measurement of MAP. In our study the blood pressure was measured in freely moving animals. Since it has been reported that restraint gives a clear enhancement of sympathetic nerve activity in the SHR (7), and moreover since increased plasma noradrenaline enhances the variability of blood pressure (10) the use of restraining cages by Frohlich and co-workers (4) may explain the variance between their data and ours.

In the aduit group of SHR with stable hypertension a significant increase in blood pressure is accompanied by a significant increase in variability. Similar results were obtained in subjects with essential hypertension $(2,9,12,13,21)$, but not in borderline hypertensive patients $(9)$.

The factors determining the variability of arterial pressure in man have been reported by several authors. These factors include: the levell of blood pressure, the plasma renin activity, the cardiac output and the baroreflex sensitivity $(1,18,20)$. It must be remembered that the baroreceptor reflex is a powerfull buffer against acute changes in blood pressure and in spite of many factors which can influence the variability of the blood pressure, an 
increase of this variability will not appear unless it is allowed by the baroreceptor reflex.

On the basis of the increased variability of blood pressure with progress:ve impairment of the sinoaortic reflex in man $(13,14)$ and the combination of a decreased baroreflex sensitivity and an increased variability of blood pressure in the adult SHR, we concluded that the decrease in baroreflex sensitivity is the most obvious explanation for the observed increase in variabillity in blood pressure in the adult SHR.

In the 5 weeks and 7-9 weeks old SHR variability in blood pressure is not increased; we even observed a depression of variability in the 7.8 weeks old SHR. The study presented in chapter III of this thesis indicates that baroreflex sensitivity is equal in very young (6-9 weeks old) SHR and WKY. This observation may explain the lack of increased variability of MAP in young SHR, but does not explain the depressed variability in $7-8$ weeks old SHR. The involvement of other (reflex-) mechanisms cannot be excluded. The influence of that part of the baroreflex, which reflexly controls the peripheral resistance and the possible influence of the low pressure recep. tor efferents on the blood pressure variability are of great interest for future studies in the SHR of that age.

\section{In conclusion}

Similar as in subjects with essential hypertension an increased variability in blood pressure was observed in the adult SHR which may be explained by a decrease in baroreflex sensitivity in the SHR.

In the younger SHR and WKY (5 weeks and 7-8 weeks old) no increase in variability exists despite a significant elevation of blood pressure in these groups. Since 7-8 weeks old SHR had a significant decrease in baroreflex sensitivity in comparison to age matched WKY we concluded that variability in blood pressure depends on other mechanisms than the baroreflex sensitivity in the 7.8 weeks old SHR. 


\section{References}

1. Birkenhäger, W.A., van Es, L.A., Houwing, A., Lamers, H.J., Mulder, A.H.: Clin.Sci. 35, 445 (1968).

2. Clement D.L., Mussche, M.M., van Houtte, G. and Pannier, R.: Clin.Sci. 57, 217 (1979).

3. Coote, J.H. and Sato, Y.: Circ.Res. 40, 571 (1977).

4. Cowley, A.W., Liard, J.F. and Guyton, A.C.: Circ.Res. 32, 564 (1973).

5. Eckberg, D.L.: Circulation 59, 632 (1979).

6. Fink, G.D., Kennedy, F., Bryan, W.J. and Werber, A.: Hypertension 2, $319(1980)$.

7. Frohlich, E.D., Pfeffer, M.A., Weiss, K.A. and Brecher, G.A.: P. Soc. Exp. M. 140, 145 (1972).

8. Ito, C.S. and Scher, A.M.: Circ.Res. 48,576 (1981).

9. Kannel, W.B., Sorlie, P. and Gordon, T.: Circulation 6, 1183 (1981).

10. Kleinjans, J., Kasbergen, C., Vervoort-Peters, L., Smits, J. and StruyKer Boudier, H.A.J.: Life Sci. 29, 509 (1981).

11. Kopin, I.J.: Ann.Intern.Med. 88, 671 (1978).

12. Littler, W.A., West, M.J., Honour, A.J. and Sleight, P.: Am. Heart J. 95, 180 (1978).

13. Mancia, G., Ferrari "A., Gregorini, L., Parati, G., Pomidossi, G., Bertinieri, G., Grassi, G., and Zanchetti, A.: Clin.Sci. 59, 401 (1980).

14. Mancia, G., Ludbrook, L., Ferrari, A., Gregorini, L. and Zanchetti, A.: Circ.Res. 43, 170 (1978).

15. Nathan, M.A. and Reis, D.J.: Circ.Res. 40, 72 (1977).

16. Norman "R.A., Coleman, T.G. and Dent, A.G.: Clin.Sci. 59, 303 (1980).

17. Sapru, H.N. and Wang, S.C.: Am.J.Physiol. 230, 664 (1976).

18. Schalekamp, M.A.D.H., Schalekamp-Kuyken, M.P.A., Birkenhäger, W.H.: Clin.Sci. 38, 101 (1970).

19. Takeshita, A., Tanaka, S., Kuroiwa, A. and Nakamura, M.: Circulation 51,738 (1975).

20. Watson, R.D.S., Stallard, T.J., Flinn, R.M. and Littler, W.A.: Hypertension 2,333 (1980).

21. Watson, R.D.S., Stallard, T.J. and Littler, W.A.: Clin.Sci. 57, 283 (1979). 


\section{Chapter III}

\section{Baroreflex sensitivity during the develop- ment of spontaneous hypertension in rats}

\section{Introduction}

The baroreflex is an important factor in the control of the cardiovascular system. It has been shown that the range of control exerted by barorecep. tors adapts to maintained high pressure both in hypertensive man $(8,13,16)$ and in several forms of experimental hypertension in animals $(1,5,15,18,19,23)$. The adlaptation of baroreceptors to a maintained high pressure has been associated with a decrease of the overall baroreflex sensitivity (BRS).

Cumulative evidence over the last decade supports reduced BRS in borderline $(12,26)$ and essential human hypertension $(8,13,25)$. In animal studies reduced BRS was shown in renal (15) as well as spontaneously hypertensive rats $(11,17,23,24)$.

Although it seems well established that the sensitivity of the baroreflex is reduced in hypertension, relatively little is known on the dynamics of this process in relation to the development of hypertension. Angell-James and co-workers $(6,7)$ studied the development of BRS in renal hypertensive rabbits.

The sensitivity was reduced progressively by a factor $2-3$ in both groups over a period of 16 weeks parallel to the development of hypertension. In contrast, Jones \& Floras (15) recently showed that in renal hypertensive rats $B R S$ is reduced by a factor 2 in an early phase of the development of hypertension. With a further increase in pressure sensitivity was reduced progressively to $4-5$ times below control values.

The present study was designed to follow BRS during the development of a spontaneous, genetically determined form of experimental hypertension. The Japanese strain of spontaneously hypertensive rats was studied, with progenitor Wistar Kyoto rats as controls.

\section{Methods}

Male spontaneously hypertensive rats and progenitor normotensive Wistar Kyoto controls (WKY) of ages ranging from 4 to 20 weeks were obtained from the Centraal Proefdierenbedrijf T.N.O., Zeilst, the Netherlands. They were housed individually and had free acces to standard laboratory food (Hope Farms, RMH-TM) and water. Under ether anaesthesia a cannula was advanced into the left femorall artery for blood pressure measurement. A silastic 0.020 inch internal diameter (i.d.) cannula with a $3 \mathrm{~cm}$ piece silastic 0.030 inch fi.d. tubing at the distal end (total volume $0.02 \mathrm{ml}$ ) was brought into the right jugular vein to allow intravenous injection. The cannulae were filled with a heparin solution in saline ( 250 units $/ \mathrm{ml}$ of sodium 
chloride solution (154 mmolll). Rats were allowed minimally 1 day to recover before the start of the experiments. They were allowed to move freely in their cages during the experiments.

Experiments were performed during daytime. Rats usually are at rest in their cages during that time. The arterial blood pressure signal was measured with a Statham P23 Db or CTC-CPO1 strain gauge and was recorded continuously with a Grass 7P Polygraph. The natural frequency response of the catheter manometer system is larger than $60 \mathrm{~Hz}$. Mean arterial pressure (MAP) was calculated as the diastolic +3 (systolic-diastolic pressure). Heart period was determined on 'a beat-to-beat basis as the reciprocal value of heart rates, which was measured from a Narco Blotachometer (type 7302 , position beat-to-beat) triggered with the blood pressure signal. According to the original method of Smyth et al (22) BRS is measured by plotting the pulse interval of each beat against the systolic pressure of the preceding beat during an increase in blood pressure induced by the pressor agents angiotensin or phenylephrine. In later studies the same authors indicated that the $\alpha$-adrenoceptor stimulating agent phenylephrine is preferable and that mean arterial pressure could be used equally well as systolic blood pressure (13). In a subsequent study Pickering and Davies (20) investigated the shift in pulse interval that gave the highest correlations between pressure and heart period. They found a shift 0 (i.e. correlating pressures with the periods of the beat in which they occur) gave the best correlations in some cases, whereas in other cases a shift +1 (i.e. using periods of succeeding beats) gave the best results. This phase shift is related to the latency of the baroreflex, which is close to $1 \sec (20,21)$. This allows the use of a phase shift of 0 or +1 .

In the rat the high heart frequency of 6-9 beats/s in combination with the approximately $1 \mathrm{sec}$ latency in the reflex-mediated change in heart rate (21) does not allow a simple phase shift of 0 or +1 .

Fig.3.1 gives an example of plots of MAP against heart period at different phase shifts during a phenylephrine injection in a normotensive WKY rat. The corresponding slopes of the linear regression lines for the rising phase of blood pressure as a measure of BRS are also indicated with their correlation coefficients. This analysis indicates the arbitrary value for BRS obtained when applying the original method of Smith et al. (22) in the rat. We therefore used an adaptation of this method by injecting six to nine doses of phenylephrine ranging from 0.1 to $30 \mu \mathrm{g} / \mathrm{kg}$ in $0.05 \mathrm{ml}$ of saline. After each dose the cannula was flushed with $0.05 \mathrm{ml}$ of saline. Cardiac sllowing in terms of the maximal heart period during the first $3 \mathrm{~s}$ after a phenylephrine injection was plotted against maximal MAP in that period (fig.3.2). The relationship heart period/MAP ( $\mathrm{ms} / \mathrm{mmHg}$ ) we expressed as a regression coefficient. Only observations with a correlation coefficient greater than 0.70 and a $P$ value less than 0.05 were used. Four percent of the correlations had to be rejected on the basis of this criterion. Results are expressed as mean \pm SEM. Linear regression for determination of BAS was performed with the least-squares method by using a Texas in- 

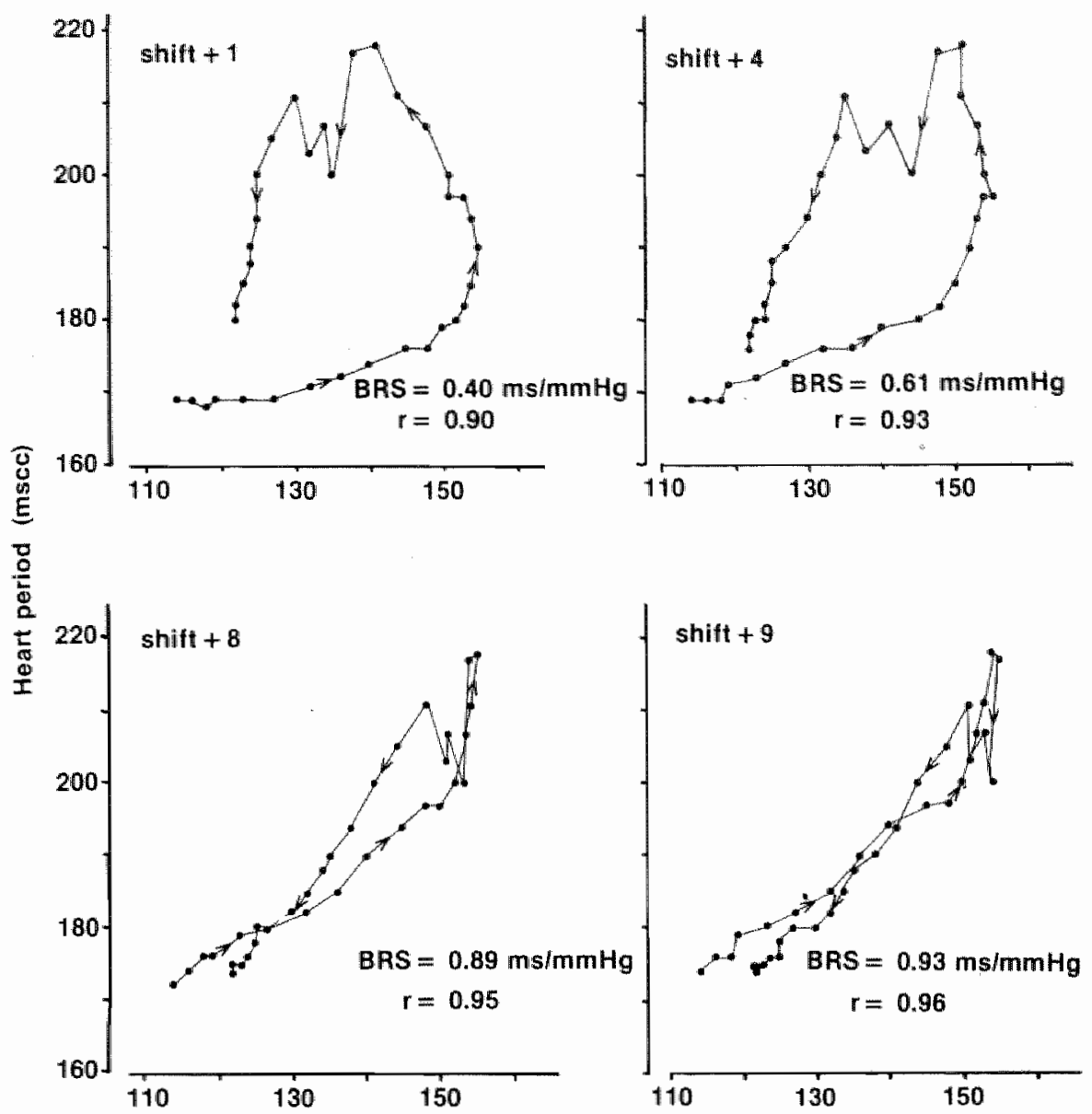

Mean Arteriall Pressure $(\mathrm{mm} \mathrm{Hg})$

Fig. 3.1 Plots of the main arterial pressure (MAP) against heart period (HP) at different phase shifts during a phenyl-ephrine-induced increase in blood pressure in a WKY (MAP $=112 \mathrm{mmHg}$ ) according to the method of Smyth et al (22). For both the increase and return of blood pressure during each consecutive heart beat MAP is plotted against HP during the pulse interval after that heart beat (shift $+n)$. BRS is expressed as the slope of the linear regression for each rising phase of MAP. $r$ is the corresponding correlation coefficient. 


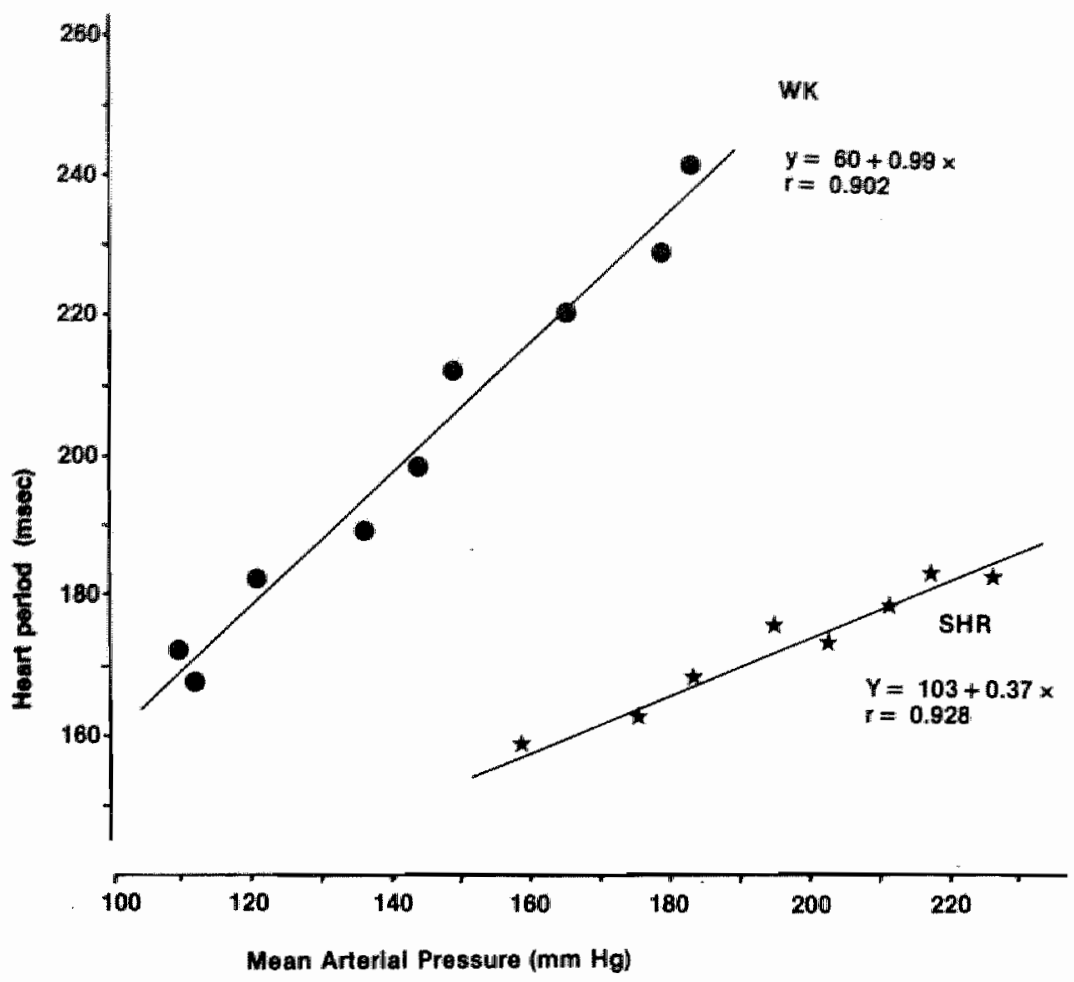

Fig. 3.2 Plots of the change in mean arterial pressure (MAP) against heart period (HP) during the injection of different doses of phenylephrine in an adult, conscious SHR (MAP $=155 \mathrm{mmHg}$ ) and WKY (MAP $=110 \mathrm{mmHg}$ ). Baroreflex sensitivity was determined as the linair regression between MAP and HP.

struments TI 59 calculator. Significances of differences between mean values was tested by using Student's unpaired t-test.

\section{Results}

Rats were divided in four groups on the basis of their age: 4-6 weeks, $6-9$ weeks, 9-12 weeks and 12-20 weeks. There were no significant differences in body weights for the SHR and WKY in equal age groups (Table 3.1). MAP in the youngest SHR $(112 \pm 2 \mathrm{mmHg}, \mathrm{n}=19)$ was already significantly $(P<0.01)$ higher than in $4-6$ weeks old WKY $(95 \pm 4 \mathrm{mmHg} ; n=10)$.

The difference increased during the further development of the animals, 52 


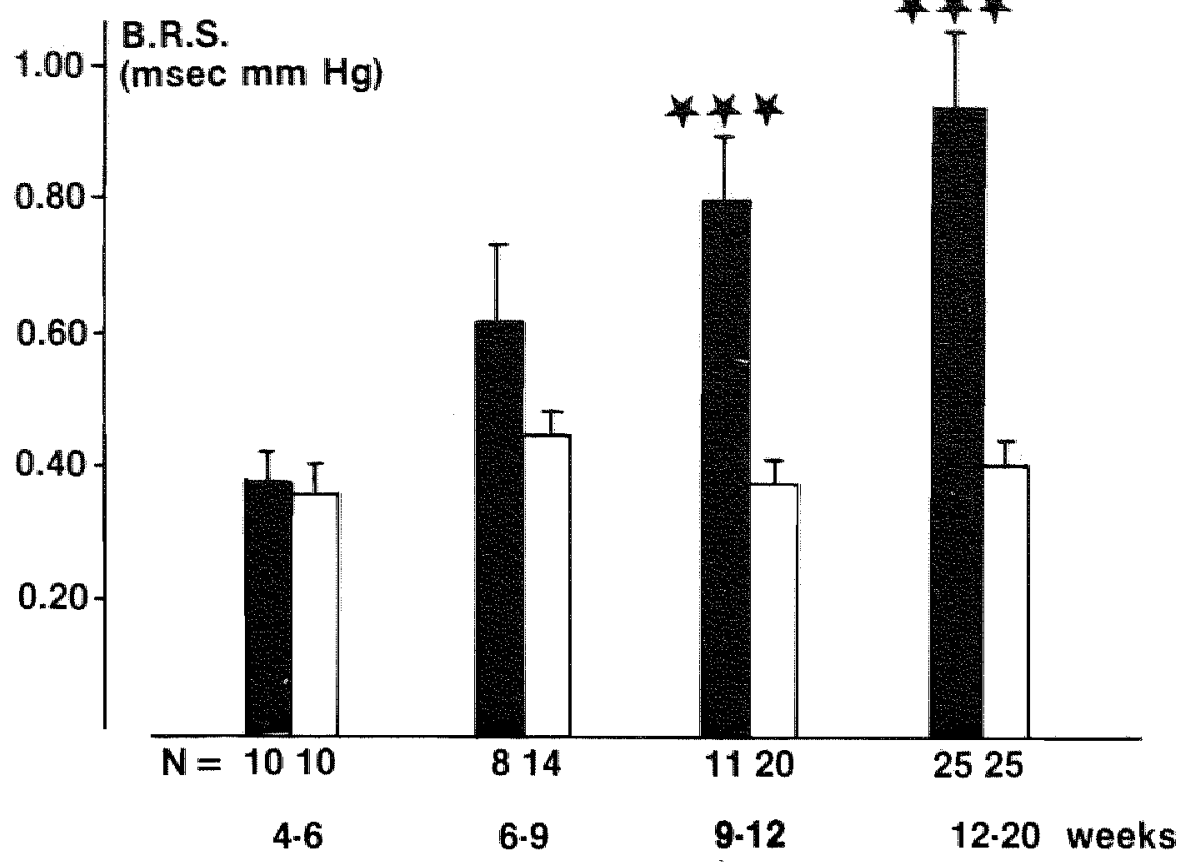

Fig. 3.3 Barorefllex sensitivity of SHR (open columns) and WKY (stipped columns) of different ages. Significances of differences between corresponding SHR and WKY:

${ }^{* * *} \mathrm{P}<0.001$.

reaching values of $166 \pm 3 \mathrm{mmHg}$ for the $12-20$ weeks old SHR $(n=25)$ and $110 \pm 6 \mathrm{mmHg}$ in the WKY $(n=25)$ (Table 3.1). Heart rate was significantly $(P<0.001)$ higher in the youngest SHR $(453 \pm 13$ beats $/ \mathrm{min})$ than in the WKY $(381 \pm 9$ beats/min). The rate decreased during the further development of the SHR; in the 9-12 weeks old animals it was no longer significantly different from WKY heart rates.

Baroreflex sensitivity is plotted against age for the different groups in fig. 3.3. Data indicate that young SHR and WKY had equally low BRS ranging from 0.18 to $0.60 \mathrm{~ms} / \mathrm{mmHg}$. Mean BRS values are equal for the youngest SHR $(0.37 \pm 0.04 \mathrm{~ms} / \mathrm{mmHg})$ and $W K Y$ rats $(0.38 \pm 0.05 \mathrm{~ms} / \mathrm{mmHg})$. BRS increased with age in WKY rats stabilizing at a mean value of $0.93 \pm 0.08$ $\mathrm{ms} / \mathrm{mmHg}$ in the $12-20$ weeks old animals. This value is significantly $(P<0.001)$ higher than that of 12.20 weeks old SHR $(0.40 \pm 0.03 \mathrm{~ms} / \mathrm{mm} \mathrm{Hg})$. In the SHR a low BRS is retained throughout the entire age range studied, with a relative maximum of $0.45 \pm 0.03 \mathrm{~ms} / \mathrm{m} \mathrm{mHg}$ in the $6-9$ weeks old rats. 


\section{Discussion}

We have used an adaptation of the method described originally by Smyth et al. (22) to measure baroreflex sensitivity during the development of hypertension in the SHR. The original BRS method was developed for use in humans and used one bolus of phenylephrine. Systolic or mean blood pressure of successive arterial pulses is plotted in that method against each pulse interval that begins with the next beat. This can be done in man, since the latency of the cardiac reflex response in many species, including man, is $0.5-2 s(10,14,20)$. Since normal heart rate in man approximates 1 beat/s, correlations with a 0 or +1 phase shift give an estimate of BRS in man (20). In the rat, however, normal heart rate is $6-9$ beats/s, with a latency of the cardiac baroreceptor-mediated reflex of $0.5-1 \mathrm{~s}(10)$. This means that phase shifts of +4 to +10 may have to be used to obtain optimal correlations. Jones \& Floras (15) recently described a method for measuring BRS in rats in which "the observer was given the facility to include delays of several cardiac cycles when computing the regression of pulse interval against preceding mean arterial pressure". With this method they found a BRS of $0.95 \mathrm{~ms} / \mathrm{mmHg}$ in normotensive rats. This value cor-

\section{Table 3.1.}

\begin{tabular}{|c|c|c|c|c|c|}
\hline $\begin{array}{l}\text { Rat } \\
\text { strain }\end{array}$ & $\begin{array}{c}\text { Age } \\
\text { (weeks) }\end{array}$ & $\mathbf{N}$ & Body weight & $\begin{array}{c}\text { MAP } \\
(\mathrm{mmHg})\end{array}$ & $\begin{array}{l}\text { Heart rate } \\
\text { (beats/min) }\end{array}$ \\
\hline $\begin{array}{l}\text { SHR } \\
\text { WKY }\end{array}$ & $\begin{array}{l}4-6 \\
4-6\end{array}$ & $\begin{array}{l}10 \\
10\end{array}$ & $\begin{array}{l}106 \pm 5 \\
107 \pm 8\end{array}$ & $\begin{array}{c}112 \pm 2^{*} \\
95 \pm 4\end{array}$ & $\begin{array}{l}453 \pm 13^{* *} \\
381 \pm 9\end{array}$ \\
\hline $\begin{array}{l}\text { SHR } \\
\text { WKY }\end{array}$ & $\begin{array}{l}6-9 \\
6-9\end{array}$ & $\begin{array}{r}14 \\
8\end{array}$ & $\begin{array}{l}197 \pm 9 \\
209 \pm 8\end{array}$ & $\begin{array}{l}136 \pm 5^{*} \\
109 \pm 3\end{array}$ & $\begin{array}{l}395 \pm 8^{\star \star} \\
363 \pm 6\end{array}$ \\
\hline $\begin{array}{l}\text { SHR } \\
\text { WKY }\end{array}$ & $\begin{array}{l}9-12 \\
9-12\end{array}$ & $\begin{array}{l}20 \\
11\end{array}$ & $\begin{array}{l}268 \pm 4 \\
263 \pm 4\end{array}$ & $\begin{array}{l}161 \pm 4^{\star *} \\
112 \pm 3\end{array}$ & $\begin{array}{l}387 \pm 7 \\
378 \pm 12\end{array}$ \\
\hline $\begin{array}{l}\text { SHR } \\
\text { WKY }\end{array}$ & $\begin{array}{l}12-20 \\
12-20\end{array}$ & $\begin{array}{l}25 \\
25\end{array}$ & $\begin{array}{l}322 \pm 7 \\
309 \pm 8\end{array}$ & $\begin{array}{l}166 \pm 3^{* * *} \\
110 \pm 6\end{array}$ & $\begin{array}{l}370 \pm 7 \\
369 \pm 11\end{array}$ \\
\hline
\end{tabular}

Body weight, mean arterial pressure (MAP) and heart rate (HR) of SHR and WKY at different ages.

Group results are means \pm SEM. Significances of differences between corresponding SHR and WKY: 
responds well to the value of $0.93 \mathrm{~ms} / \mathrm{mmHg}$ we found in nomotensive adult WKY rats. Coleman (10) measured BRS recenlly in conscious normotensive rats by a method comparablle with that we have used. Although he expressed his results in a different manner, recalculation of the data presented suggests a BRS of $0.8-1.0 \mathrm{~ms} / \mathrm{mmHg}$. Moreover, the data by Coleman (10) indicate that BRS with phenylephrine is independent of the dose, confirming the linearity we find in our correlations of maximal heart period against maximal MAP.

Our results show that BRS is significantly lower in the SHR with established hypertension than in the WKY. Similar conclusions were reached by others on the basis of different methods $(11,17,23,24)$. Moreover many authors have shown that the adaptation of baroreceptors to a maintained high blood pressure is associated with reduced BRS in other forms of clinical and experimental hypertension (see the introduction). As a cause of reduced BRS several authors have suggested that during hypertension the distensibility of the vessels in which baroreceptors are located decreases. Others (17) favour an abnormality in the central nervous system processing of baroreceptor reflex activity. On the other hand, it has been suggested that a change in baroreceptor elements themselves plays a role in the reduced sensitivity of the baroreflex. Such mechanisms could involve a change in membrane permeability to $\mathrm{Na}^{+}$or $\mathrm{K}^{+}$, or a change in the membrane $\mathrm{Na}^{+}$electrogenic pump $(3,9)$. Recent evidence favouring such a non-structural cause for reduced BRS in hypertension came from Jones and Floras (15), who studied the time course of BRS changes in renova* scular hypertension in rats. They found a significant diminution of BRS within 3 days after clipping the renal artery, at a time when structural changes in the heart or vasculature were not yet present.

The primary purpose of our study was to follow the dynamics of the change in BRS during the development of spontaneous hypertension.

The most surprising result was that during development of hypertension BRS did not decrease in the SHR, but rather increased in the WKY. During the phase of maturation of the animals ( $c$. the increase in body weight) BRS increased by a factor 2-3 in WKY rats, whereas it remained relatively constant in SHR rats. In fact, sensitivity of the SHR increases slighty up to weeks 6-9 and then diminishes again. These results do not point to a BRS decrease in the SHR as a consequence of structural vascular changes after hypertension. Rather, they could indicate a difference in the development of baroreceptor properties during maturation of the two stralns of rats. Interestingly, Andresen et al. (4) by measuring single aortic barore. ceptor fibre discharges to increasing pressure, as an index of receptor gain, found a gradual increase in sensitivity in WKY rats from 5 to 30 weeks of age whereas the baroreceptor sensitivity in the SHR failed to in. crease. These authors speculated that the large changes in vessel (aorta) morphology during maturation are matched in WKY rats by changes in the mechano-transduction of the baroreceptors, thus preventing changes in the pressure threshold $(2,4)$. In the SHR, on the other hand, the different 
pattern of developments of the aorta (smaller internal and externall radii, smaller circumferential wall strain) is not matched by an adequate adapta. tion of mechanotransduction in SHR baroreceptors, according to Brown's group $(2,4,9)$. The same group speculated earlier that a change in membrane permeability to $\mathrm{Na}^{+}$of $\mathrm{K}^{+}$, or changes in the membrane $\mathrm{Na}^{+}$electrogenic pump might underly this abnormality in SHR baroreceptors $(3,9)$. The implications of these findings for our insight in the pathogenesis of spontaneous hypertension remain to be further investigated. Our SHR's were slightly hypertensive already before major changes in baroreceptor reflex properties seemed to take place. On the other hand, the period of drastic rise in pressure coincides with the time when baroreceptor properthes apparently adapt to keep pressure normal in WKY. A similar increase in the sensitivity of baroreflex was described by Vatner and Manders (27) during early postnatal development of normotensive dogs. It thus seems that increase in BRS is part of the development of a normotensive cardiovascular system, whereas in the SHR the responsiveness of the baroreceptor reflex remains depressed. 


\section{References}

1. Aars, H:: Acta Physiol. Scand. 72, 298 (1968).

2. Andresen, M.C. and Brown, A.M.: Circ. Res. 47, 829 (1980).

3. Andiresen, M.C., Krauhs, J.M.., and Brown, A.M.: Circ. Res. 43, 728 (1978).

4. Andresen, M.C., Kuraoka, S. and Brown, A.M.: Circ. Res, 47, 821 (1980).

5. Angell-James, J.E.: Circ. Res. 32, 149 (1973).

6. Angell-James, J.E. and George, M.J.: Clin.Sci.Mol.Med. 51, suppl. 3, 369 (1976).

7. Angell-James, J.A., George, M.J. and Peters, G.J.:

Clin.Exp.Hypertens. 2, 321 (1980).

8. Bristow, J.D., Honour, A.J., Pickering, G.W., Sleight, P. and Smyth, H.S.: Circulation 39, $48(1969)$.

9. Brown, A.M.: Circ. Res. 46, 1 (1980).

10. Coleman, T.G.: Am.J.Physiol. 238, H515 (1980).

11. Coote, J.H. and Sato, Y.: Circ. Res. 40, 571 (1977).

12. Eckberg, D.L.: Circulation 59, 632 (1979).

13. Gribbin, B., Pickering, T.G., Sleight, P. and Peto, R.: Circ. Res. 29, 424 (1971).

14. Jewett, D.L.: J. Physiol. (London) 175, 321 (1964).

15. Jones, J.V. and Floras, J.S.: Clin.Sci. 59, 347 (1980).

16. Kezdim P.: Arch.Inter.Med. 91, 26 (1953).

17. Lee, JY., Walsh, G.W., Mokler, C.M. and Tobia, A.J., Res.Commun.Chem.Pathol.Pharmacol. 29, 27 (1980).

18. McCubbin, J.W., Green, J.H. and Page, I.H.: Circ. Res. 4, 205 (1956).

19. Nosaka, S. and Wang, S.C.: Am.J.Physiol. 222, 1079 (1972).

20. Pickering, T.G. and Davies, J.: Cardiovasc.Res. 7, 213 (1973).

21. Pickering, T.G., Gribbin, B. and Sleight, P.: Cardiovasc.Res. 6, 277 (1972).

22. Smyth, H.S.L., Sleight, P. and Pickering, G.W.: Circ. Res. 24, 109 (1969).

23. Sapru, H.N. and Krieger, A.J.: Am.J.Physiol. 236, H174 (1979).

24. Sapru, H.N. and Wang, S.C.: Am.J.Physiol. 230, 664 (1976).

25. Simon, A.Ch., Safar, M.E., Weiss, Y.A., London, G.M. and Milliez, P.L.: Br.Heart J. 39, 799 (1977).

26. Takeshita, A., Tanaka, S., Kuroiwa, A. and Nakamura, M.: Circulation 51,738 (1975).

27. Vatner, S.F. and Manders, W.T.: Am.J.Physiol. 237, H40 (1979). 


\section{Chapter IV}

\section{Systemic and peripheral hemodynamics during the development of spontaneous hypertension in rats.}

\section{Introduction}

Present theories on the herrodynamic events leading to and maintaining essentlal hypertension are almost exclusively derived from observations on central hemodynamics, viz. measurement of arterial pressure, cardiac output, intravascular volumes and the calculated total peripheral resistance and vascular compliances. In a recent review Lund-Johansen (24) argued that the circulatory pattern would undergo a change with time from the typical high blood flow-normal resistance pattern in young age towards a normal blood flow-high resistance pattern in old age. The link between those two hemodynamic patterns can be explained by the so called autoregulation theory, originally developed by Borst and Borst de Geus (4), modified by Ledingham and Cohen (21) and Guyton and co-workers from whose laboratory two recent reviews have appeared on this concept $(7,10)$. Before further discussing the role of autoregulation in hypertension it is appropriate to define this term as applied in this thesis. Autoregulation refers to local tissue mechanisms which act intrinsically to control vascular resistance and thereby flow through a particular tissue. The underlying mechanisms in this process are poorly understood but by definition occur independently of the central nervous system or circulating hormones (10). The time period in which tissues autoregulate appears to differ in different tissues and wide ranges from highly autoregulated tissues such as brain and kidney, towards relatively passively reacting organs, such as skin have been described (10).

The possible role of autoregulation in hypertension is obvious. An increased cardiac output (index) in an early phase of the hypertension may lead to an autoregulatory response in the major vascular beds of the body and provides for an elevation of total peripheral resistance, which reduces cardiac output ( $(n d e x)$, but increases the mean arterial pressure. Although the importance of autoregulation as a local tissue mechanism has been accepted, only few authors reported on the regional hemodynamics in borderline and essential hypertension. Temmar et al. (35) reported an increased lower limb flow, and a normal renal and hepatic flow when borderline hypertensives are compared with normotensive controls, whereas in patients with an established essential hypertension a normal fllow distribution was found in most organs, with an exception for the kidney in which a decreased flow was found (35). This study suggests that the increased cardlac output is mainly transmitted to skeletal muscle, which implies either that autoregulation is not a rapidly reacting mechanism in skelletal 
muscle, when compared to other organs (kidney and liver). However, the influence of other flow regulating systems (e.g. the sympathetic nervous system) and structural adaptations cannot be excluded from this study. A major problem in the study of the dynamics of human essential hypertension is the extremely llong time-scale for the full development of this disease. Therefore, animal models have been used frequently to follow central hemodynamics during the development of hypertension. Recently the SHR has attracted special attention in this respect, since several techniques (flow probe-, dye dilution- and reference sample microsphere technique) have given the further opportunity to investigate central hemodynamics in conscious rats.

In an early phase this form of hypertension is characterized by an increase in cardiac output and a normal total peripheral resistance $(27,34)$, whereas in the established phase cardiac output is normalized and peripheral resistance is increased $(11,34)$. Recently the reference sample microsphere technique has given the opportunity to study not only central hemodynamics but also peripheral hemodynamics (28). In the adult SHR (4 month old) and young SHR (9-8 weeks old) this technique has led to the observation that the total peripheral resistance increased and that almost all organs contribute equally to this increased peripheral resistance $(11,30,39)$. Until now no studies have been performed on the peripheral hemodynamics in SHR during the hyperkinetic circulatory state.

Since Smith and Hutchins (34) found that around an age of 5 weeks the cardiac index is significantly increased (thereafter it returns to normal), the present study was aimed at an analysis of central and regional hemodynamics in conscious 5 and 7 weeks old SHR and WKY (during and directly after the hyperkinetic circulatory state).

\section{Materials and methods}

For animals see preceding chapters.

Animal preparation

During ether anaesthesia a PE10 catheter was inserted into the left femoral artery and passed into the abdominal aorta $11 / 2 \mathrm{~cm}$ below the renal artery.

A second PE10 catheter (stretched over a hot soldering iron) was passed down the right carotid artery into the left ventricle (the position of the catheter was controlled by the left ventricle pressure curve on a television monitor).

The external segments of the two catheters were exteriorized through a cutaneous tunnel on the back of the neck.

Four to five hours after full recovery from ether anaesthesia and surgery blood pressure and heart rate were measured, whereas cardiac output was measured thereafter. 
R.S.M. technique

The reference sample technique was used for the determination of cardiac output in the conscious freely moving rat. A reference sample was taken from the abdominal aorta at a constant rate of $0.61 \mathrm{~m} / \mathrm{min}^{-1}$ with a Harvard suction pump for a time period of $90 \mathrm{sec}$. Ten seconds after starting the pump 250.000 microspheres were injected (suspended in $100 \mu$ l $0.9 \% \mathrm{NaCl}$ ) with a Hamilton Syringe. At the end of the experiment the animals were killed by an overdosage of pentobarbital, the animals were dissected, organs were taken out and counted in an autogamma scintillation spectrometer model 5220.

These data were used for the calculation of blood flows and resistances in a computerprogram according to that of Saxena et al. (33).

\section{Microspheres}

Carbonized plastic microspheres $(15 \pm 1.5 \mu \mathrm{m})$ labelled with $95 \mathrm{Nb}$ and $113 \mathrm{Sn}$ were obtained from N.E.N. Just prior to use they were suspended in $0.9 \% \mathrm{NaCl}$ (containing $0.02 \%$ Tween 80 ) by ultrasonication for 10 minutes.

\section{Statistics}

Values indicated represent means \pm S.E.M. The unpaired two tailed Student's t-test was used for the comparison of weights, blood flows, blood pressures and resistances.

\section{Results}

Systemic hemodynamics (Table 4.1)

Both in 5 and 7 weeks old SHR mean arterial blood pressure and heart rate were significantly elevated when compared to WKY. A significant increase in cardiac output ( $37 \%$ ) was observed in the 5 weeks old SHR, whereas this parameter was normal in 7 weeks old SHR. An increase in total peripheral resistance $(56 \%)$ was observed in the 7 weeks old SHR when compared to age matched WKY (P.<0.01).

Interestingly this increase in total peripheral resistance was not due to a significant increase of total peripheral resistance during aging of the SHR, but to a significant decrease of total peripheral resistance of the WKY.

Regional hemodynamics (Table 4.2 and 4.3 )

Differences in regional hemodynamics are mainly observed in the 5 weeks old SHR. The fractional cardiac output ( $\% \mathrm{CO}$ ) was significantly decrea- 


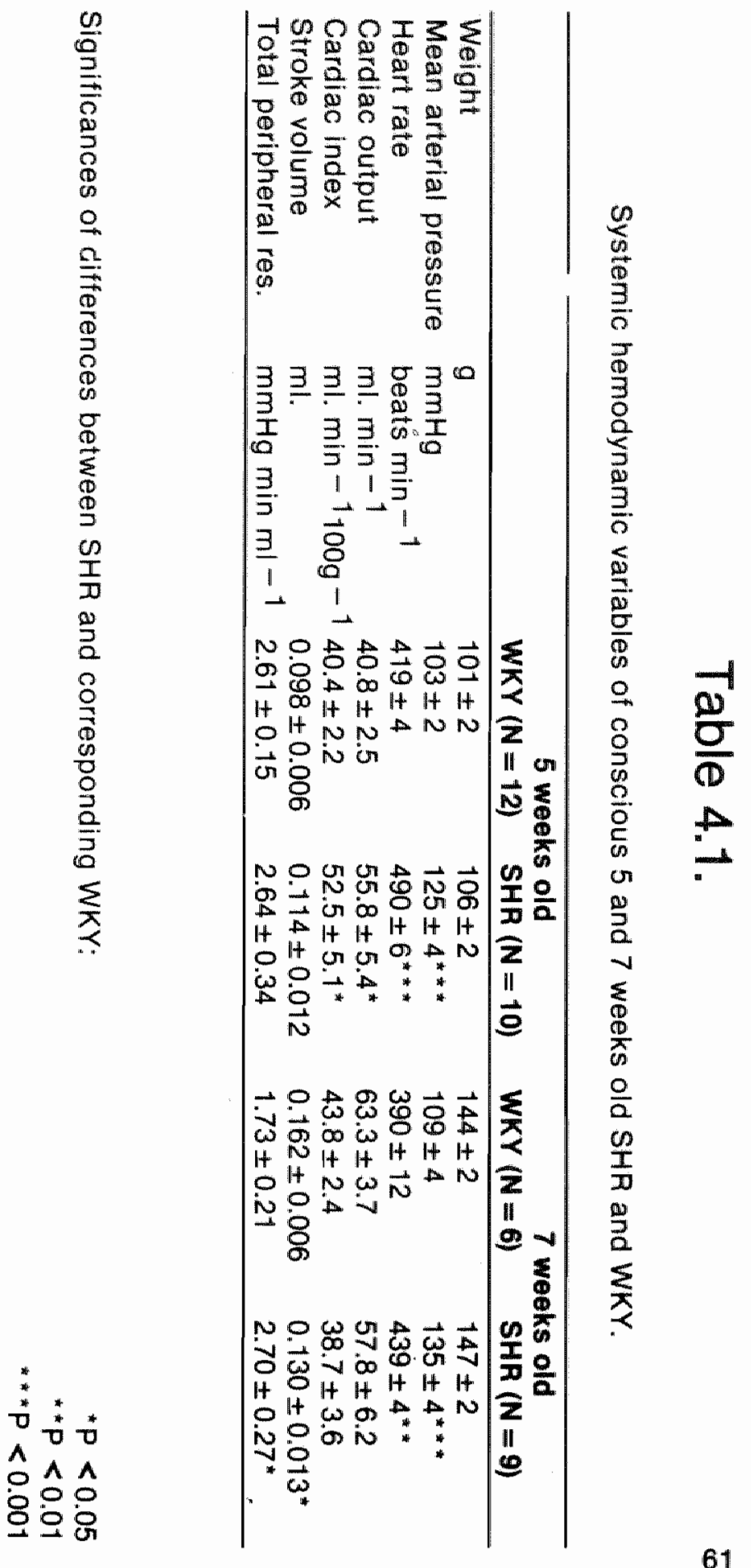




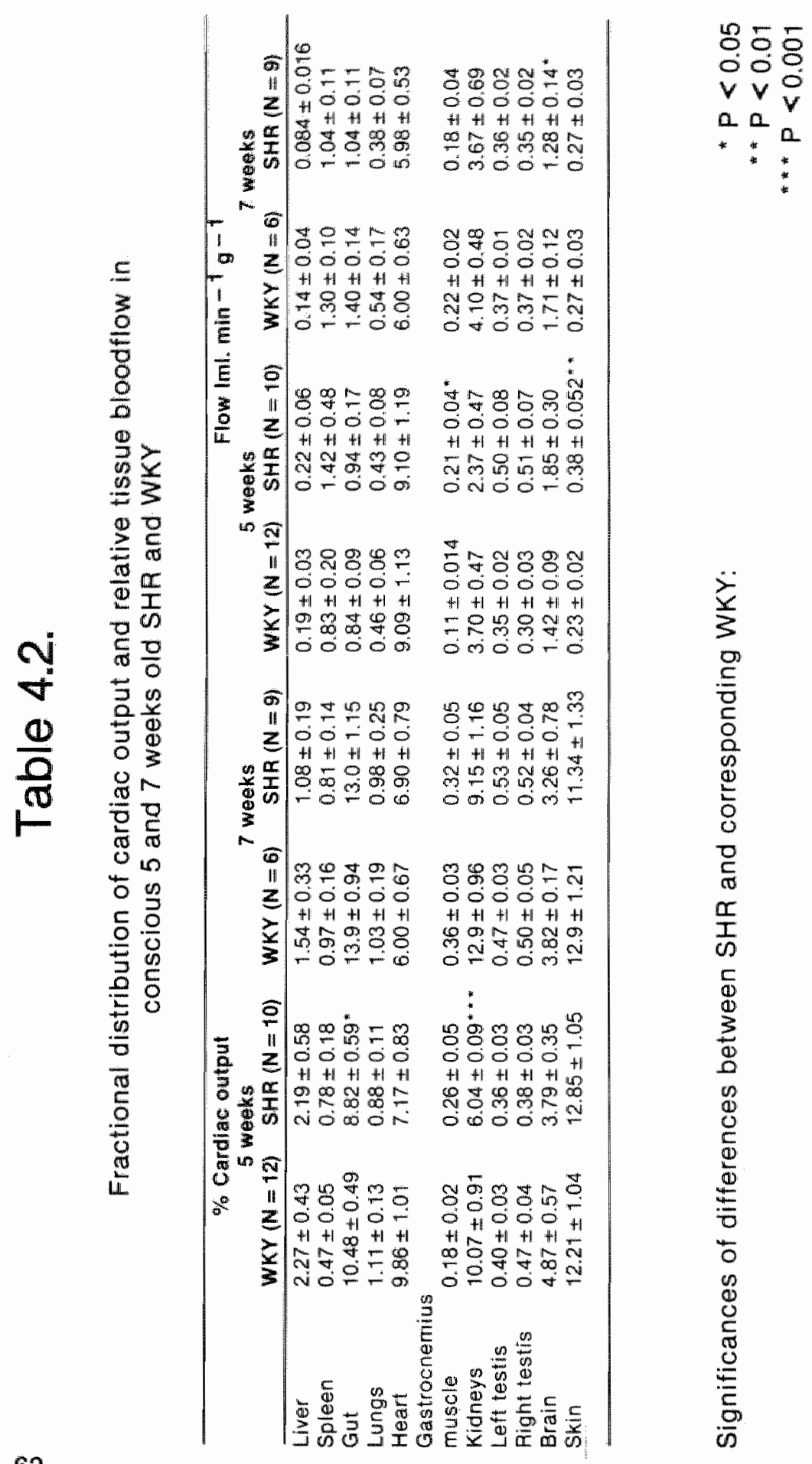




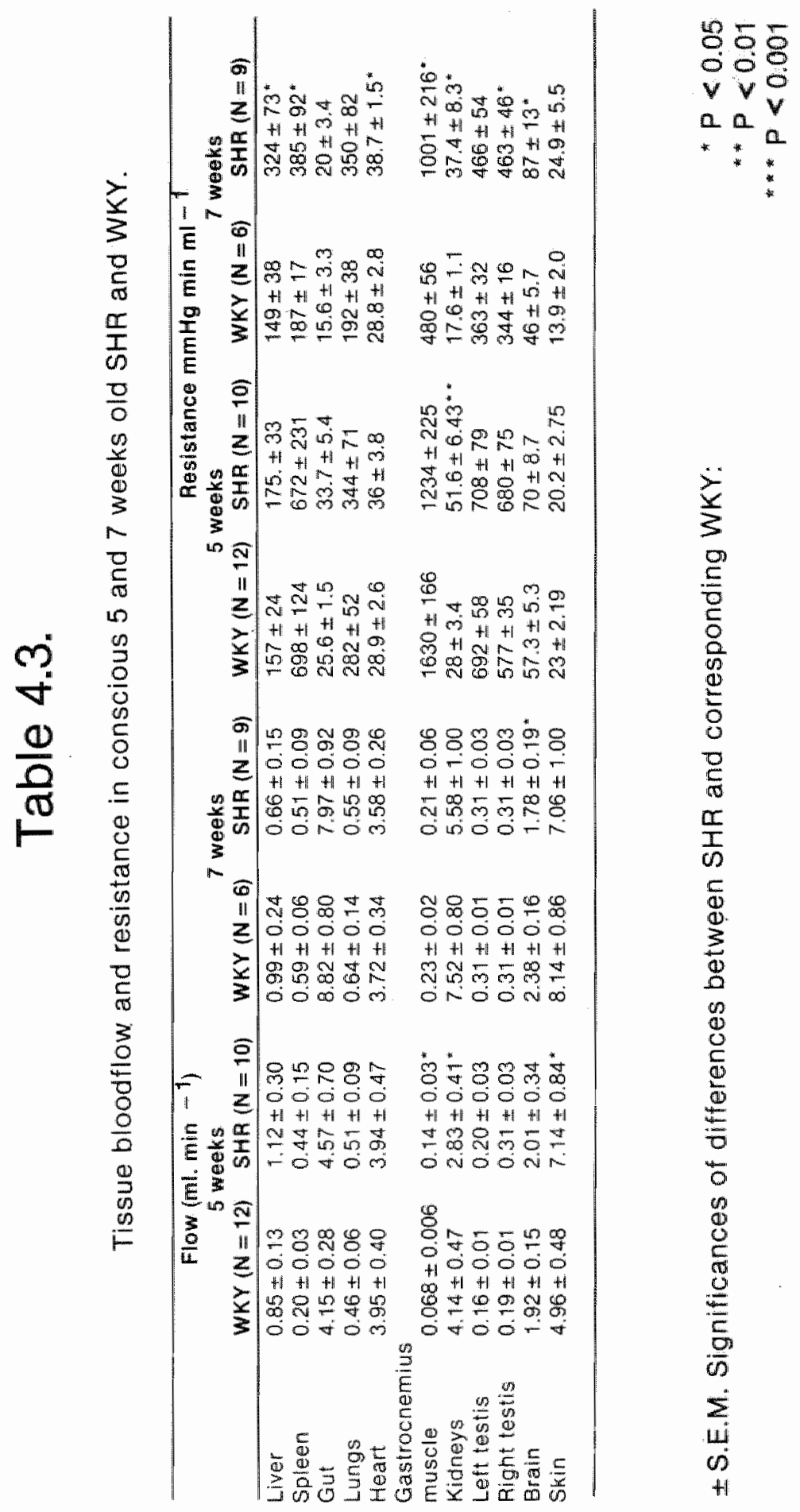


sed in gut (16\%) and kidneys $(40 \%)$. The absolute flow (mllmin) was increased in gastrocnemius $(106 \%)$ and skin $(44 \%)$, whereas a $31 \%$ decrease in absolute blood flow was obtained in the kidneys of the 5 weeks old SHR. Similar results were observed in the relative blood flow (ml. $\mathrm{min} .-1.9-1$ ): a significant increase was observed in gastrocnemius and skin (resp. $91 \%$ and $65 \%)$. A significant decrease was not observed in the kidney $(P=0.07)$ in contrast to the absolute kidney flow.

In the 7 weeks old SHR a significant decrease in absolute and relative fllow was observed in the brain, whereas no statistical significant differences were observed in relative, absolute and fractional flow of the other tissues of the 7 weeks old SHR in comparison to WKY.

An increase in resistance was observed in all organs studied.

This reached statistical significance in the liver $(117 \%)$, spleen $(106 \%)$, heart $(34 \%)$, gastrocnemius $(109 \%)$, kidneys $(113 \%)$, testis $(47 \%)$ and brain $(89 \%)$.

\section{Discussion}

The first studies on systemic hemodynamics of the SHR were done in open chest animals under anaesthesia (15). Since anaesthesia has a myocardial depressant effect (37), the reference sample microsphere technique originally developed by Rudolph and Heymann (32) and adapted for the use in conscious rats by Malik (28) was an advantage.

With this method not only cardiac output could be measured, but also its distribution in peripheral organs.

The microsphere technique, however, needs proper attention with respect to the following:

1. Enough microspheres must be present in organs and reference sample (385 or more) for statistical analysis $(16,18)$.

2. Attention must be given to the size of the microspheres $(15 \mu \mathrm{m}$ is the optimum size for the rat $(5,28)$ ).

3. If only a part of the skin is taken attention must be given to the variation in blood flow in that organ (25).

4. The amount of microspheres must not disturb the circulation (17).

5. Microspheres must not be suspended in dextran for the application in rats (12).

In our study 250.000 plastic carbonized microspheres $(15 \mu \mathrm{m})$ suspended in $0.9 \% \mathrm{NaCl}$ were used for injection.

With respect to the amount of microspheres even the injection of 450.000 microspheres has been reported not to influence cardiac output and its distribution (17). Moreover injection of 250.000 microspheres resulted in a statistically acceptable number of microspheres in the reference sample and all tissues used in this study ( 450 microspheres or more).

The size of the microsphere $(15 \mu \mathrm{m})$ was chosen to ensure complete entrapment in the microcirculation and equal distribution over the crosssection of the aorta. Even in the gut where A-V shunts could hamper our 
results it has been reported that entrapment was almost complete (31). Another factor which could influence our results is the unequal flow distribution in the skin (25); therefore the whole skin was used in this study. In this study we investigated the cardiac output and its distribution during and shortly after the hyperkinetic circulatory phase in rats with spontaneous hypertension. We found a significant increase in cardiac output for the 5 weeks old SHR when compared to age matched controls (resp. $55.8 \pm 5.4$ and $40.8 \pm 2.5 \mathrm{ml} / \mathrm{min}$ ). These values correspond well with the values obtained by Smith and Hutchins (34) in conscious 5 weeks old SHR and WKY with the electromagnetic flow probe technique (resp. $54 \pm 3$ and $46 \pm 4 \mathrm{ml} / \mathrm{min})$.

An increased cardiac output in the young SHR (6 weeks) was also found by Lundin and Hallbäck-Nordlander (27) when compared to age-matched WKY (resp. 79.8 and $67 \mathrm{ml} / \mathrm{min}$ ), with the dyedilution technique.

In comparison to our results the cardiac outputs of both SHR and WKY are somewhat higher in the study of Lundin and Hallbäck-Nordlander. The rats used by Lundin and Hallbäck-Nordlander were heavier than our rats (resp. 140 and $100 \mathrm{~g}$ ); this may explain the difference.

On the other hand the dyedilution technique may result in a higher cardiac output than other techniques.

In our study the increased cardiac output in the SHR was associated with a significant increase in heart rate $(17 \%)$ whereas no difference in stroke volume was observed in the 5 weeks old SHR when compared to WKY.

Since mental stress increases the heart rate and cardiac output more in the SHR than in the WKY (27), and moreover since autonomic blockade of the nervous system to the heart leads to a reduction of cardiac output in the 6 weeks old SHR to the level obtained in the WKY, the increase in heart rate in combination with an increased cardiac output in the SHR may be the result of an increased central neurogenic drive to the heart in the SHR (27).

An alternative explanation for the observed increased cardiac output in the 5 weeks old SHR is an increased preload to the heart. Several arguments supports this theory. An increased left atrial pressure has been reported in the SHR (29), probably as a consequence of an increased "central blood volume" (26), (chapter $V$ of this thesis). In the 5-6 weeks old SHR no data on atrial pressures are available. However, the increased total plasma volume observed in chapter $V$ of this thesis and the indication that the centralization of blood volume is already present in the 5 weeks old SHR (26), points to an increased atrial pressure in the 5 weeks old SHR. It is, however, unlikely that an increased volume load to the heart is the only cause of the increased cardiac output:

1) in a typical "volume dependant" form of hypertension (the Milan hypertensive rat), the hypertension is associated with an increased stroke volume and a decreased heart rate (in contrast to the SHR (13);

2) in contrast to the situation in dogs (3), volume loading in the 5 weeks old $\mathrm{SHR}$ is associated with a bradycardia rather than tachycardia (Struyker. 
Boudier, unpublished results). Thus, a possible role of a potentially increased atrial pressure in the 5 weeks old SHR is prevention of a reduction in stroke volume rather than an increased stroke volume at this age.

Another interesting observation in this chapter is a decrease of kidney and an increase in resistance in the kidney, which suggests that the kidney has a role in the induction of the spontaneous hypertension. One should keep in mind that an increase in plasma volume observed in chapter $V$ also provides arguments for a primary function of the kidney in this type of hypertension. Many other authors have also provided arguments for an inductive role of the kidney both in spontaneous and essential hypertension (6). It has been reported that the increase in resistance in the kidney is mainly the result of a preglomerular (afferent arteriolar) increase in resistance $(1,6)$. Direct nerve recordings of the sympathetic nerves supplying the kidney have led to the suggestion that an increased sympathetic tone may contribute to this increased resistance in the kidney of the $\operatorname{SHR}(19,36)$. In 6 weeks old SHR Collis et al $(8,19)$ demonstrated an increased release of noradrenaline after stimulation of the sympathetic nerves supplying the kidney in the SHR. Further arguments for an increased activity of the renal sympathetic nerves and the contribution of this system to the hypertension were given by several authors, who observed an inhibition of the hypertension after specific sympathetic denervation of the kidneys $(20,22,39)$.

The major goal of our study was to investigate possible autoregulative mechanisms involved in the induction and stabilization of spontaneous hypertension.

In the 5 weeks old SHR the increased cardiac output was mainly distributed to skin and skeletal muscle (a similar pattern was observed in borderline hypertension (35) and other experimental forms of high cardiac output hypertension (23). It must be concluded that skin and skeletal muscle are relatively slowly autoregulated organs, whereas other organs are relatively quick in autoregulation. The significant decrease in flow in the kidney cannot be explained by autoregulation, since "hypoperfusion" is present in that organ and an autoregulative mechanism must normalize a flow instead of reducing it.

In the 7 weeks old SHR the increase in peripheral resistance was present in all organs examined in this study. This difference reached statistical significance in the liver $(117 \%)$, spleen $(106 \%)$, heart (34\%), gastrocnemius $(109 \%)$, kidneys $(113 \%)$ and brain $(89 \%)$.

The increased resistance in skeletal muscle and skin in the 7 weeks old SHR may be the result of the preceding increased flow in those tissues. Although autoregulation seems a likely mechanism for the explanation of this sequence of events, other mechanisms like structural adaptations and even damage of blood vessels as a consequence of the increased flow cannot be excluded from this study. Alternatively other mechanisms may also be involved in the increased resistance of several organs in the 7 weeks old SHR (e.g. the sympathetic nerve activity, or the sensitivity of the 
vessels smooth muscle to noradrenaline $(13,14)$. Although the autoregulation and fluid retention by the kidney could contribute to the induction of hypertension, the role of the central nervous system cannot be neglected. It must be noted that some differences observed in the peripheral and central hemodynamics in the 5 weeks old SHR can be explained by the so called hypothalamic defence reaction $(2,14)$ (e.g. increased heart rate, increased flow through skeletal muscle, increased cardiac output). At the other hand an increased blood flow through brain and myocardium, which are also part of the defence reaction were not found in this study. In spite of this a central nervous system disorder resulting in a disbalance of the autonomic nervous system in rats with spontaneous hypertension remains an attractive alternative for the explanation of the differences between 5 weeks old SHR and WKY.

In conclusion:

1) Skin and skeletal muscle are relatively slowly autoregulated organs, whereas other organs (e.g. gut, brain, etc.) are relatively quick in autoregulation in the 5 weeks old SHR.

2) The kidney may be involved in the induction of spontaneous hypertension.

3) An increased heart rate, cardiac output and a decreased renal flow may be the result of neurogenic mechanisms in an early phase of spontaneous hypertension. 


\section{References}

1. Arendshorst, W.J. and Belerwaltes, W.H. Am. U. Physiol. 236246 (1979).

2. Azevedo, A.D., Hilton, S.M. and Timms, R.J. Proc. Physiol. Soc. 301, $56 \mathrm{P}(1979)$.

3. Bishop, V.S. and Peterson, D.F. Am. J. Physiol. 231, 854 (1976).

4. Borst, J.G.G. and Borst de Geus, A. Lancet I, 677 (1963).

5. Casellas, D. and Mimran, A. Cardiovasc. Res. 14, 577 (1980).

6. Coleman, T.G., Guyton, A.C., Young, D.B., de Clue, J.W., Norman, R.A. and Manning, R.D.: Clin. Exp. Pharmacol. Physiol. 2, 571 (1975).

7. Coleman, T.C., Samar, R.E. and Murphy, W.R. Hypertension 1, 324 (1979).

8. Collis, M.G., De Mey, C. and Vanhoutte, P.M. Hypertension 2, 45 (1980).

9. Collis, M.G. and Vanhoutte, P.M. Clin. Sci. Mol. Med. 55, suppl. 4 $233(1978)$.

10. Cowley, A.W. Am. J. Med. 68, 906 (1980).

11. Ferrone, R.A., Walsh, G.M., Tsuchiya, M. and Frohlich., E.D. Am. J. Physiol. 236, 403 (1979).

12. Flaim, F.S., Zachary, Q.M. and Kennedy, T.J. Am. J. Physiol. 235, 587 (1978).

13. Folkow, B. Clin. Sci. Mol. Med. 55, suppl. 4, 3 (1978).

14. Folkow, B. Clin. Sci. 57 suppl. 5, 83 (1979).

15. Genest, J., Kolw, E., Kuchel, P, Hypertension, McGrawhill Inc. New York (1977) p.27.

16. Heymann, M.A.y Payne, B.D., Hoffman, J.I.E. and Rudolph, A.M. Prog. Cardiovasc. Dis. 20, 55 (1977).

17. Idvall, J. Aronsen, K.F., Nilsson, L. and Nosslin, B. Eur. Surg. Res. 11, $423(1979)$.

18. Ishise, S., Pegram, B.L., Yamamoto, J., Kitamura, Y. and Frohlich, E.D.: Am. J. Physiol. 239, 443 (1980).

19. Judy, W.V. Watenabe, A.M., Henry, D.P., Besch. H.R., Murphy, W.R. and Hockel, G.M. Circ. Res. 38, suppl. 221 (1976).

20. Kline, R.L., Kelton, P.M. and Mercer, P.F. Can. J. Physiol.

Pharmacol. 56, 818 (1978).

21. Ledingham, J.M. and Cohen, R.D. Lancet II, 887 (1963).

22. Liard, J.F. Experientia 33, 339 (1977).

23. Liard, J.F. Clin. Sci. 54, suppl. 6355 (1980).

24. Lund-Johansen, P. Clin. Sci. 59, suppl. 6, 343 (1980).

25. Lundberg, C. and Smedegárd, G. Acta Physiol. Scand. 111, 491 (1981).

26. Lundin, S.A. Folkow, B. and Rippe, B. Acta Physiol. Scand. 112, 257 (1981).

27. Lundin, S.A. and Hallbäck-Nordlander, Cardiovasc. Res. 14, 561 (1980). 
28. Malik, A.B., Kaplan, J.E. and Saba, T.M. J. Appl. Physiol. 40, 472 (1976).

29. Noresson, E., Ricksten. S.E. and Thoren, P. Acta Physiol. Scand. 107, 9 (1979).

30. Nishiyama, K., Nishiyama, A. and Frohlich, E.D. Am. J. Physiol. 230, 691 (1976).

31. Norlen, K., Rentzogh, L. and Wikström, S. Upsala J. Med. Sci. 83, 163 (1978).

32. Rudolph, A.M. and Heymann, M.A. Circ. Res. 21, 163 (1967).

33. Saxena, P.R., Schamhardt, H.C., Forsyth, R.P. and Loeve, J. Comput. Biomed. 12, 63 (1980).

34. Smith, T.L., Hutchins, P.M. Hypertension 1, 508 (1979).

35. Temmar, M.M., Safar, M.E., Levenson, J.A. Totomoukouo, J.M. and Simon, A. Ch. Clin. Sci. 60, 653 (1981).

36. Thorén, P. and Ricksten, S.E. Clin. Sci. 57, suppl. 5197 (1979).

37. Tobia, A.J., Walsh, G.M., Tadepalli, S.A. and Lee, J.Y. Blood Vessels 11, 287 (1974).

38. Tsuchiya, M. Walsh, G.M., Ferrone, R.A. Isishe, S. and Frohlich, E.D. Jpn. Circ. J. 44, 400 (1980).

39. Winternitz, S.R., Katholi, R.E. and Oparil, S., J. Clin. Invest. 66, 971 (1980). 


\section{Chapter V}

\section{Total plasma volume and its regional distri- bution during the development of spontane- ous hypertension in rats}

\section{Introduction}

The role of body fluid volumes in the hemodynamics of early and established hypertension has been the subject of extensive discussion. Human essential hypertension is generally associated with a normal or slightly decreased total plasma and blood volume $(5,21,24,29,35)$. In borderline hypertension in young human subjects a range of relatively low to high plasma and blood volume values has been found $(9,17,21,39)$. The positive correlation between total blood volume and cardiac output in these patients would support the role of intravascular volumes in maintaining cardiac output during the development of hypertension $(21,39)$. Safar et al. (27) have suggested that from a hemodynamic point of view the distribution of vascular fluid volumes within the vascular system should be considered in addition to the total volumes. It is of interest that a centralization of the blood volume to the cardiopulmonary region has been found in borderline hypertensive patients (18) and has a higher correlation with the cardiac index than the total blood volume in those patients (22).

The study of the hemodynamic role of body fluid volumes in essential hypertension is hampered by the long time-scale of development of this form of hypertension. The recently introduced rat models of genetic hypertension offer an attractive alternative, since hypertension develops in these species within weeks rather than years. In adult genetically hypertensive rats with established hypertension of both the New-Zealand and Okamoto strains reduced plasma and blood volumes were found $(2,11,20,25)$, although others found a normal (30) or even increased (23) plasma and blood volumes in the adult Okamoto spontaneously hypertensive rat (SHR).

In different series of studies in 2-6 weeks old rats normal total plasma and blood volume values were reported in very young New Zealand hypertensive rats (10) and SHR $(20,36)$.

The distribution of plasma and blood volume in rat models of hypertension has not been investigated in detail. Lundin et al. (20) recently indicated a centralization of blood to the cardiopulmonary region in the young SHR. However, it remains to be established whether an eventual decrease in intravascular volumes is related to structural or functional changes of the venous side of the circulation in different regional vascular beds. The purpose of the present experiments was to follow plasma volumes in SHR of a range of ages derived from one source. In addition, we investigated the distribution of plasma volume in different tissues during the development of spontaneous hypertension. 


\section{Materials and methods}

Animals

Male pneumonia-free spontaneously hypertensive rats (SHR) and genetically related Wistar Kyoto rats (WKY) were used in this study. These anl: mals were born in our own laboratory facilities from systematically inbred SHR and WKY strains. At an age of 21-24 days after birth rats were separated from their mothers and housed at a temperature of $24 \pm 1^{\circ} \mathrm{C}$ in cages with 4-6 animals per cage. They were given standard laboratory diet and tap water ad libitum. Conscious freely-moving animals were used in this study at different moments after birth, ranging from 5-16 weeks.

Surgery

Under ether anaesthesia catheters were inserted into the right carotid artery and into the left jugular vein (PE-10 or PE-50 depending on the age of the animal).

The ends of the catheter were tunneled subcutaneously to the neck and the skin was closed. This allowed blood pressure measurements and intravenous injections in freelly moving unanaesthetized animals. Animals were allowed 4-5 hours to recover before the start of experiments. Their blood pressures were then measured with a P23 Db Statham pressure transducer and recorded on a DMP $4 B$ Narcobiosystems recorder. The pressure signal was filtered using a low pass filter with a cut-off frequency of $0.5 \mathrm{~Hz}$, to obtain mean arterial pressure (MAP) values.

\section{Total plasma volumes and regional plasma volumes}

a. Albumin preparations

For the determination of total plasma volumes (PVo) and tissue plasma volumes (TPV) $125 \mu-\mathrm{HSA}(5-10 \mu \mathrm{ci})$ respectively 131 I. HSA $(2.5 \mu \mathrm{ci})$ obtalned from IRE or Amersham were used.

The free iodine fraction as measured by trichloro acetic acid precipitation was comparable for IRE and Amersham 125/.HSA $(2 \%)$ and for IRE and Amersham $131_{1-H S A}(4 \%)$, but not for $1251_{-H S A}$ and $131_{1-H S A}$, which is dicussed below.

\section{b. Sampling procedure}

To determine total plasma volumes and regional plasma volumes $100 \mu$ m of iodine labelled HSA (respectively 125 I-HSA and $131_{1}$.HSA) was injected into the jugular vein with a Hamil ton syringe (possible error less than $1 \%$ ), immediately followed by $0.1 \mathrm{ml}$ of saline to avoid trapping of tracer in the catheter. At least 20 minutes after injection of the tracer, when mixing is regarded to be complete (23), bloodsamples were collected from the carotid artery for the determination of plasma volumes and haematocrits. For each sampling $0.5 \mathrm{ml}$ of blood was taken from the arterial catheter (and gi. ven back after sampling), after which $40 . \mu l$ of blood was taken. 
This blood was centrifuged in $250 \mu$ heparincoated microtubes to obtain plasma. Two samples of $10.0 \mathrm{~m} /$ plasma were each pipetted into $1.0 \mathrm{ml}$ of water and thoroughly mixed. Radioactivity of these samples was counted in a Packard autogram scintillation spectrometer model 5220. 131/-HSA was counted from $240-380 \mathrm{kev}$ and $125 \|$-HSA was counted from 15-60 kev. These latter counts were corrected in the calculations for a $19.7 \%$ overlap of $131_{1-H S A}$ counts.

\section{Total plasma volumes}

Total plasma volumes were measured with a dilution technique with 125 . HSA as an indicator. To account for the loss of albumin to the extravascular space during the experiment, 125 - HSA concentration (CPM/10 $\mu \mathrm{l}$ ) was determined in arterial plasma samples at 30,60,90 and 120 minutes after injection of the tracer.

These data were used to calculate the plasma concentration of 125/.HSA at the time of injection $(t=0)$ by log linear extrapolation, after which the plasma volume at $t=0(p \vee o)$ was calculated by the formula

$$
\text { PVo }(\mathrm{m} \mid)=\frac{\text { total }^{125} \mid \mathrm{cpm} \text { injected }}{125 \mathrm{cpm}|10 \mu| \text { plasma at } t=0 \times 100}
$$

A similar calculation was used for the determination of plasma volume 20 minutes after injection of the tracer $\left(P_{20}\right)$.

\section{Regional plasma volumes}

To permit simultaneous measurement of $P V$ and tissue plasma volumes (TPV), exactly 100 minutes after injection of ${ }^{125}$. HSA a second label $\left({ }^{131}\right.$. HSA) was injected for the determination of TPV's Twenty minutes after injection of the last tracer a blood sample was taken and the animals were killed either by a short ether anaesthesia and dislocation of the neck or an abrupt blow in the neck and submersion in liquild nitrogen (according to Everett et al., 8). Both killing techniques will be compared in the result section.

Whole skin, liver, spleen, both kidneys, both testes, the heart (after cleaning the endocard with filtering paper), whole gut (including the mesenterium), lungs, the gastrocnemius muscle (including the plantaris muscle) and the soleus muscle were taken out and used for the determination of tissue plasma volumes. No visible blood loss was observed from the tissues during dissection. Since $131_{1}$-HSA had a slightly higher free iodine fraction than 125.-HSA, TPV's were determined in separate groups of SHR and WKY, by simultaneous injection of both agents in each animal. This resul. ted in all tissues in a constant lower plasma volume obtained by 125 . HSA, in comparison to tissue plasma volumes obtained by $13^{\|}$I-HSA. Therefore 
these data were used for the calculation of correction factors (c) for the transformation of tissue plasma volumes measured with 131 . HSA into tissue plasma

volumes measured with 125 H.HSA ( $c=\frac{125 \text { I.HSA tissue plasma volume }}{131 \text { I-HSA tissue plasma volume }}$ )

(see table 5.1).

The plasma volume was expressed per gram tissue and was calculated as

$\operatorname{TPV}(\mu \mathrm{l} / \mathrm{g})=\frac{131_{1} \mathrm{cpm} \text { total organ sample }}{131 / \mathrm{cpm} 1 \mu / \text { plasma at } \mathrm{t}=20 \text { min sample weight (gram) }}$

Finally the similarity of plasma volumes of individual tissues was tested for IRE and Amersham 131\%.HSA after correction in two groups of adult WKY's (Table 5.2).

Both agents are completely comparable since no difference was observed between the TPV's measured with IRE or Amersham Albumin.

Statistics

Values indicated represent means \pm S.E.M. The unpaired two-tailed student's t-test was used for statistical comparison of different variables between SHR and WKY.

\section{Results}

Methods of TPV measurement

Figure 5.1 illustrates the relative plasma volumes of muscle, testes, kidney, liver, spleen, gut, lungs and heart in 5 adult WKY killed by the liquid nitrogen freezing method and 11 adult WKY killed by ether anaesthesia and cervical dislocation. A significantly $(P<0.05)$ larger TPV was found in the muscle, skin, spleen, lungs and heart with the liquid nitrogen method. Macroscopical spot-bleedings were observed in the lungs, skin and muscle of these animals. The loss of blood through the freezing is also indicated by the high relative plasma content of heart $(448 \pm 134 \dot{\mu} \mathrm{l} / \mathrm{g}$ tissue) and lungs $(414 \pm 77 \mu \mathrm{l} / \mathrm{g}$ tissue). In all further experiments the ether method was therefore used.

MAP, PV and hematocrit

Table 5.3 summarizes the body weights, mean arterial pressures, plasma volumes calculated as $P V o$ as well as $P V_{20}$ and the hematocrits of 4 groups of SHR and WKY of different ages.

There are no significant differences in the body weights of each age- 


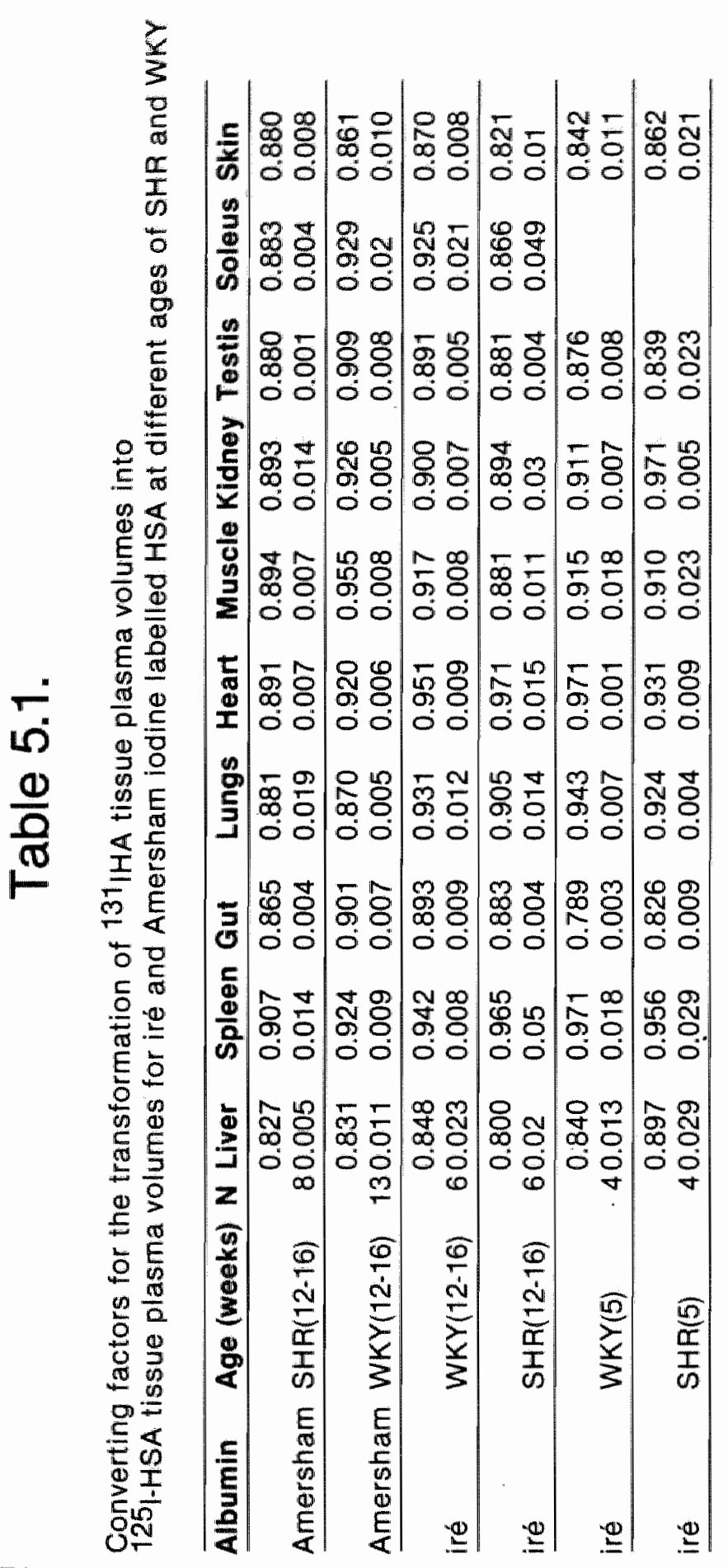




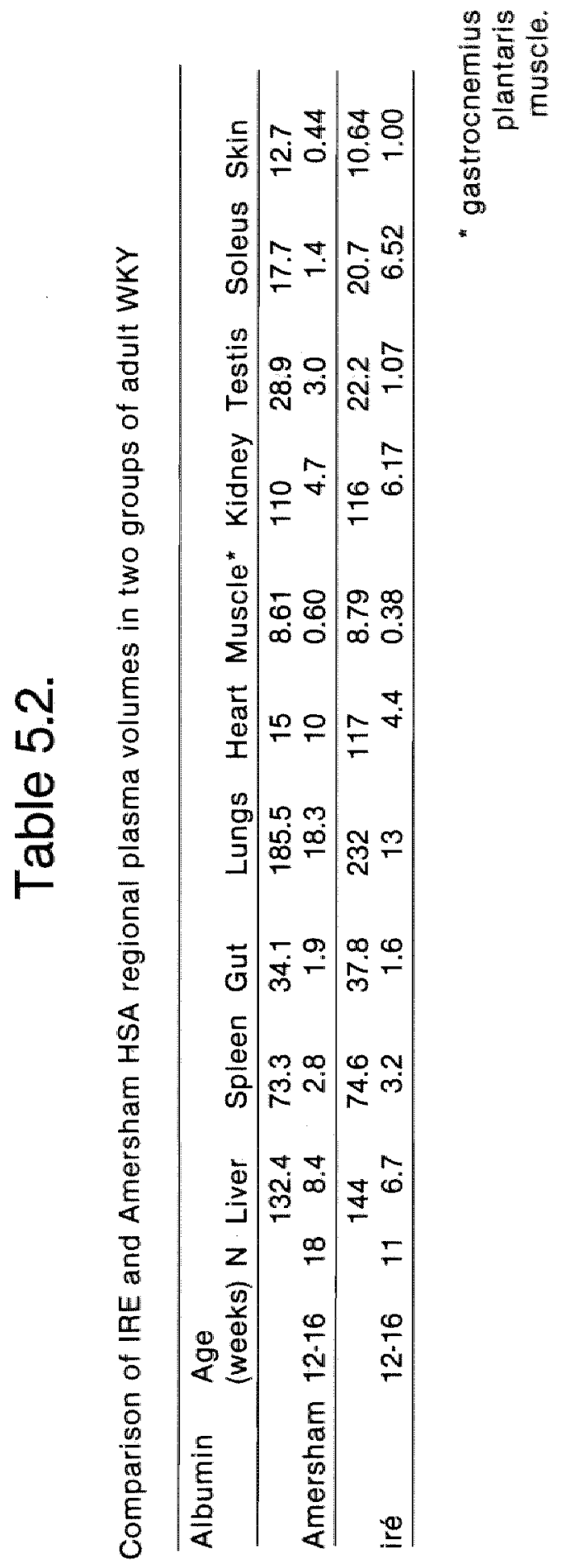




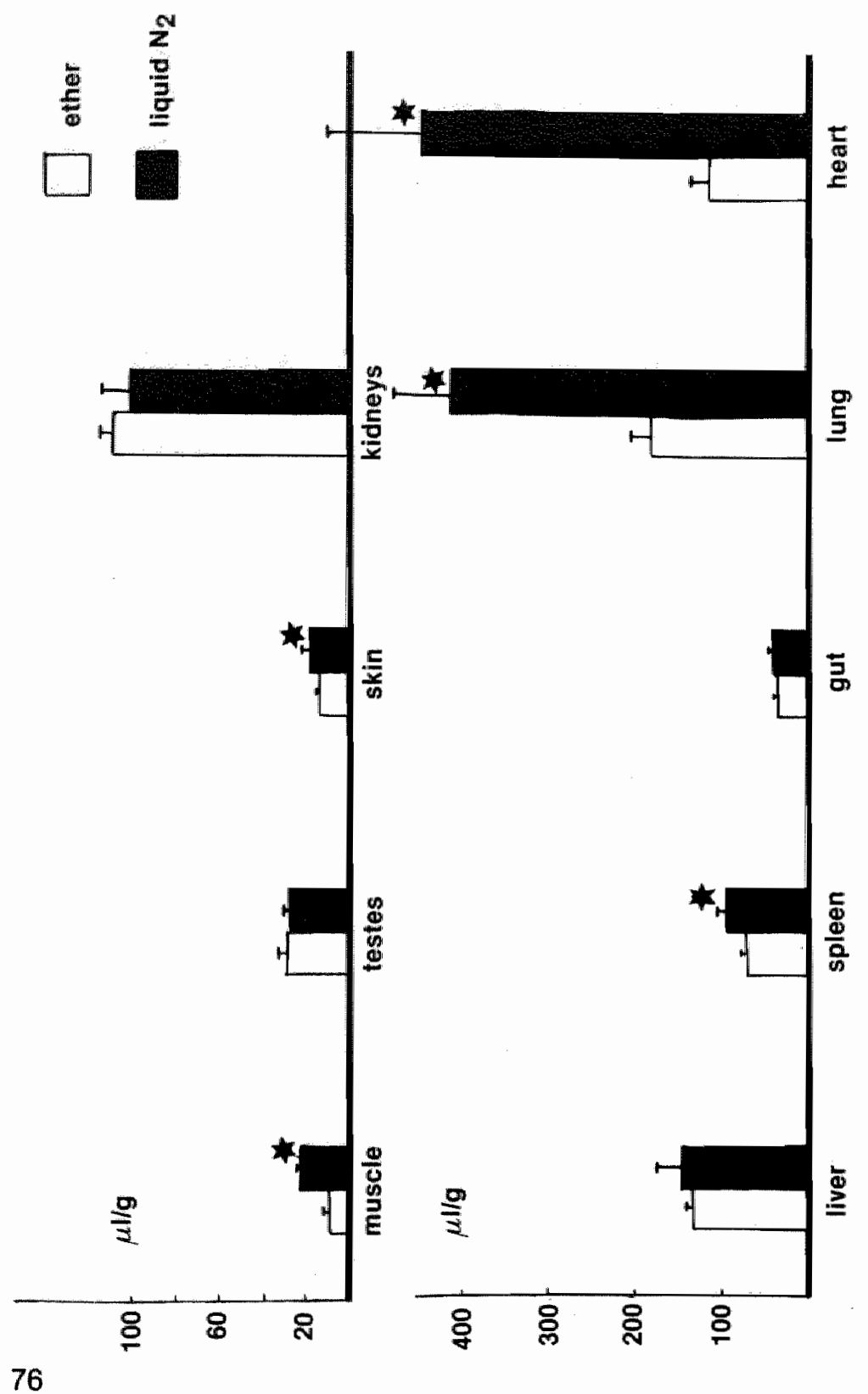

$\begin{array}{lll}\frac{1}{5} & 0 & 0 \\ 5 & 0 & 0 \\ 0 & 0 & 0 \\ 0 & 0 & 0\end{array}$

$\leqq \frac{3}{3}$

$\leq>$

迹 $\div \frac{x}{3}$

$\infty \geq$

등

$>$ 은

$\geq \frac{2}{2}$

300

응 $\frac{10}{0}$

क $\overline{0}$

의

(1) $>$

3 正

us $0 \frac{1}{0}$

흥

웅

니 3

잉ㅇㅁㅇ

등

¿

- 9

는 은

世 1)

둥

(1) II

跑

क o 0

$\div$ 등

엥

(1)

on 5 드

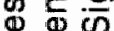

E

은

¿

E $\frac{0}{3}+1$

응

음

들

(⿻)

눙 동

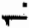

10

욘 
matched group SHR and WKY. SHR showed a significant increase in MAP when compared with WKY for all groups. Already at an age of 5 weeks MAP was significantly $(P<0.001)$ higher in the SHR $(127 \pm 4 \mathrm{mmHg})$ vs WKY $(107 \pm 2 \mathrm{mmHg})$. The difference in MAP increased during further ageing.

Plasma volumes showed a different pattern in subsequent age groups. The $P V_{20}$ value was systematically higher (range 3-10\%) than the $P V_{0}$. In the further text we will concentrate on the $P V_{O}$. In the very young group PV $O$ is significantly $(P<0.001)$ higher in the SHR $(4.81 \pm 0.08 \mathrm{ml})$ vs WKY $(4.35 \pm 0.09 \mathrm{ml})$. In the older age groups $\mathrm{PV}_{\mathrm{O}}$ was lower in the SHR, although the difference became significant $(P<0.001)$ only in the oldest age group (SHR: $8.52 \pm 0.12 \mathrm{ml}$ vs WKY: $9.91 \pm 0.29 \mathrm{ml}$ ).

The hematocrits did not differ significantly in the four groups of SHR and WKY.

Regionall plasma volumes

Organ plasma volumes of rats killed by ether are presented in figures 5.2 , $5.3,5.4$ and 5.5 for the $5,7-9,9-12$ and $12-16$ weeks old SHR and WKY respectively.

The Soleus muscle is not included in the 5 weeks old animals, since the amount of cpm per tissue sample was too low in these animals to allow calculation of TPV. In contrast, we have lumped all tissues not calculated individually into "rest" of the body for the 5 weeks old animals.

The relative plasma volumes in the 5 weeks old group were significantly lower in the SHR m.gastrocnemius (including the plantaris muscle) (19\% lower, $P<0.001)$, testes $(50 \%, P<0.001)$, gut $(16 \%, P<0.01)$ and "rest" $(13 \%, P<0.05)$. In the $7-9$ weeks and $9-12$ weeks old animals the only statistically significant decrease in relative organ plasma volume was observed in the SHR testis $(7-9$ weeks: $48 \%, P<0.05 ; 9.12$ weeks: $36 \%$, $P<0.01$ ).

In the $9-12$ weeks old SHR a small $(12 \%)$ but significantly $(P<0.05)$ higher relative heart plasma volume was observed.

In the oldest age group a significant decrease in relative plesma volume was found in the SHR m. gastrocnemius and plantaris muscle $(21 \%$, $P<0.01)$, testis $(46 \%, P<0.01)$, skin $(34 \%, P<0.001)$ and gut $(29 \%$, $\mathrm{P}<0.001$ ).

\section{Discussion}

In this study total plasma volume and plasma volumes in individual organs were investigated during the onset, development and stabilization of spontaneous hypertension in rats. Total plasma volume with an indicator dilution technique (125)-HSA). Since albumin is lost from the intravascular compartment by transvascular escape total plasma volume was calculated by extrapolating plasma albumin disappearance curves to time zero 


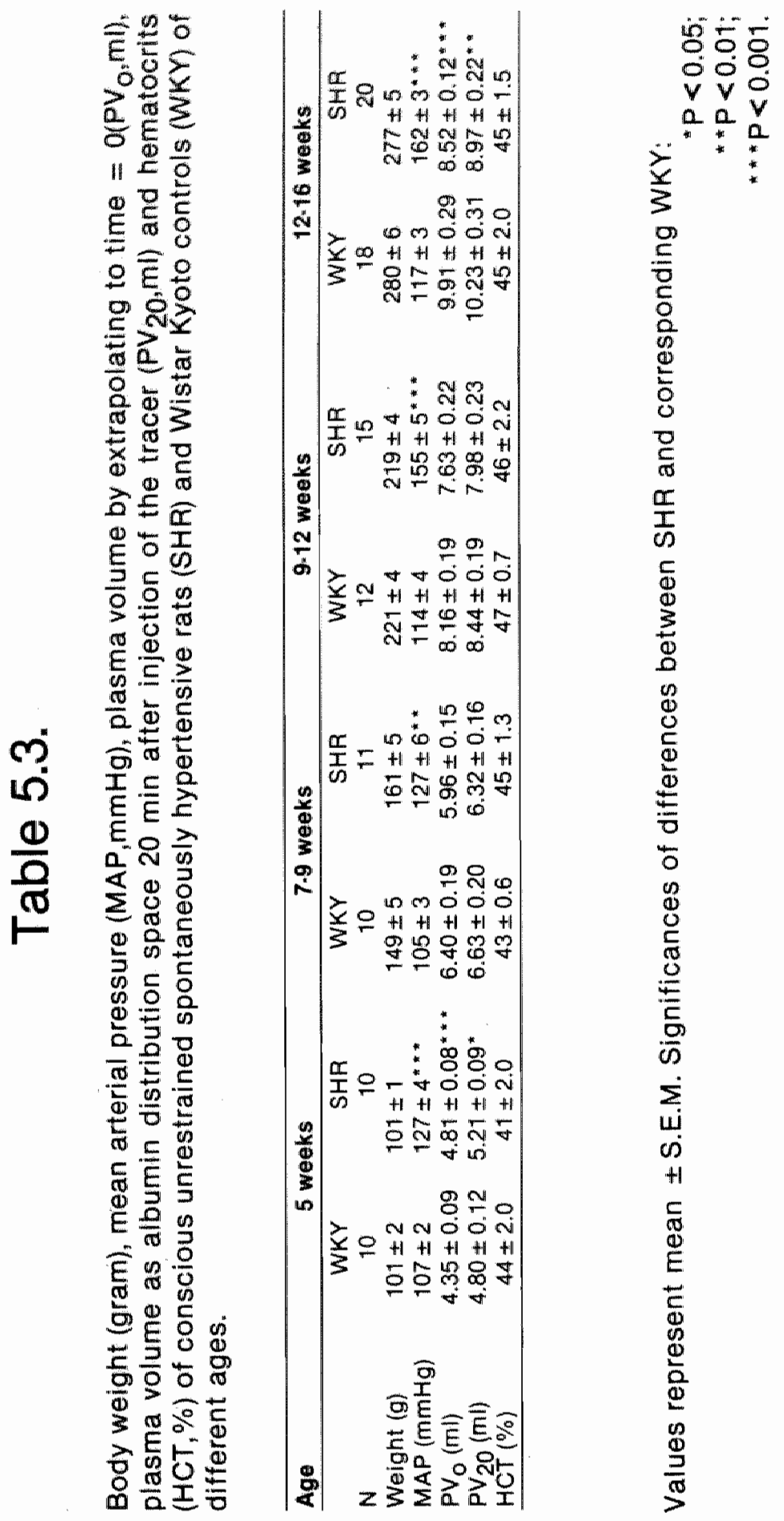




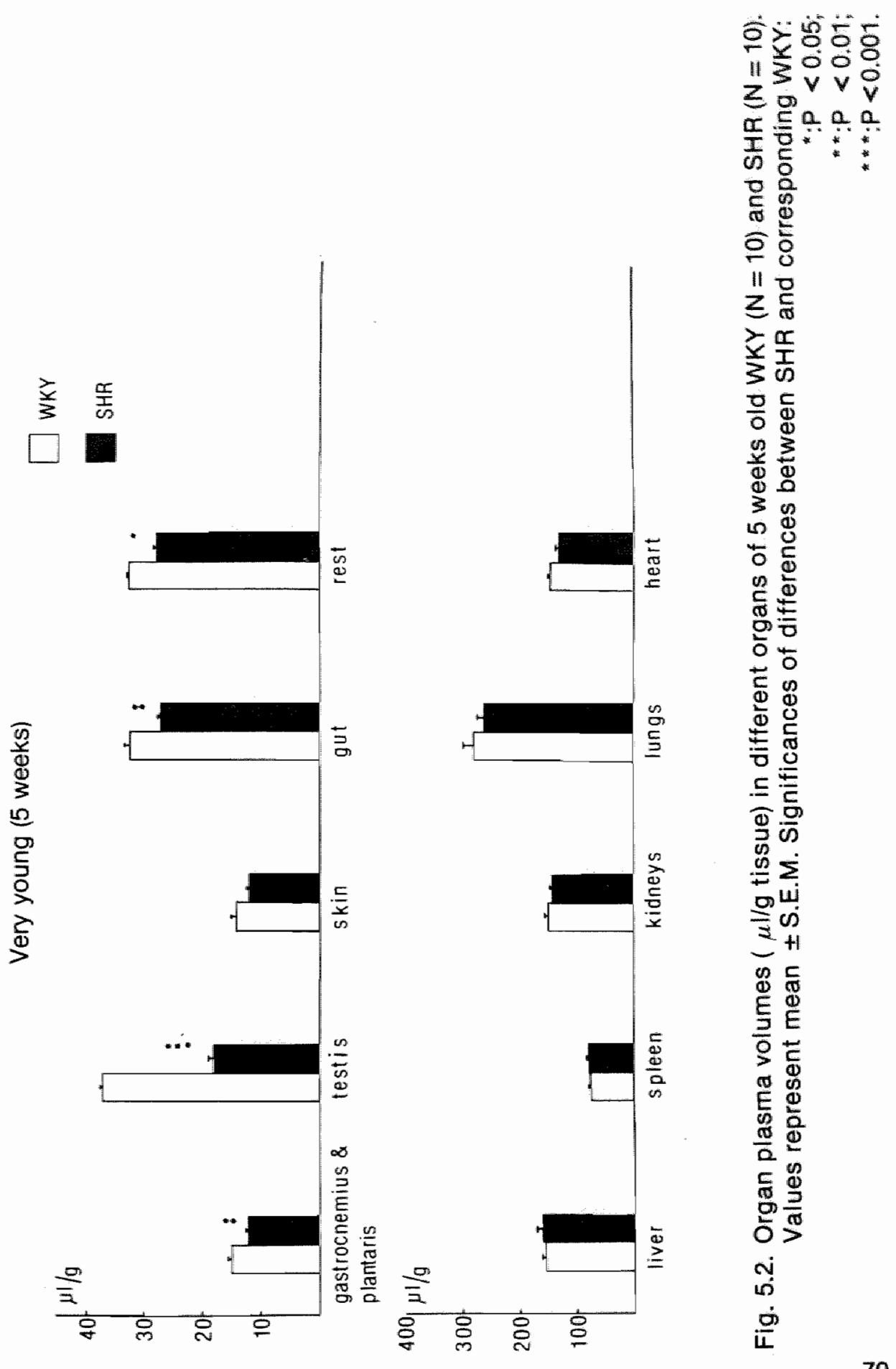




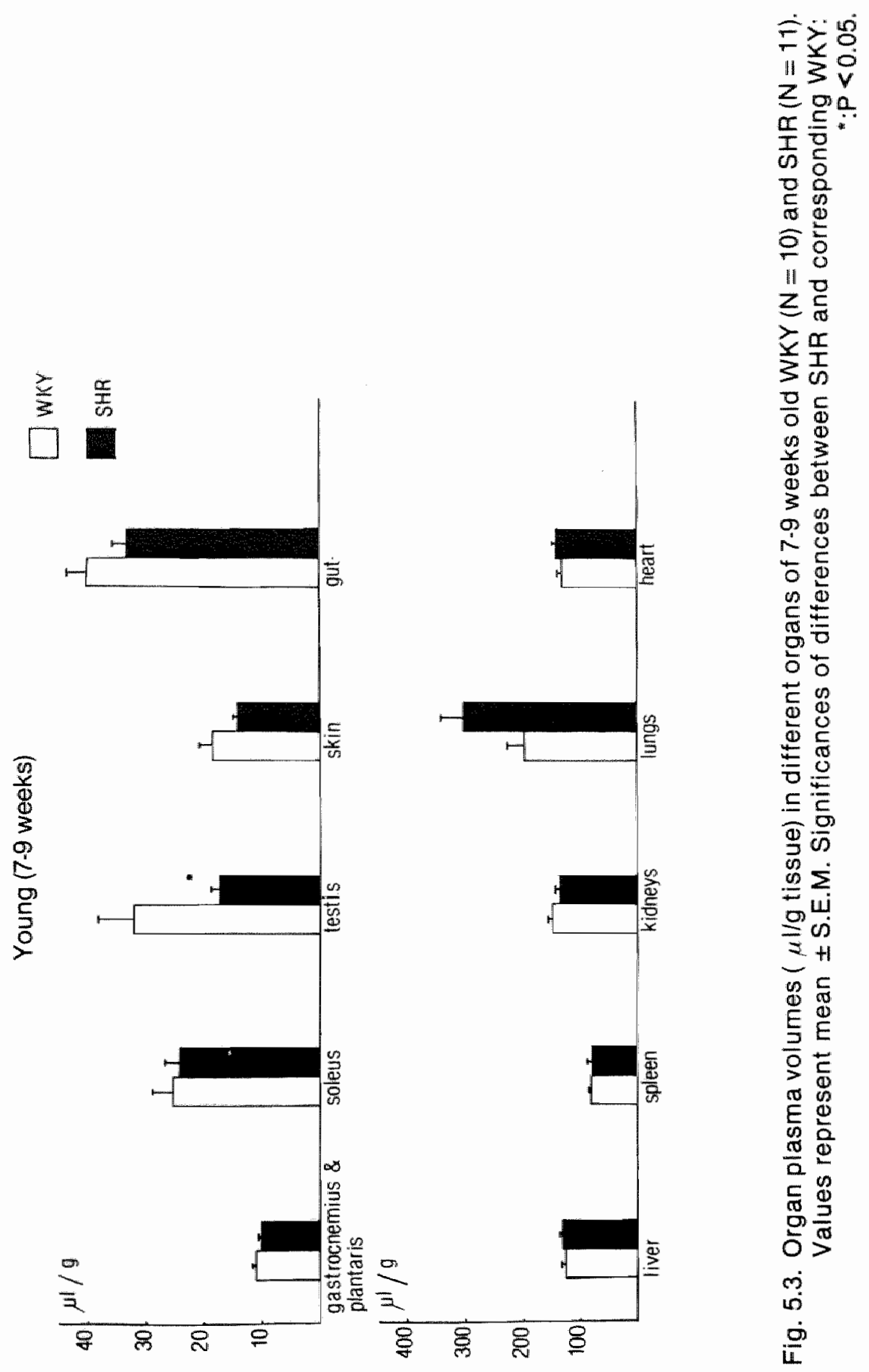




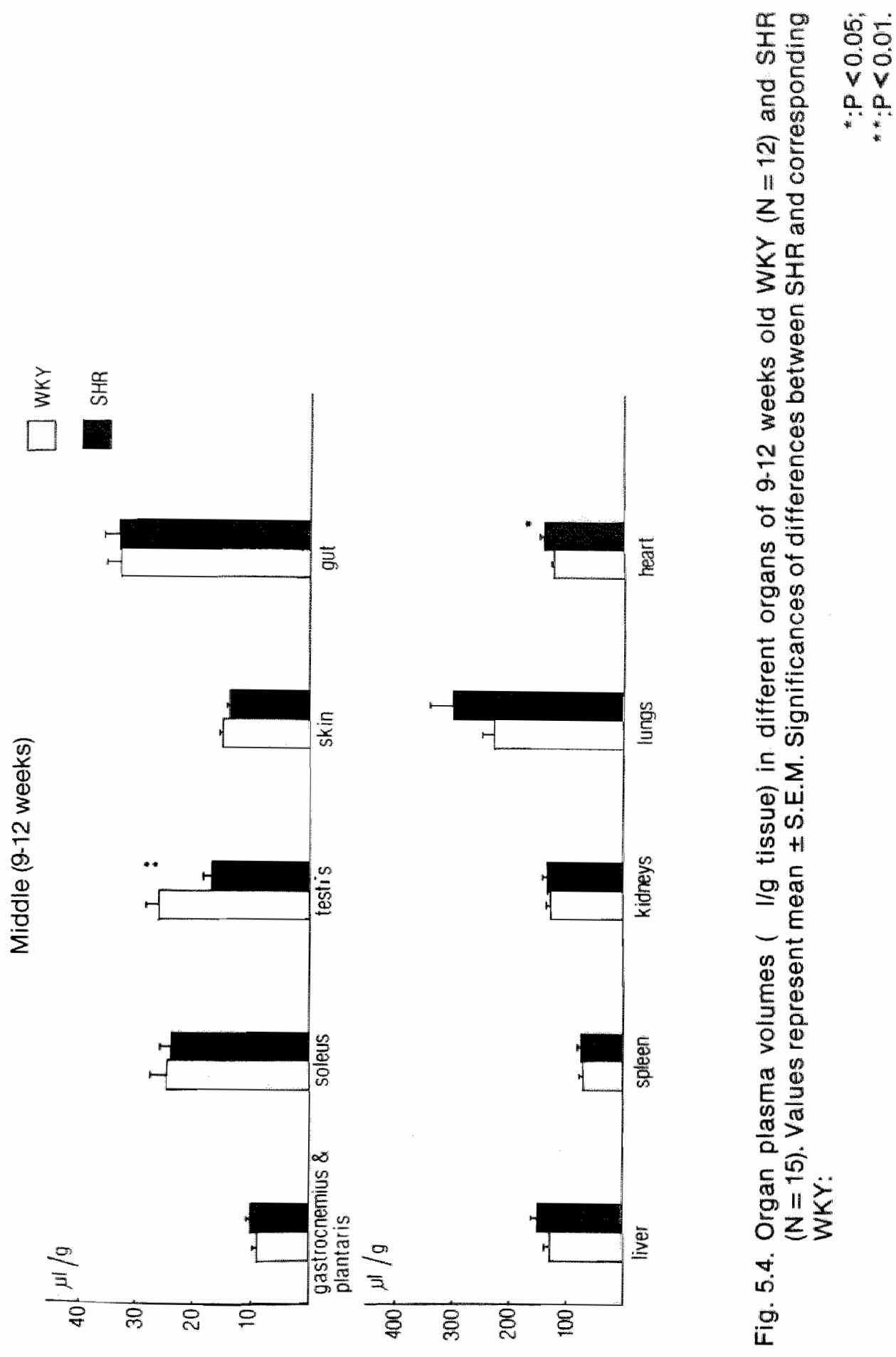




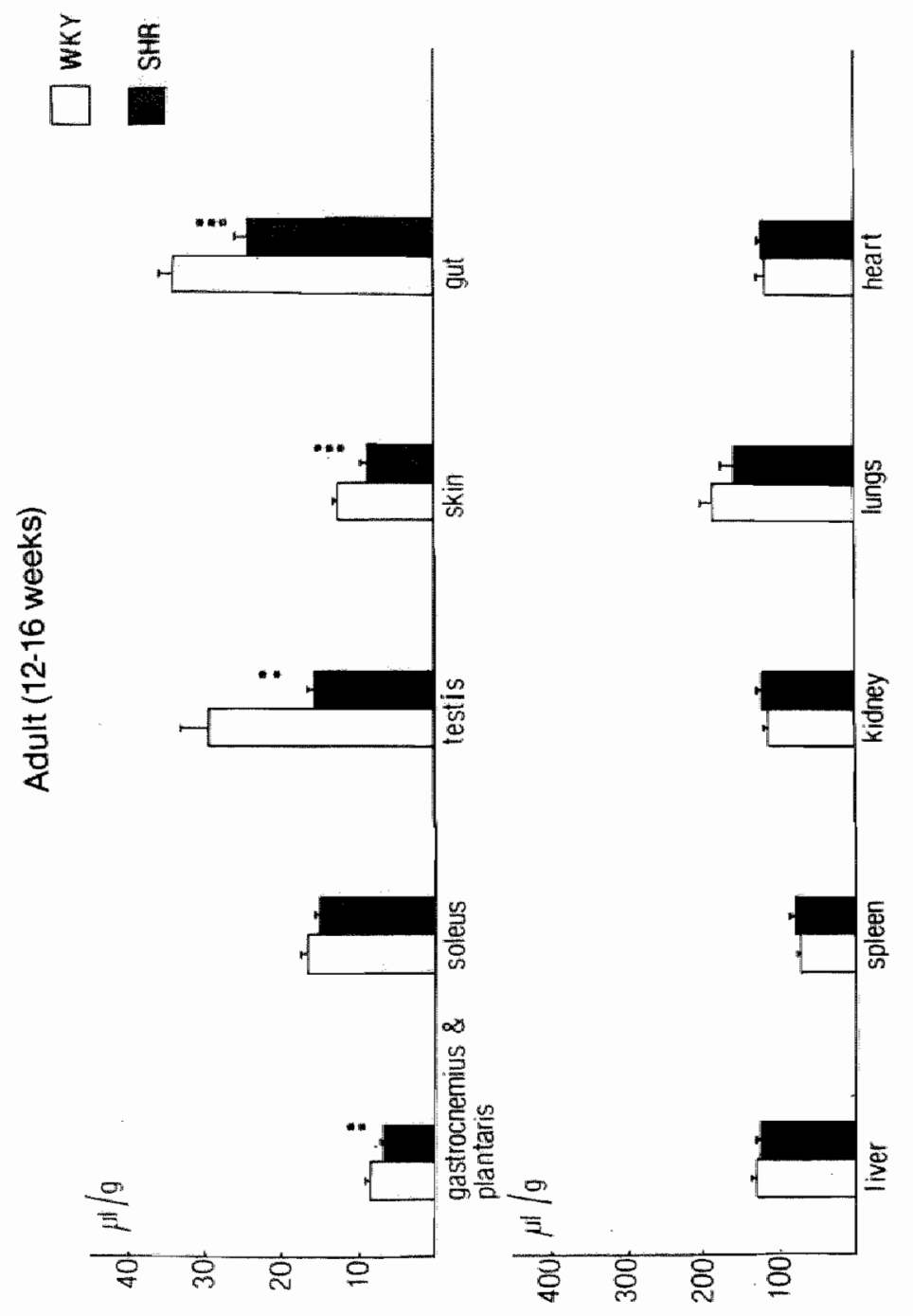

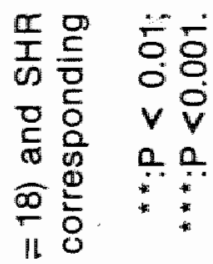

Z号

$\frac{\searrow}{3} \frac{\pi}{\infty}$

믕

os

0

(-)

3 in

- 8

둥

$\div \frac{1}{4}$

立

党

ส

응

○

등

은

는

늠

的

$\leq \Sigma^{3}$

क山

$D_{0}^{\circ}$

只

몽

$\equiv \stackrel{\Phi}{E}$

닫

(1)

E

동 은

(

E $\frac{2}{\pi}$

क $>$

․․

워

on 11

잉 $\geq \frac{x}{3}$

uा

in 
( $P V_{o}$ ) Such extrapolation cannot be performed for individual organs. To ensure complete mixing of albumin over the entire intravascular space a distribution period of 20 minutes is necessary. Organ plasma volumes were thus calculated 20 min after injection of the tracer. Since albumin transvascular escape tends to be even thigher in the SHR than in the WKY the organ pllasma volumes in SHR may even be lower than calculated, thus further increasing the differences already found in this study.

Although hematocrits were included in this study the total blood volumes were not calculated, since the hematocrit measured from one individual blood vessel may not be representative for the hematocrits in different organs. Moreover, there may be a large variation in hematocrits between diffierent organs of the rat (8). An alternative for determining blood volume is the separate measurement of the erythrocyte distribution space apart from the plasma volume measurements. Since others $(28.30)$ reported an equal erythrocyte distribution volume in SHR and WKY, we believe that the differences we found in plasma volumes reflect differences in the to. tal intravascular volume.

We used conscious, unrestrained rats for the measurement of total plasma. A similar in vivo technique is not available for organ plasma volume determination, since organs have to be dissected from previously killled animals. The most appropriate method for killing in order to measure organ plasma volumes is still unknown. Everett et al. (8) suggested thad rapid liquid nitrogen freezing gives reliable results. However, these authors failed to compare the individual organ intravascular volumes with those in adequate control animals. In our hands the liquid nitrogen freezing method caused spotbleedings in lungs, skeletal muscle and skin. Moreover, the albumin distribution spaces in these organs as well as the heart and spleen seemed to be considerably larger with the liquid nitrogen freezing method. For the other organs the plasma volumes we found are comparable to those reported by Everett er al (8).

Our findings of a significant increase in the $P V_{O}$ in the very young SHR (5 weeks mean body weight: 101 gram) versus agematched WKY (101 gram) is at variance with the results of Trippodo et al. (36), who reported equal plasma volumes for $10-14$ days SHR and WKY (16 resp. 21 gram) and $18-43$ days SHR and WKY (57 resp. 68 gram). Recently, Lundin et al. (20) also reported equal total plasma volumes in 6 weeks old SHR and WKY (114 resp. 109 grams). Several reasons can explain this discrepancy. First, we used extremely homogeneous groups of animals with close age-matching whe. reas especially in the study of Trippodo et al. (36) animals of a relatively wide age range were lumped into one experimental group. Secondly, we calculated our $\mathrm{PV}_{\mathrm{O}}$ on the basis of actual albumin disappearance curves after complete mixing of albumin in the intravascular space, whereas in previous studies either a very short ( $2 \mathrm{~min}$ ) mixing time was allowed (36) or a fixed value for the albumin disappearance was used (20). A third reason for the discrepancy between our results and those of Trippodo et al. (36) and Lundin et al. (20) could be the small difference in age in each of the 
studies. Smith and Hutchins (33) recently showed an increased cardiac in. dex in SHA during only a short time period around the fifth week after birth. Interestingly, this period coincides with our moment of increased plasma volume in SHR.

During further development PVo decreases in SHR when compared with WKY. In the 12-16 weeks old animals this difference is statistically significant. These data agree with those of other authors who measured plasma volume in adult SHR and WKY, but are at variance with the data of Nikodijevic et al. (23). The latter authors, however, used a normotensive Wistar control group not related to the original SHR strain.

In the very young SHR the increase in total plasma volume is parallelled by a decrease in the relative plasma volume contained in the intestines, the m.gastrocnemius and plantaris muscle, the testis and "rest" group of tissues.

Since the majority of the blood plasma is located on the venous side of the circulation (12) a decreased venous volume in these organs seems the most likely explanation for the reduction in organ plasma volume. Such reduced venous volume could originate either from structural or functional vascular changes. With respect to structural changes investigations of the microcirculation of young SHR are scarce.

A few authors $(3,4,6,7,13,16)$ have studied the morphological characteristics of different vascular beds of 6-8 weeks old SHR and normotensive controlls. Several of these authors $(4,6,7$,$) only studied the precapillary re-$ sistance section of the cremaster muscle. These authors found a reduced number of arterloles in young SHR. Moreover, the diameters and wallthickness of young SHR cremaster muscle arterioles do not differ from those in WKY. On the venous side, an equal number of venules was repor. ted in the skin of young SHR compared to WKY (13), whereas Hutchins and Darnell (16) even found an increased number of venules in the cremaster muscle of young SHR. Since such microcirculation studies are performed in anaesthetized animals functional, e.g. neural influences on venous tone may be eliminated.

We therefore interpret our data of reduced organ plasma volumes in young SHR as evidence for a functional venoconstrictive influence. This factor could be an enhanced sympathetic tone (26), although other influences cannot be excluded.

The combination of an increased total plasma volume and decrease in several organ plasma volumes strongly indicates a centralization of plasma to the larger veins. Lundin et al. (20) recently came to the same conclusion. The centralization of the blood could support the enhanced cardiac output in the early phase of spontaneous hypertension. The observations of Smith and Hutchins (33) and Lundin and Hallback-Nordlander (19) show an increase in the cardlac index of conscious. SHR exactly around 5-6 weeks after birth, with a rapid normalization afterwards. In this respect, the young SHR closely resembles the borderline hypertension in man. In this phase of human hypertension the increased cardiac output is positi- 
vely correlated with the total blood volume $(21,39)$. And even more so with central blood volume (22). The young SHR also resembles the Milan strain of genetically hypertensive rats. Blanchi et al (1) found an increased plasma volume only in the early phase of this form of hypertension, probably related to a change in renal function. It remains to be established whether a similar renal defect underlies the SHR form of experimental hypertension,

The relative decrease in total plasma volume during further development of spontaneous hypertension is parrallelled by an initial normalization of organ plasma volumes, with the exception of the testes and later decrea. se the relative plasma volumes of the gastocnemius and plantaris muscle, the skin and the intestines. Since the differences of organ plasma volumes disappear in the 7-12 weeks old animals, it seems attractive to suggest that during this phase the functional differences in venous capacity disappear to be taken over by structural vascular changes at ages later than 12 weeks. This hypothesis is supported by microcirculatory studies in the adult SHR and WKY (15). In the mesentery of the 18-20 weeks old SHR a rarification of pre-as well as postcapillary blood vessels has been reported (15). Although these microcirculatory studies do not confirm additional volume decrease through smaller vessel diameters, vessel wall hyperthrophy may also contribute to the decreased regional venous capacity in adult conscious SHR $(31,37)$. The finding of a reduced total plasma volume during the further development of spontaneous hypertension agrees with most observations in patients with established essential hypertension $(5,21,24,29,35)$. The negative relationship between intravascular volume and blood pressure in essental hypertensives has been interpreted as an increased pressure-related transcapillary fluid shift $(24,38)$ or a pressure-related renal fluid loss (5), An alternative explanation could be structural changes in different vascular beds, especially on the venous side of the circulatory system. One factor could be a reduced compliance of the venous system, as was suggested to occur both in SHR (31) and in subjects with essential hypertension. Samar an Coleman (28) could not confirm a reduced venous compliance in adult SHR. Therefore other structural factors may play a role in the reduced venous capacity in the adult SHR. A clear possibility in this respect may be the reduced amount of per. fused microvessels.

In conclusion, the present study indicates that an increased total plasma volume in combination with reduced intravascular volumes in several vas. cular beds in the young SHR is related to venoconstrictive influences that support an enhanced venous return of blood to the heart and subsequent increased cardiac output. Moreover, the reduction in both total and regional plasma volumes during the later phases of spontaneous hypertension in rats may by related to structural changes on the venous side of the circulation. 


\section{References}

1. Bianchi, G., Baer, P.G., Fox, U., Duzzi, L., Caravaggi. A.M.,Möhring, $\mathrm{J}$. and Cusi, D., In: The kidney in arterial hypertension (G. Bianchi and G. Bazzato, Eds.). Bunge Scientific Publishers, Utrecht, (1979).

2. Blanchi, M., Bellini, G., Hessan, H., Kim, K.E., Swartz, C. and Fernandes, M., Clin. Sci. 61, 685, (1981).

3. Bohlen, H.G., J. Appl. Physiol. 236, H157, (1979).

4. Bohlen, H.G. and Lobach, D., Blood Vessels 15, 322, (1978).

5. Chau, N.P., Safar, M.E., London, G.M. and Weiss, Y.A., Hypertension 1, 86, (1979).

6. Chen, I.I.H., Prewitt, R.L. and Dowell, R.F., Am. J. Physiol. 241, H306, (1981).

7. Dusseau, J.W. and Hutchins, P.M., Am. J. Physiol. 236, H134, (1979).

8. Everett, N.B., Simmons, B. and Lasher, E.P., Circ. Res. 4, 419, (1956).

9. Fouad, F.M., Tarazi, R.C., Dustan, H.P. and Bravo, E.L., Am. Heart J. 96, 646, (1978).

10. Gresson, C.R., Bird, D.L. and Simpson, F.O., Life Sci. 12, 393, (1973).

11. Gresson, C.R., Bird, D.L. and Simpson, F.O., Clin. Sci. 44, 349, (1973).

12. Guyton, A.C., Textbook of Medical Physiology, W.B. Saunders Company, Philadelphia, (1976). page 237.

13. Haack, D.W., Schaffer, J.J. and Simpson, J.G., Proc. Soc. Exp. Biol. Med. 164, 453, (1980).

14. Harper, R.M., Moore, M.A., Marr, M.C., Watts, L.E. and Hutchins, P.M.: Microvasc. Res. 16, 369, (1978).

15. Henrich, H., Hertel, R. and Assman, R., Pflügers Arch. 375, 153, (1978).

16. Hutchins, P.M. and Darnell, A.E., Circ. Res. 34 and 35, suppl. 1, 161, (1974).

17. Julius, S., Pascual, A.V., Reilly, K. and London, R., Arch. Intern. Med. 127, 116, (1971).

18. Julius, S. and Essler, M., Cli. Sci. Mol. Med. 51, 207, (1976).

19. Lundin, S. and Hallbäck-Nordiander, M., Cardiovasc. Res. 14, 561, (1980).

20. Lundin, S., Folkow, B. and Rippe, B., Acta Physiol. Scand. 112, 257, (1981).

21. Messerli, F.H., Christie, B., DeCarvalho, J.G.R., Aristimuno, G.G., Suarez, D.H. Dreslinski , G.R. and Frohlich, E.D., Arch. Int. Med. 141, 81, (1981).

22. Messerli, F.H., DeCarvalho, J.G.R., Christie, B. and Frohlich, E.D.: Circulation 58, 441, (1978).

23. Nikodijević, B., Dolgova-Korubin, V. and Tadzer, I.S., Acta Med. lug. 26, 251, (1972).

24. Parving, H.H. and Gyntelberg, F., Circ. Res. 12, 643, (1973).

25. Rippe, B., Lundin, S. and Folkow, B., Clin. Exp. Hypert. 1, 39, (1978). 
26. Schramm, L.P. and Barton, G.N., Am. J. Physiol, 236, R147. (1979).

27. Safar, M.E., London, G.M., Levenson, J.A., Simon, A.Ch. and Chau, N.P., Hypertension 1, 615, (1979).

28. Samar, R.E. and Coleman, T.G., Am. J. Physiol. 237, H584, (1979).

29. Schalekamp, M.A.D.H., Beevers, D.G., Lebel, M., Fraser, R., Kolsters, G. and Birkenhäger, W.H., Lancet 2, 310, (1974).

30. Sen, S., Hoffman, G.C., Stowe, N.T., Smeby, R.R. and Bumpus, F.M., J. Clin. Invest. 51, 710, (1972).

31. Simon, G., Circ. Res. 38, 412, (1976).

32. Simon, G., Franciosa, J.A. and Cohn, J.N., Angiology 30, 147, (1979).

33. Smith, T.L. and Hutchins, P.M., Hypertension 1, 508, (1979).

34. Takeshita, A. and Mark, A.L., Hypertension 1, 202, (1979).

35. Tarazi, R.C., Frohlich, E.D. and Dustan, H.P., New Engl. J. Med. 278, $762,(1968)$.

36. Trippodo, N.C., Walsh, G.M. and Frohlich, E.D., Am. J. Physiol. 235, H52, (1978).

37. Trippodo, N.C., Yamamoto, J. and Frohlich, E.D., Hypertension 3, 104, (1981).

38. Ulrych, M., Clin. Sci. 45, 173, (1973).

39. Weiss, Y.A., Safar, M.E., London, G.M., Simon, A.Ch., Levenson, J.A. and Milliez, P.M., Am. J. Med. 64, 382, (1978). 


\section{Chapter VI}

\section{Transcapillary escape rate and organ clea- rance of albumin during the development of spontaneous hypertension in rats}

\section{Introduction}

Several authors have demonstrated an increased transcapillary escape rate (TER) for different plasma proteins in human essential hypertension $(17,18,28)$ and an increased TER for albumin in spontaneously hypertensive rats (21). The parameter TER in these studies is calculated as the rate of disappearance of protein from blood plasma during the initial phase after a bolus injection of a tracer amount of this protein. It is assumed in these studies that the initial rate of disappearance from the plasma is determined by transvascular transport of the protein. Although mechanisms of transvascular transport of plasma proteins have been studied in detail in individual tissues, the mechanism and sites of enhanced TER in hypertension remain unclear. An increased capillary pressure has been implied in the increased TER both in essential and spontaneous hypertension $(17,21)$. Indeed, the increased capillary pressure in the nail bed of patients with essential hypertension (13) and the cremaster muscle of SHR (2) supports this concept. In this case the increased filtration of albumin at the capillary level as the consequence of the elevated capillary pressure causes the higher TER.

Alternatively, the observation of a direct correlation between arterial blood pressure and TER could support the idea that increased TER in hypertension is the consequence of abnormal leakage of plasma proteins through the arteriolar wall rather than increased capillary filtration $(17,18)$. The use of overall plasma disappearance curves of albumin is of limited value when considering transvascular transport processes in individual vascular beds. The plasma disappearance curve represents the sum of distribution processes to different tissues with widely varying kinetics of transvascular albumin uptake $(3,25,26)$. Moreover the slope of the initial plasma disappearance curve may be influenced by other mechanisms of plasma elimination of albumin than transvascular transport, such as metabolism of the albumin molecule.

In the present study we used a new technique for the determination of regional transvascular albumin transport based on the original organ albumin clearance methods developed by Dewey (3) and Studer et al. $(25,26)$. We applied this technique to measure regional albumin extravasation in SHR and progenitor normotensive Wistar Kyoto rats (WKY) of different ages. 


\section{Materials and methods}

The source of the animals, surgery, blood pressure measurements, albumin preparations, injection and blood sampling techniques have been described in detail in chapter $V$. A number of the animals used for the tis. sue plasma volume measurements were used in this study for the determination of TER and regional albumin clearance.

\section{Transcapillary escape rate (TER)}

After the intravenous injection of $100 \mu$ l of a 125 -human serum albumin (HSA) solution radioactivity was counted in two arterial plasma samples of $10 \mu \mathrm{l}$ each at $30,60,90$ and 120 minutes. Radioactivity was expressed as counts. $\min ^{-1} \cdot \mathrm{ml}^{-1}$ plasma. After logarithmic transformation of the amount of radioactivity, the linear regression equation for the activitytime was determined by the method of least squares. TER (dimension: $\% \cdot \mathrm{hr}^{-1}$ ) was calculated from the slope of this equation.

\section{Regional albumin clearance}

The measurement of regional albumin clearance is based upon the use of a double-isotope method for the determination of intra- and extravascular albumin concentration and is modified from the methods for measurement of regional protein extravasation described by Dewey (3) and Studer et al. $(25,26)$. In this method $100 \mu$ of two tracer solutions ( $125_{-1}$ - HSA and 131. I-HSA, cf. also chapter $V$ ) are injected at $t=0$ respectively $t=100$ min. 120 Minutes after injection of the first tracer animals were killed by ether anaesthesia and cervical dislocation. Individual tissues were rapidly removed and counted for each individual tracer in a Packard autogamma scintillation spectrometer model 5220 . The 131 .- -albumin activity is taken as the indicator of intravascular volumes. However, since there is a systematic difference between the tissue 125 - H-HSA and 131. I-HSA distribution volume (cf. Chapter $V$ ) this value is corrected for by the factors given in table 1 of Chapter $V$. These intravascular volumes were multiplied by the 125.I-HSA cpm per $\mu$ l plasma obtained from the arterial plasma sample at $t=120 \mathrm{~min}$. Thus, the equivalent amount of intravascular 125. 1 -HSA counts per minute ( $\mathrm{cpm}$ ) can be calculated. In a separate experiment the sequence of tracer injection was reversed in a group of adult SHR in order to check for the comparability of the two preparations.

The extravascular 125.I-HSA cpm is calculated by subtracting from the total tissue 125 .I.HSA cpm the calculated amount of intravascular 125.1-HSA $\mathrm{cpm}$. According to classical clearance methods the tissue plasma albumin clearance can now be calculated as:

Extravascular 125 - $\mathrm{H}$-HSA cpm at $\mathrm{t}=120 \mathrm{~min}$.

$$
t=120 \mathrm{~min} \text {. }
$$

$t=0 \sqrt{125} .4 \cdot$ HSA cpm in plasma. $\mu l-1 . d t$ 
In this formula the denominator represents the area under the plasma TER curve from 0 to 120 minutes. This area can be calculated with the trapezold rule (interval of 10 minutes each were used) from the nonlogarithmic plasma concentration-time curve.

Finally, the tissue plasma albumin clearances thus calculated were normalized for the plasma volume per organ sample in order to allow comparlsons of the clearances per tissue. They were also multiplied by a factor 60 to obtain the amount of plasma cleared per hour rather than minute. The normalized tissue clearance thus has the same dimension as the TER (hour -1 ), which means the fraction or percentage of tissue plasma volume cleared from 125.-HSA per hour.

\section{Statistics}

Values indicated represent means \pm S.E.M. unless stated otherwise. The unpalred two-talled Student's t-test was used for statistical analysis.

\section{Results}

\section{Comparison of albumin preparations}

In the previous paper we showed a difference in the free iodine concentration of $125,1-H S A(2 \%)$ and 131 -I-HSA $(4 \%)$. This difference leads to slight differences in the tissue distribution spaces of the two albumin preparations. These are corrected for by the correction factors in table 6.1. In order to further evaluate the equivalence of these two preparations after the use of the proper correction factors, tissues clearances were determined in several tissues in adult SHR by changing the sequence of label injection. The results of this experiment are presented in table 6.1 .

The data indicate the equivalence of the two albumin preparations after proper correction, since the clearances do not differ for the sequence of tracer injection. Similarly, the TER values do not differ significantly in adult SHR injected with 125.I-HSA $\left(N=10 ; 13.4 \pm 0.5 \%\right.$.hour $\left.{ }^{-1}\right)$ or $131_{-1-}$ HSA $(N=5 ; 14.5 \pm 1.4 \%$.hour -1$)$.

To evaluate possible metabolic breakdown of the different albumin preparations, $125_{-1}$ and $131_{-1-H S A}$ were injected simultaneously into 4 adult SHR. All tissues for which clearances were measured, were removed after 20 minutes $(N=2)$ or 2 hours $(N=2)$. Free lodine, as measured by the trichloro-acetic acid precipitation, constituted less than $2 \%$ of the total radioactivity both after 20 minutes and 2 hours in all tissues except for the gut in which $10-12 \%$ of the radioactivity was unbound to protein. This may be related to a role of the gut in the metabolism of plasma albumin (29).

Mean arterial pressure and albumin transcapillary escape rates

Table 6.2 summarizes the MAP and TER values of the SHR and WKY of different ages. MAP is higher in the SHR of all ages. Already at an age of 5 weeks the MAP of SHR $(132 \pm 6 \mathrm{~mm} \mathrm{Hg} ; \mathrm{N}=7)$ is significantly $(P<0.01)$ 


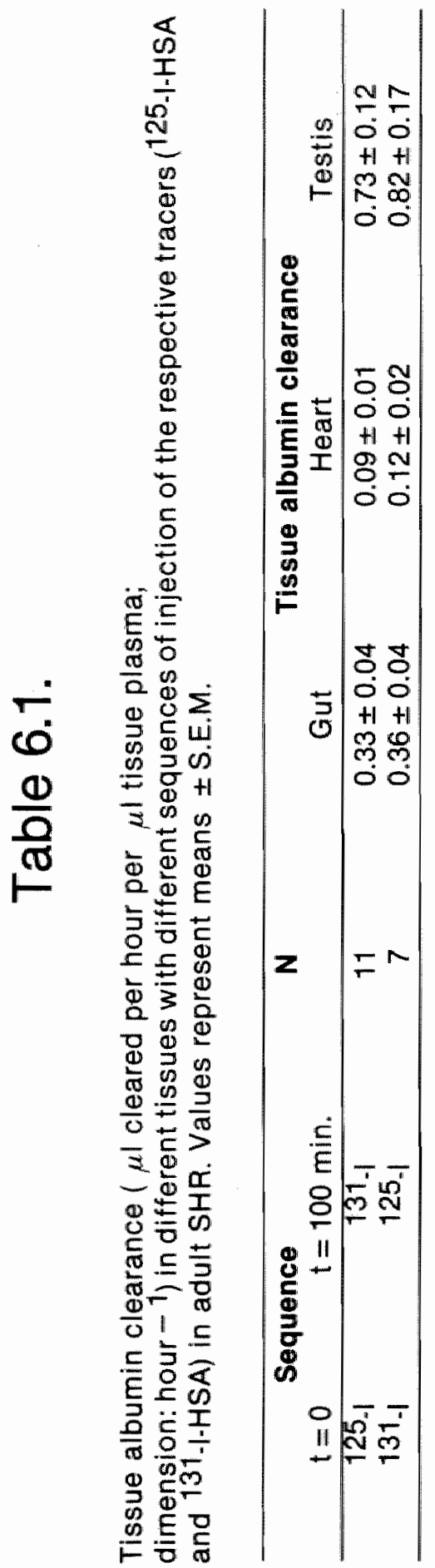




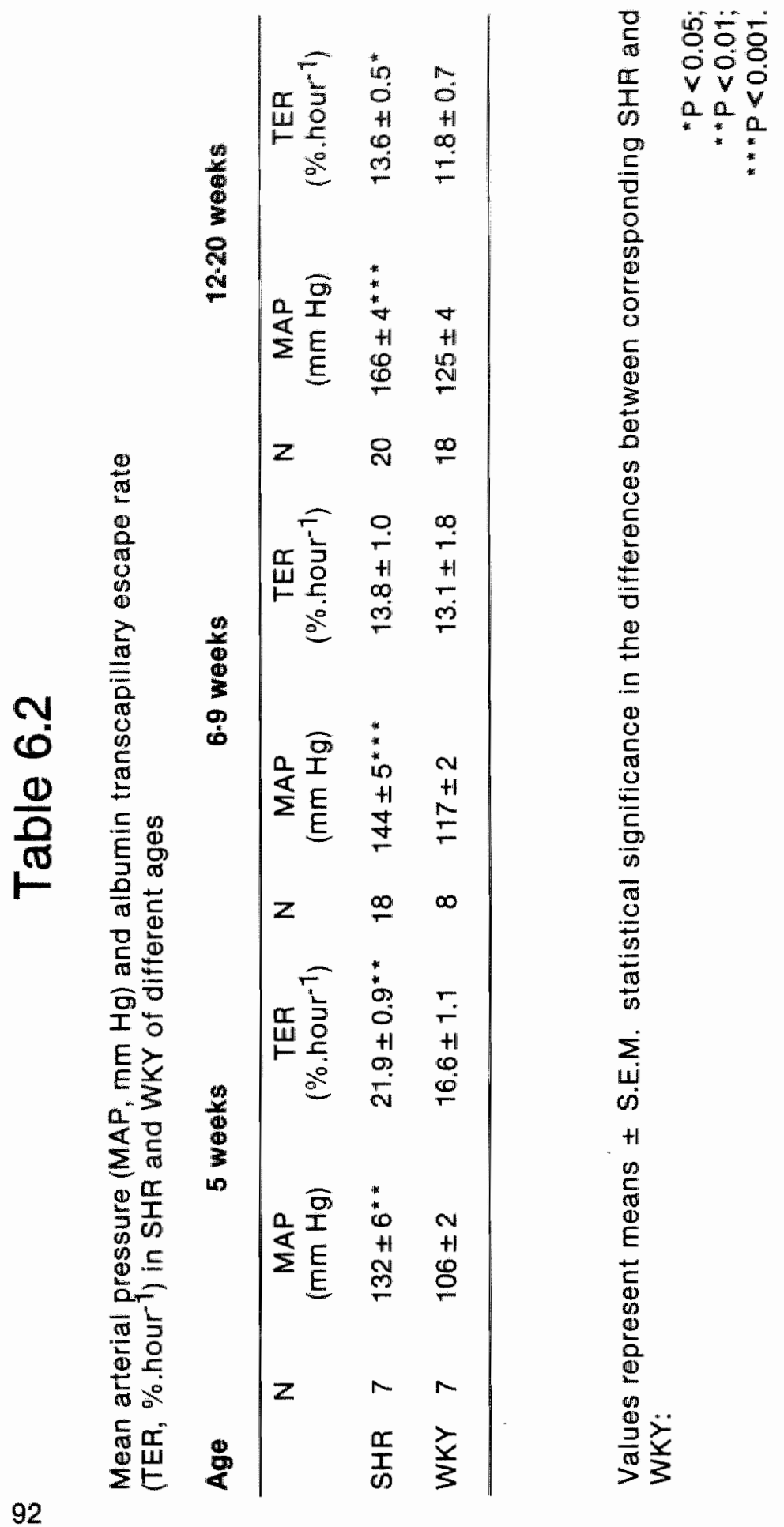


higher than that of WKY $(106 \pm 2 \mathrm{~mm} \mathrm{Hg} ; \mathrm{N}=7)$.

The albumin TER is higher in SHR of all ages. However, the difference is statistically significant only for the 5 weeks old animals $(21.9 \pm 0.9$ vs $16.6 \pm 1.1 \%$.hour $-1 ; P<0.01)$ and $12-16$ weeks old animals $(13.6 \pm 0.5$ vs $11.8 \pm 0.7 \%$.hour $-1 ; P<0.05)$.

Tissue albumin clearance

The clearance of albumin from the plasma in different tissues was studied in SHR and WKY of different ages. In the very young ( 5 weeks) animals the soleus muscle was not included, since the amount of cpm per tissue sample was too low in these animals to allow calculation of tissue albumin clearance. In contrast, all tissues not used individually were lumped into a "rest" group in these animals. Due to technical problems the skin could not be included in the 6-9 weeks old animals. The results of the tissue albumin clearance experiments are presented in figures 6.1,6.2 and 6.3.

In 5 weeks old animals the enhanced plasma albumin disappearance in SHR can be attributed to a significant $(P<0.05)$ increase in the albumin clearance in the skin ( $42 \%$ higher in SHR), the gastrocnemius muscle $(47 \%)$ and the "rest" $(21 \%)$. In the $6-9$ weeks old animals a significant $(P<0.01)$ elevation $(52 \%)$ was observed only in the SHR gastrocnemius muscle. In the adult group highly significant $(P<0.001)$ increased albumin clearances were found in the gut $(46 \%)$ and skin $(43 \%)$, whereas the difference in the gastrocnemius muscle $(42 \%)$ was also significant $(P<0.05)$. 


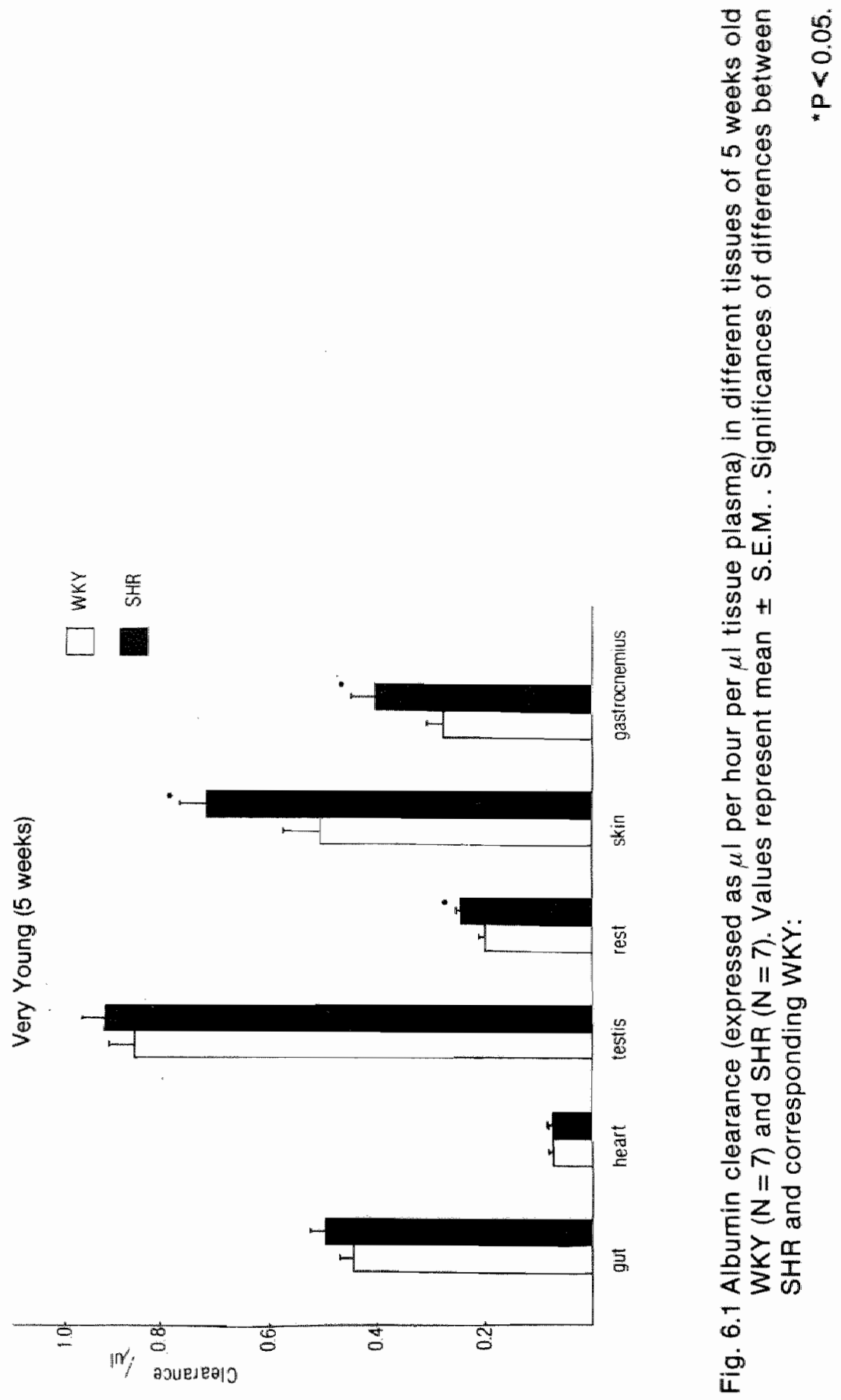




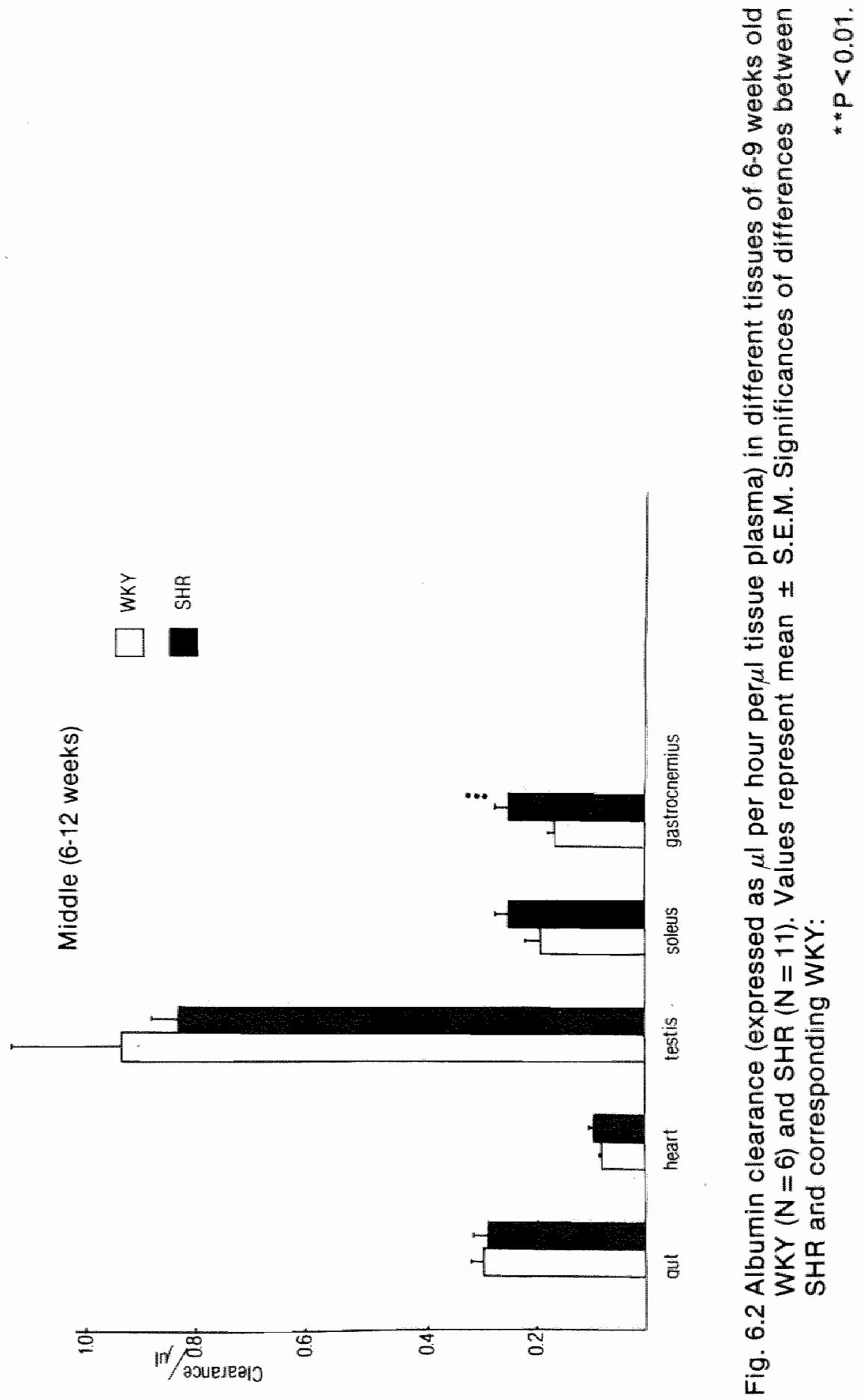




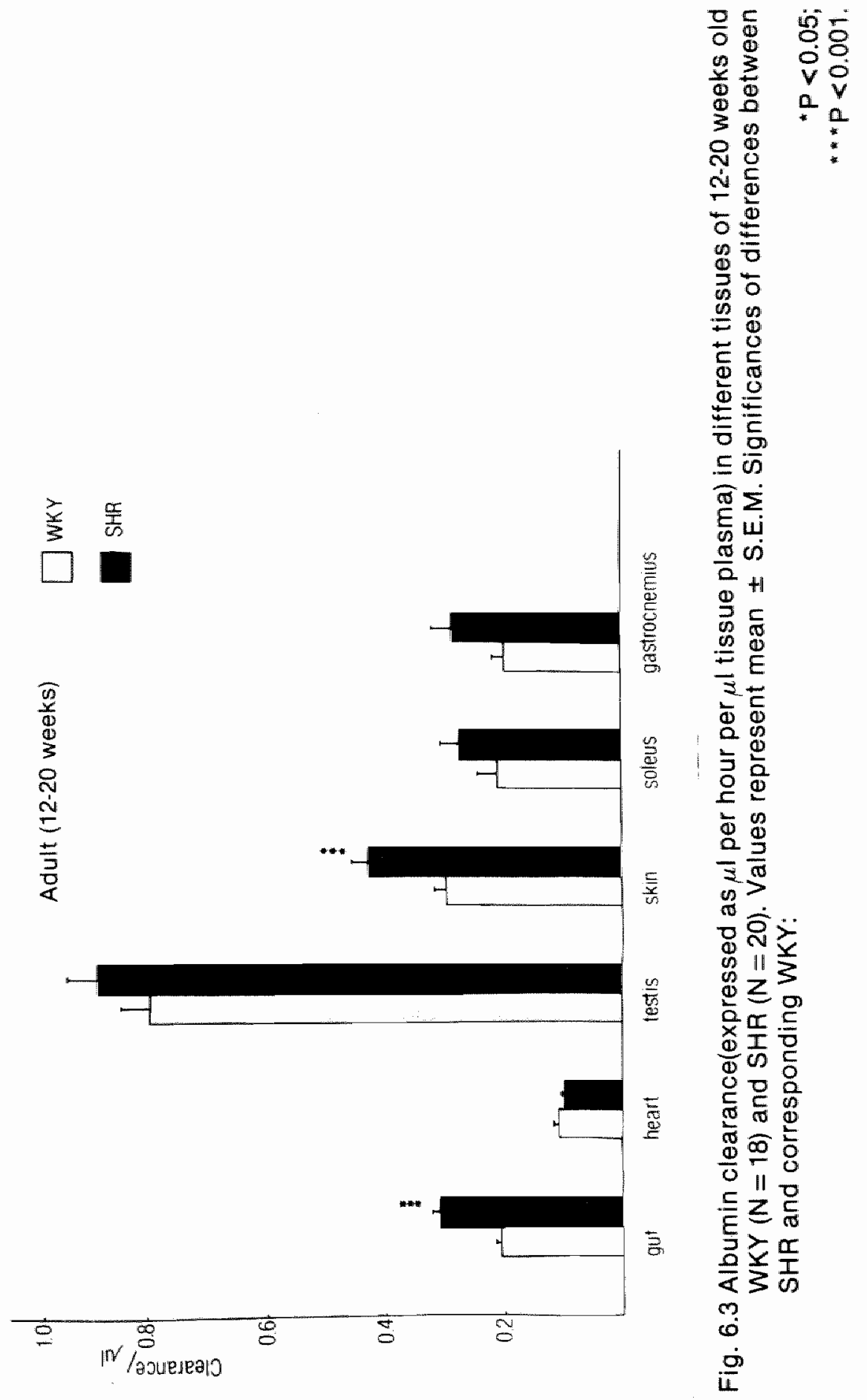




\section{Discussion}

In the present study we investigated the kinetics of albumin disappearance from the intravascular space in rats with spontaneous hypertension of different ages. Progenitor normotensive animals of the wistar - Kyoto strain (WKY) were used as controls. The overall extravasation of albumin was expressed as the plasma transcapillary escape rate (TER, dimension $\%$. hour -1 ), whereas disappearance to the extravascular space of different tissues was ecpressed as clearance (dimension: $\mu \mathrm{l}$. hour-1) which was normalized for the intravascular plasma content of the tissue sample (dimension after normalization: fraction . hour ${ }^{-1}$ ). The tissue clearance method was based upon a double-isotope method developed originally by Dewey (3) and Studer et al. $(25,26)$. Both the tissue clearance and the overall transcapillary escape were measured within 2 hours after injection of the tracers. This period was chosen to allow enough time for intravascular mixing, but to avoid significant backflow of tracer from the extravascular space. In the detailed studies of Studer and co-workers $(25,26)$ it was shown that extra-intravascular equilibration of albumin takes several hours to days for most tissues, except for the adrenals, kidney and liver. In those organs equilibrium and subsequent backflow is reached within one hour, probably due to the fenestrated or discontinuous capillary structure (26). We have therefore not included clearance measurements for these tissues. In the rat liver an extravascular albumin space is even lacking according to Studer and Potchen (26). We could confirm this in our study, since liver albumin clearance calculated according to our technique was zero or close to zero in all animals.

The major goal of our study was to investigate the contribution of individual tissues to the enhanced TER in spontaneous hypertension.

In the very young SHR (5 weeks old) an increase in TER of $32 \%$ was found in combination with an increase in albumin clearance of the gastrocnemius muscle $(47 \%)$, skin $(42 \%)$ and rest of the animal $(18 \%)$. In the $6-9$ weeks old SHR a small, not significant increase in TER was measured in combination with a $52 \%$ increase in albumin clearance of the gastrocnemius. In the adult group a significant increase in TER $(14 \%)$ occurred in combination with an increased clearance in gut $(46 \%)$, gastrocnemius $(42 \%)$ and skin $(43 \%)$. Thus, differences in clearances in several of the tissues we measured are higher than differences in TER, specially in the middle and adult group. If we realize that the TER as measured in plasma reflects the sum of all individual clearances in tissues, we can conclude that several factors may contribute to this larger difference: (1) some organs (not measured in this study) may have a lower clearance in the SHR in comparison to WKY (2) some organs with a rapid intra-extravascular equilibration of protein could have apparently lower clearance in the SHR in comparison to WKY due to recirculation of labelled protein; (3) the SHR may have a larger part of plasma volume which is not exposed to extravasation (e.g. veins and intracardiac blood). The observation of a relatively larger "central" blood volume in the SHR supports this possibility. (14, chapter V). 
In our study differences in TER and tissue clearance were observed specially in the very young and adult SHA in comparison to WKY. The mechanism by which more plasma protein escapes from the circulation in hypertension remains a subject of speculations. Parving et al. (17-19) suggested that an increased capillary permeability could contribute to the enhanced TER in hypertension. However, observations in the isolated hindquarters of the SHR indicate that an increased caplllary permeability may not occur in the SHR if the pressure is equal to that in control WKY $(22,23)$. Another explanation for an enhanced TER in hypertension is an increased leakage of plasma proteins through arterioles caused by an increased blood pressure. Although an increased arteriolar leakage for smaller molecules has been reported in the SHR (11), our study indicates that if arteriolar leakage occurs, it is not exclusively pressure-dependent, since not all organs respond to an increased arterial pressure with an increased albumin clearance.

A third explanation for an increased TER and tissue clearance of albumin in spontaneous hypertension is an unequal distribution of blood flow to several tissues. The observation of a flow dependency of albumin clearance in the isolated hindquarters supports this possibility (20). An additional argument for a flow dependency of transvascular escape of albumin is the reduced TER during beta-adrenoreceptor blockade - which lowers cardiac output and thus blood flow through a number of tissues in essential hypertension (19). In the 5-6 weeks old SHR an increased total blood flow (cardiac output) has been reported indepently by Lundin and HallbäckNordlander (15) and Smith and Hutchins (24). In the present study an increased TER and albumin clearance of gastrocnemius and skin was observed in 5 weeks old SHR; preliminary data from our laboratory on the basis of the microsphere method indicate an increased cardiac output in 5 weeks old SHR in combination with an increased flow through skin and gastrocnemius muscle. A similar observation was made in patients with borderline hypertension by Temmar et al. (27) who reported both an increased cardiac output and an increased lower limbflow. Therefore, the increased blood flow to skin and skeletal muscle may provide a suitable explanation for the increased TER and tissue albumin clearance in the very young SHR.

Another mechanism which can provoke an increased transvascular escape of albumin is an increased venous pressure, as was observed by Rippe et al. (20) in the isolated hindquarters of rats and by Hesse et al. (8) in patients with congestive heart failure. Venoconstriction or increased venous filling therefore remains one of the mechanisms which can contribute to the enhanced TER in adult spontaneous and essential hypertension $(17,18,21)$.

In chapter $V$ we speculated that venoconstriction may lead to a decrease in tissue plasma volume. In fact a reduced volume was found in the gut, skeletal muscle and testis of the adult SHR. Venoconstriction does not seem to play a major role in enhanced albumin disappearance in the very 
young SHR, since albumin clearance is not higher in the gut and testes. However, in the adult SHR there is a close parallel to the tissues with reduced plasma volume and those with enhanced albumin clearance. Therefore, localized venoconstriction may play a decisive role in the higher TER and tissue albumin clearances observed in the adult SHR.

Recent microcirculatory studies provide evidence against a constriction of microvessels in several organs of the adult SHR. Specially the studies by Henrich et al. (9-11) in the mesentery of the SHR point to a decreased number of vessels (arterioles, capillaries and venules) rather than a decreased lumen. This observation may have important implications for the understanding of the regional albumin extravasation.

If we assume an equal total blood flow in the mesentery of adult SHR and WKY (16), a reduction of the number of capillaries must lead to an increased flow and pressure in individual capillaries, whereas a reduction of venules would lead to an increased capillary pressure. An increased capllary pressure associated with a decreased number of microvessels thus also leads to an increased albumin clearance per caplllary. If the total number of capillaries, and thus the exchangeable surface area for albu$\mathrm{min}$, is reduced this may not lead to an overall increased tissue albumin clearance. Rippe (23) pointed out that an increase of capillary pressure above a critical level (ca. $45 \mathrm{mmHg}$ ) causes a dramatic increase in transvascular albumin escape due to the so called stretched pore phenomenon. Although the microcirculation of other tissues has been studied in less detail, a reduced number of microvessels was reported in the skin (6) and skeletal muscle $(1,4,5,12)$ of SHR as well as in the conjunctiva of patients with essential hypertension (7). Additional investigations on the microcirculatory dynamics and albumin extravasation are clearly indicated to further define the role of the microcirculation in the enhanced transvascular transport of albumin in hypertension.

In conclusion, we suggest that an increased capillary pressure in several tissues, either caused by increased blood flow in the early phase of hypertension, or by venoconstriction or a reduced number of microvessels in the established phase, leads to an increased transvascular escape of albumin in hypertension. The overall transvascular escape of albumin in SHR is associated with increased clearance in several specific tissues. 


\section{References}

1. Bohlen, H.G.: J. Appl. Physiol. 234, 157 (1979).

2. Bohlen, H.G., Gore, R.W. and Hutchins, P.M.: Microvasc. Res. 13, $125(1977)$.

3. Dewey, W.C.: Am. J. Physiol. 197, 423 (1959).

4. Dusseau, J.W. and Hutchins, P.M.: Am. J. Physiol. 236, H 134 (1979).

5. Ferrone, E.D.: Am. J. Physiol. 236, H403 (1979).

6. Haack, D.W., Schaffer, J.J. and Simpson, J.G.: Proc. Soc. Exp. Bioll. Med. 164, 453 (1980).

7. Harper, R.N., Moore, M.A., Marr, M.C., Watts, L.E. and Hutchins, P.M.: Microvasc. Res. 16, 369 (1978).

8. Hesse, B., Parving, H.H., Lung-Jacobsen, H. and Noer I.: Circ. Res. $39,358(1976)$.

9. Henrich, H. and Hertel, R.: Bibl. anat., 18, 184 (1979).

10. Henrich, H., Hertel, R. and Assman, R.: Pflügers Arch. 375, 153 (1978).

11. Hertel, R. and Henrich H.: Bibl. anat. 18, 180 (1979).

12. Hutchins, P.M. and Darnell, A.E.: Circ. Res. 34 and 35 suppl.1, 161 (1974).

13. Landau, J., and Davis, E.: Lancet 1, 1327 (1957).

14. Lundin, S., Folkow, B. and Rippe, B.: Acta Physiol. Scand. 12, 257 (1981).

15. Lundin, S. and Hallbäck-Nordlander, M.: Cardiovasc. Res. 14, 561 (1980).

16. Nishiyama, K., Nishiyama, A. and Frohlich, E.D.: Am. J. Physiol. 230, 691 (1976).

17. Parving, H.H. and Gyntelberg, F.: Circ. Res. 32, 643 (1973).

18. Parving H.H. and Gyntelberg, $F_{\text {.: }}$ Scand. J. Clin. Lab. Invest. 32, 105 (1973).

19. Parving, H.H., Jensen, H. and Westrup, M.: Scand. J. Clin. Lab. Invest., 37, 223 (1977).

20. Rippe, B., Kamiya, A. and Folkow, B.: Acta Physiol. Scand. 105, 171 (1979)

21. Rippe, B., Lundin, S. and Folkow, B.: Clin. Exp. Hypertension. 1, 39 (1978).

22. Rippe, B. and Folkow, B.: Acta Physiol. Scand. 101, 72 (1977).

23. Rippe, B.: Relationships between diffusion and convection across capillary walls, Ph.D. Thesis Götenborg, (1978).

24. Smith, T.L. and Hutchins, P.M.: Hypertension 1, 508 (1979).

25. Studer, R.K., Morgan, J., Penkoske, M. and Potchen, E.J.: Am. J. Physiol. 224, 699 (1973).

26. Studer, R.K. and Potchen, E.J.: Microvasc. Res. 3, 35 (1971).

27. Temmar, M.M., Safar, M.E., Levenson, J.A., Totomoukouo, J.M. and Simon, A.Ch.: Clin. Scl. 60, 653 (1981).

28. Ulrych, M.: Clin. Sci. Mol. Med. 45, 173 (1973). 
29. Wetterfors, J.R., Gullberg, R., Liljedahl, S.O., Plantin, L.O., Birke, G. and Olhagen, B.: Acta Med. Scand. 168, 347 (1960). 


\section{Chapter VII}

\section{Extracellular fluid volume in young and adult spontaneously hypertensive rats.}

\section{Introduction}

It has been postulated by Borst and Borst-de Geus (5) and by Ledingham and Cohen (12) that hypertension starts with a deficient sodium output by the kidneys, which results in an increase in extracellular fluid volume (ECFV).

In essential hypertension data on extracellular fluid volume are conflicting. Two extensive reviews $(14,15)$ reported both studies in which the extracellular fluid volume was found to be normal as well as studies in wich the extracellular fluid volume was found to be increased.

Part of this discrepancy can be explained by variability of characteristics of the patients, (e.g. the occurrence of cardiac failure, malignant hypertension etc. (4)). The recently introduced rat models of genetic hypertension, and earlier rat models in which hypertension was induced offer attractive alternatives to investigate the fluid volumes in hypertension, since a great variabillty of characteristics is not likely in those models. In the Milan hypertensive rat strain (M.H.S.), a genetic form of hypertension in the rat, fluid retention can be demonstrated by an increased plasma volume $(1,2)$ and a significant sodium retention during the development of the hypertension, but not by significant increase in extracellular fluid volume ( $\mathrm{Bi}$ Space.)

In adult genetically hypertensive rats with established hypertension of both the New Zealand and Okamoto strain reduced plasma and blood volumes and resp. reduced and normal values for the extracellular fluid volume were obtained $(3,8)$. In different series of studies in 2.6 weeks old rats normal total plasma and extracellular fluid volumes were reported in very young New Zealand hypertensive rats (7) and in SHR (16).

In these studies different substances were used for the determination of extracellular fluid volume (e.g. ferrocyanide, inuline etc.). These substances yield different absolute values for extracellular fluid volumes and the. refore only extracellular fluid volumes measured with the same substance can be compared $(9,14)$.

It will be clear from the discussion above that the exact extracellular fluid volume is still not known both in man and in experimental animals. Since a simple single injection technique has been developed for ${ }^{51} \mathrm{Cr}$ EDTA we prefer this substance in our study (6).

The present study was aimed at measurement of extracellular fluid volume in both young ( 5 weeks old SHR) and adult ( 15 weeks old SHR) in which the same substance $\left({ }^{51} \mathrm{Cr}\right.$ EDTA) was used. 


\section{Materials and methods}

\section{General procedure}

For animals, direct blood pressure recordings and heart rates cf. the me. thods of chapter II.

\section{Determination of extracellular fluid volume ${ }^{51} \mathrm{Cr}$-EDTA space)}

The volume of distribution $(\mathrm{Vd} \beta)$ for ${ }^{51} \mathrm{Cr}$-EDTA was calculated from the plasma disappearance curve after a single intravenous injection.

Arterial blood samples were drawn from an in-dwelling arterial catheter in the abdominal aorta. Blood $(200 \mu l)$ were taken at $2,5,10,15,20,30,45,60$ and $90 \mathrm{~min}$. after injection. Each blood sample was immediately replaced by an equal volume of fresh donorblood from litter-mates. Blood was centrifuged and ${ }^{51} \mathrm{Cr}$-EDTA was measured in plasma by radiation counting in a Packard Gamma Counter model 5220.

The plasma concentration time curve thus obtained was fitted for a two compartment open model according to the equation:

$$
C(t)=A e^{-\alpha t}+B e^{-\beta t}
$$

using a non-linear regression analysis routine.

Area under the curve (AUC) was calculated from the un fitted data by use of the trapezoidal rule, where $(A+B)$ was used for $\mathrm{C}(\mathrm{t}=\mathrm{o})$ and $\frac{\mathrm{C}(\mathrm{t}=90)}{\beta}$ for extrapolation to infinity. Clearance $(\mathrm{CL})$ was cal-
culated as :

$$
\mathrm{CL}=\frac{\text { Dose injected }}{\mathrm{AUC}}
$$

The volume of distribution $(\mathrm{Vd} \beta)$ was then calculated from clearance as:

$$
\operatorname{Vd} \beta=\frac{\mathrm{CL}}{\beta}
$$

expressed $\mathrm{ml}$ and normalized for the body weight.

Uptake of ${ }^{51} \mathrm{Cr}$ EDTA into blood cells was tested by incubating blood with a known amount of tracer for one hour at $37^{\circ} \mathrm{C}$. After this incubation less than $0.1 \%$ of the tracer had accumulated in the cell fraction. 


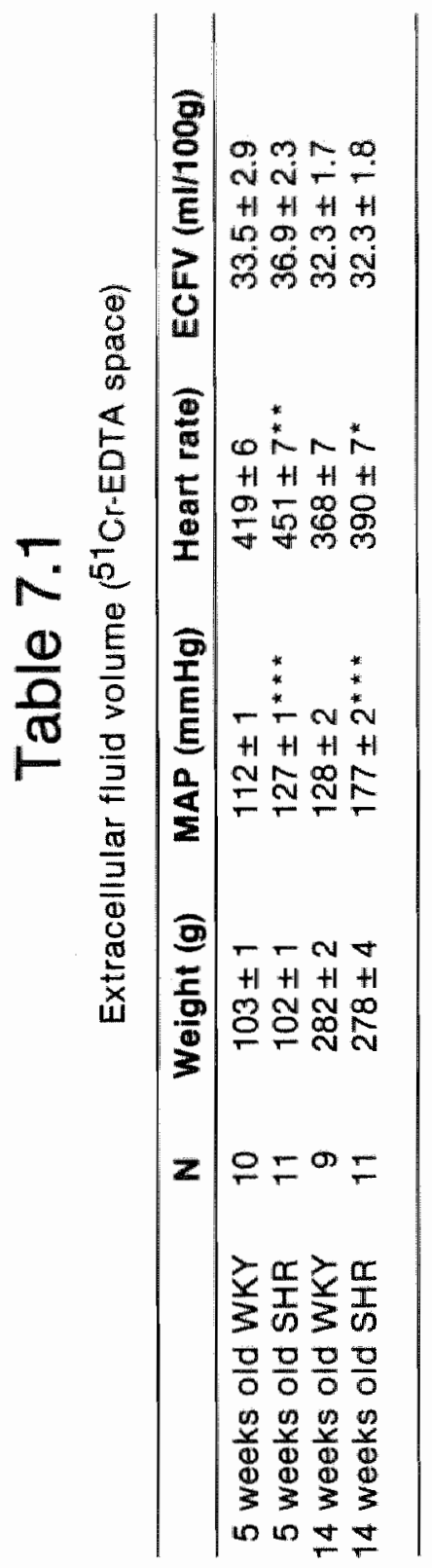

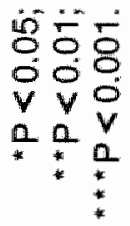

3

$\frac{0}{0}$

0

는

$\frac{x}{\operatorname{In}}$

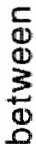

$\frac{9}{0}$

a)

$\frac{\mathscr{U}}{\frac{0}{0}}$ 


\section{Results}

Mean arterial pressure (MAP), heart rate and ECFV ( ${ }^{51} \mathrm{Cr}$ EDTA space) of 5 weeks old and 14 weeks old SHR are summarized in table 7. 1.

Both in 5 weeks old and in 14 weeks old SHR a significant increase in MAP and heart rate was observed. Although the extracellular fluid volume was circa 10\% higher in the young SHR, the difference did not reach a statistically significant level. In the adult SHR and WKY equal values were obser. ved for the extracellular fluid volume.

\section{Discussion}

In the present study ECFV was estimated by the ${ }^{51} \mathrm{Cr}$ EDTA space in 5 weeks old and 14 weeks old SHR and WKY.

In 5 weeks old SHR and WKY the ${ }^{51}$ Cr EDTA spaces were resp. 33.5 and $36.9 \mathrm{~m} / 100 \mathrm{~g}$; similar data were observed in the 14 weeks old SHR and WKY resp. 32.3 and $33.3 \mathrm{ml} / 100 \mathrm{~g}$.

In the 14 weeks old SHR comparable results were observed by Bianchi et al. (3) who demonstrated a ECFV of $31.0 \mathrm{ml} / 100 \mathrm{~g}$ (thiocyanate space).

Lower values of ECFV were estimated by Trippodo et al. (16) in 4-6 weeks old SHR and WKY when the inuline space was used as a parameter for ECFV (16 ml/100 g.). It has been reported that the insuline method for the determination of excellular fluid volumes gives consistently lower extracellular fluid volumes than most other substances used for the determination of extracellular fluid volume (4). This could account for the lower values observed by Trippodo et al in comparison to our study. Although the absolute values differ for each substance used for the determination of extracellular fluid volumes, no significant differences can be detected in either young and adult SHR and WKY in Trippodo's study, Bianchi's study and in our study.

In spite of this lack of significance, an increase of $10 \%$ in extracellular fluid volume was observed in the 5 weeks old SHR in comparison to WKY, which needs further evaluation.

In chapter $V$ of this thesis a significant increase in plasma volume was observed $(11 \%)$ in the 5 weeks old SHR. It seems logical that a retention of fluid by the kidney, which leads to an increased plasma volume would under normal circumstances also lead to an increase in extracellular fluid volume. The lack of significance in the difference between the extracellular fluid volumes of 5 weeks old SHR and WKY was due to the relatively high standard deviations in these data. Since relatively lower standard deviations were observed in the plasma volumes of the 5 weeks old SHR and WKY, it seems obvious that this difference can be explained either by the different methods used for extracellular fluid volume and plasma volume determination or by the lower variability in plasma volume in individual rats as a consequence of better regulation mechanisms for intravascular volumes than for extravascular volumes. 
Alternatively the larger plasma volumes observed in chapter $V$ and the lack of a significant increase in extracellular fluid volume in this chapter may point to a shift in starling equilibrium of capillary exchange in the 5 weeks old SHR (e.g. an increased plasma oncotic pressure).

Future studies on plasma oncotic pressure and microvascular studies on capillary exchange in the 5 weeks old SHR and other mechanisms invollved in the regulation of extracellular fluid volume and plasma volume should define these changes in more detall. 


\section{References}

1. Bianchi, G., Baer, P.G., Fox, U., Duzzi, L., Caravaggi, A.M., Mönring, J. and Cusi, D. In: The kidney in arterial hypertension, (G. Blanchi and G. Bazzato, Eds.) Bunge Scientific Publishers, Utrecht (1979).

2. Bianchi, G., Baer, P.G., Fox, U., Duzzi, C., Pagetti, D. and Giovannetti, A.M.: Circ. Res. 36, 153 (1975).

3. Bianchi, M., Bellini, G., Hessan, H., Kim, K.E., Swartz, C. and Fernandez, M.: Clin. Sci. 61, 685 (1981).

4. Biewald, N. and Billmeler, J.: Experientia 34, 412 (1978).

5. Borst, J.G.G. and Borst de Geus, A.: Lancet 1, 677 (1963).

6. Brøcher-Mortensen, J.: Scand, J. Clin. Lab. Invest. 40, 567 (1980).

7. Gresson, G.R., Bird, D.L. and Simpson, F.O.: Life Sci. 12, 393 (1973).

8. Gresson, C.R., Bird, D.L. and Simpson, F.O.: Clin. Sci. 44, 349 (1973).

9. Guyton, A.C.: Textbook of Medical Physlology, 5th edition, W.B. Saunders Company, New York (1975).

10. Ibsen, $H$. and Leth, A.: Acta Med. Scand. 194, 93 (1973).

11. Kunes, J. and Jelinek, J.: Clin. Exp. Pharmacol. 6, 507 (1979).

12. Ledingham, J.M. and Cohen, R.D.: Lancet 1, 887 (1963).

13. Poulsen, H.L., Jensen and Parving, H.H.: Scand. J. Clin. Lab. Invest. 37, 691 (1977).

14. Schalekamp, M.A.D.H.: Hypertension Physiopathology and treatment. Genest E, Kuchel, O., McGraw Hill, New York, (1977) p. 49.

15. Tarazi, R.C.: Circ. Res. 38 suppl.2, 73 (1976).

16. Trippodo, N.C., Walsh, G.M. and Frohlich, E.D.: Am. J. Physiol. 235, H52 (1978). 


\section{Sympathetic activity in young and adult SHR and WKY}

Many investigators have suggested that the development and stabilization of spontaneous hypertension in rats and essential hypertension in humans may involve neurogenic factors, and an increased sympathetic nerve activity has been reported in both types of hypertension.

The plasma noradrenaline concentration is frequently used as an index of sympathetic nervous activity. However, studies on this parameter in patlents with essential hypertension have led to conflicting results. In a recent extensive review of 32 studies comparing plasma noradrenaline concentrations in groups of patients with essential hypertension and normotensive control individuals, Goldstein (5) showed that $88 \%$ of the studies reported higher levels in essential hypertension, whereas in only $41 \%$ statistical significance was reached, partly as a consequence of improper selection of control individuals. This author concludes that there is fair evidence for an increased sympathetic activity in at least a portion of the patlents with essential hypertension.

Direct nerve recordings from sympathetic nerves have also been used as an index of sympathetic activity in hypertensive patients. Wallin et al. (23) reported a significant correlation between sympathetic nerve activity from muscle branches and the diastolic blood pressure in hypertensive patients. This study also indicates that the diastolic blood pressure threshold for sympathetic nerve activity was reset in patients with essential hypertension. These authors suggested that these differences between hypertensive and normotensive subjects are secondary to the hypertension. Specific interest has also been given to the sympathetic nervous system in young borderline hypertensive patients with a possible hyperkinetic circulation. Miura et al. (12) reported an increase in plasma noradrenaline concentration. In contrast normal plasma noradrenaline concentrations were found by Henquet et al. (8) in borderline hypertensive subjects under resting conditions or during exercise. It was suggested by these latter authors that in stressful situations such subjects are particulary prone to react with an enhanced release of noradrenaline into the circulation, which may explain the discrepancy between their study and that of Miura et al. So far it may be concluded that an increased sympathetic activity is present in essential hypertension, but not in borderline hypertension, when proper attention has been given to the normotensive controls.

Special interest has also been paid to the sympathetic nervous system of the SHR. In young (4-6 weeks) and adult SHR (11-20 weeks) an increase in sympathetic nerve activity was demonstrated on the basis of different techniques, e.g. direct nerve recordings $(9,21,22)$, measurement of organ noradrenaline turnover $(15,25)$, measurement of the activity of noradrenali- 
ne synthesizing enzymes $(7,13)$. Plasma noradrenaline levels have also been used as an index of sympathetic activity. However, studies on this parameter have led to conflicting results: an increase in plasma noradrenaline concentrations has been reported in the young SHA $(6,13,14)$ and adult SHR (2), while others could not demonstrate a difference in the young adult SHR vs their normotensive controls (11). This discrepancy could be explained by the difference in experimental circumstances under which blood samples were taken for the determination of plasma noradrenaline concentrations. Optimal results may be obtained if blood samples for the determination of plasma noradrenaline concentration are measured in arterial blood of undisturbed freely moving animals in their home cages several days after surgical implantation of the indwelling arterial catheters which are used for the blood sampling.

Other methods deviating from the procedure above e.g. the usage of deca. pitation blood; restraining the animals; the usage of intravenous catheters will result in erroneously high plasma noradrenaline concentration values $(2,4,11,17)$.

Up to date no studies have been performed in SHR using the correct method for blood sampling described above. One study in stroke prone SHR revealed increased noradrenaline levels in both young and adult animals when blood was sampled correctly (20).

In the present study plasma noradrenaline concentrations were measured in 5 weeks and 15 weeks old SHR and WKY with proper attention to the blood sampling procedure to evaluate the involvement of sympathetic nervous activity in the development and stabilization of the hypertension in this species.

\section{Materials and methods}

\section{General procedure}

For animals, direct blood pressure recording and heart rates $c f_{\text {. the me- }}$ thods of chapter II.

\section{Blood sampling}

To ensure that the rats are not stressed during the blood sampling proce: dure we developed a relatively unstressfull method in our laboratory. On the first day catheters were inserted into the right carotid artery under ether anaesthesia and the animals were taken to a quiet room for recovery. On the second day the conscious animals were trained for the blood sampling procedure in their home cages in the same room. On the third day $1 \mathrm{ml}$ blood was taken from the undisturbed animals for the determina. tion of plasma noradrenaline.

Determination of plasma noradrenaline

Determination of noradrenalin (NA) concentrations in plasma were performed according to the method of Peuler and Johnsson (16) with slight mo- 
dificatlons. For each plasma sample 6 tubes were incubated with catechol-0-methyl-transferase (COMT) (Axelrod and Tomchick (1)), in the presence of 3 H-S-adenosyl-L-methionine. Two of the tubes contained 50 $\mu l$ plasma, 2 others contained $50 \mu$ plasma $+100 \mathrm{pg} N A$ and the last two tubes contained $50 \mu$ bi-distilled water. To each tube $25 \mu$ of a buffersolution was added. The buffer-solution contained TRIS-HCL (to a final concentration of $100 \mathrm{mM}), \mathrm{MgCl}_{2}(60 \mathrm{mM})$, ethyleneglycol-bis-( $\beta$ aminoethyl-ether) $\mathrm{N}, \mathrm{N}^{\prime}$ - tetra acetic acid (EGTA) (10 $\left.\mathrm{mM}\right)$ and reduced glutathione (GSH) ( $1 \mathrm{mM})$.

After mixing the buffer-solution with the plasma $10 \mu$ of COMT-solution and $2.5 \mu \mathrm{Ci} 3 \mathrm{H}$-S-adenosyl-L-methionine (NET-155H, NEN, Boston) were added and the tubes were capped and incubated at $37^{\circ} \mathrm{C}$ for 1 hour under continuous agitation. Final $\mathrm{pH}$ was 8.20 .

After 60 minutes the enzyme-reaction was stopped by adding $50 \mu l$ of a solution of $8000 \mathrm{mM}$ boric acid, $80 \mathrm{mM} \mathrm{Na}_{2}$ EDTA $_{4} 4 \mathrm{mM}$ normetanephrine (NM) and ${ }^{14} \mathrm{C}$-labelled $\mathrm{NM}(\sim 1000 \mathrm{dpm})$ dissolved in $1 \mathrm{~N} \mathrm{NaOH}$ and placing the tubes one ice. NM was extracted from the water-phase into $4 \mathrm{ml}$ toluene/iso-amylalcohol (60:40). The organic phase was transferred to another tube and NM was extracted into $100 \mu 10.1 \mathrm{~N}$ acetic acid. The acid waterphase was washed twice with $1 \mathrm{ml}$ toluene/iso-amylalcohol (60:40) and after discarding the organic phase $150 \mu$ lethanol was added to the acetic acid phase, which was then applied to a sillicagel thinlayer chromatography plate with concentrating zone (Merck, Kieselgel 60F, 254).

Chromatograms were developed in $30-40 \mathrm{~min}$ with a mixture of chloroform, methanol and ethylamine (16:3:2). After drying the plates the spots containing NM were visualized under UV-light and scraped into $25 \mathrm{ml}$ glass tubes. To the silica $1 \mathrm{~m} / \mathrm{NH}_{4} \mathrm{OH}(50 \mathrm{mM})$ and $50 \mu \mathrm{l} \mathrm{Na} 10_{4}(4 \% \mathrm{w} / \mathrm{v})$ were added to oxidize NM to vanillin. After 5 min oxidation was stopped by the addition of $50 \mu$ glycerol in water $(10 \%)$. Toluene $(10 \mathrm{ml})$ and $1 \mathrm{ml}$ acetic acinol $(0.1 \mathrm{~N})$ were added to extract vanillin from the water-phase.

After centrifugation the organic layer was transferred to a scintillation vial and $1 \mathrm{ml}$ of a scintillation-solution containing $100 \mathrm{mg} / \mathrm{ml} 2,5$ diphenyl oxazol (PPO) and 1,52 $\mathrm{ml} / \mathrm{ml}$ 2,2' -p-phenylen bis (5-phenyloxazol) (POPOP) was added. Vials were counted in a liquid scintillation counter for $3 \mathrm{H}$ and ${ }^{14} \mathrm{C}$. The amount of tritium incorporated was taken as a measure for plasma NA concentration, whereas losses during work-up were calculated from ${ }^{14} \mathrm{C}$-counts.

\section{Statistics}

Values indicated represent means \pm S.E.M. unless stated otherwise. Student's t-test was used to compare plasma noradrenaline concentrations, mean arterial pressures and heart rates.

\section{Results}

Heart rate and MAP (Table 8.1.) 

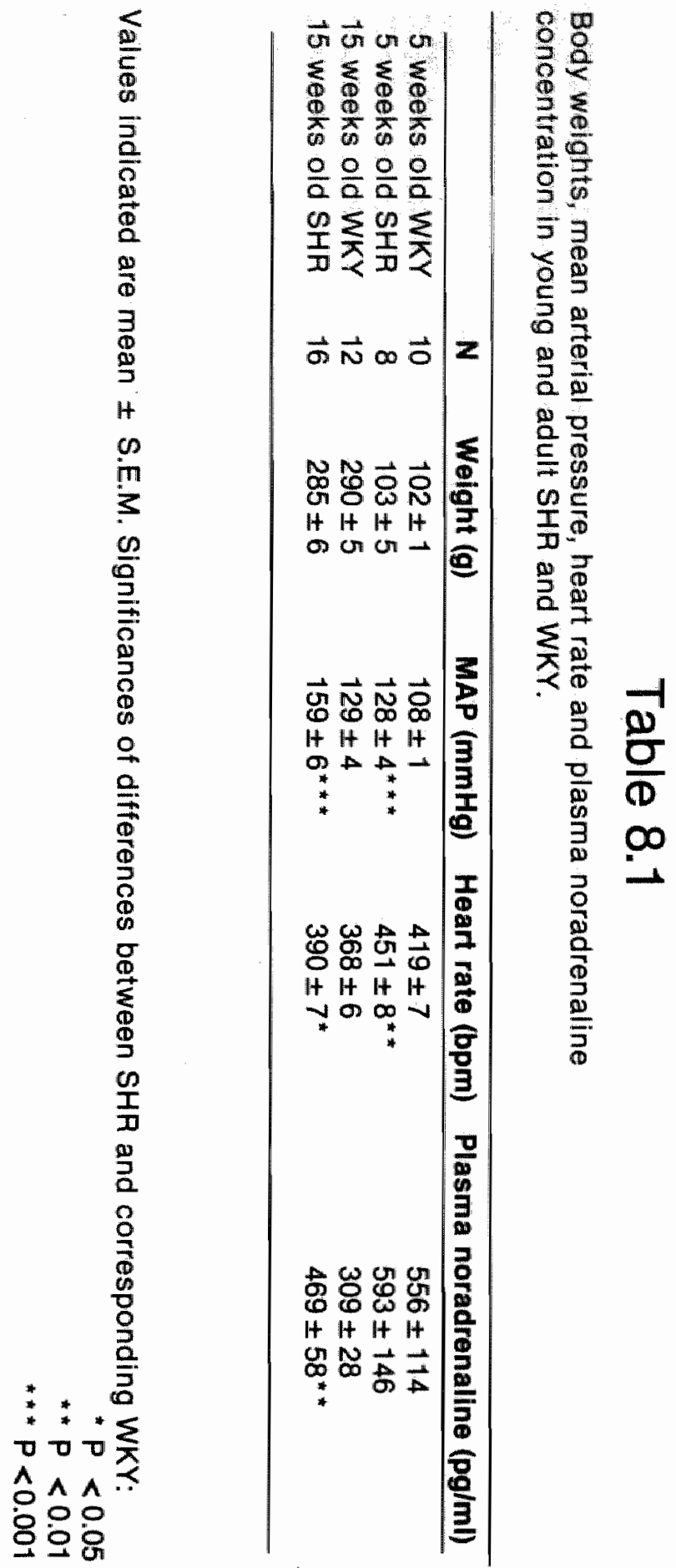
In both 5 weeks old and 15 weeks old SHR a significant increase in MAP was observed (resp. 19 and $23 \%$ ). The heart rates were also elevated in both groups of SHR (resp.. 8 and $6 \%$ ).

\section{Plasma noradrenaline concentration (Table 8.1.)}

No significant difference was observed between the plasma noradrenallne concentration of 5 weeks old WKY $(556 \pm 114 \mathrm{pg} / \mathrm{ml})$ and SHR $(593 \pm 146$ $\mathrm{pg} / \mathrm{ml})$. However, in the 15 weeks old animals a significant $(P<0.01)$ increase was observed in SHR $(469 \pm 58 \mathrm{pg} / \mathrm{ml})$ when compared to WKY $(309 \pm 28 \mathrm{pg} / \mathrm{ml})$.

\section{Discussion}

In the present study plasma noradrenaline concentrations were measured in plasma obtained from arterial blood of 5 and 15 weeks old freely moving SHR and WKY in their home cages after a training of the blood sampling procedure.

A number of factors have been reported to influence the plasma noradrenallne concentration in experimental animals. Decapitation leads to dramatic increases in plasma noradrenaline levels $(4,13)$. Surgical implantation of arterial catheters for blood sampling also leads to increased plasma noradrenaline concentrations if blood is withdrawn one day after the operation (17). Furthermore, increases in plasma noradrenaline concentrations have been reported after handling, restraining and the use of anaesthetics $(2,4,17,18)$. Therefore comparative studies on plasma noradrenaline concentration of SHR and WKY in which decapitation blood has been used $(6,11)$ or blood has been taken too soon after the operation (11) are not indicative for the sympathetic activity under resting conditions in the SHR and WKY. In our study special attention has been given to the blood sampling procedure for the estimation of plasma noradrenaline concentration. This resulted in normal plasma noradrenaline concentrations in the 5 weeks old SHR, whereas significant increases were found in the adult SHR. This latter result is consistent with the observations of an increased sympathetic activity by direct nerve recordings of several visceral sympathetic nerves $(9,21,22)$ and increased activity of synthetizing enzymes (13).

Studies on sympathetic nerve activity estimated by the turnover of noradrenaline in several organs have led to conflicting results. In adult SHA Yamorl et al. (25) reported an increased turnover in heart and kidneys, whereas Patel et al (15) were not able to demonstrate a difference in turnover of noradrenaline in the kidneys and heart of adult SHR and WKY. This discrepancy can be explained by the different techniques used by these two groups of authors.

Patel et al. estimated the turnover of noradrenaline by the rate of decline of noradrenaline after blockade of the synthesis of noradrenaline with $\alpha$ methyldopa, whereas in Yamori's study the turnover of noradrenaline was 
estimated by the decay of specific activity of tritium labelled noradrenallne, a substance which if applied in small amounts does not interfere with the normal turnover of noradrenaline. In young SHR (4-6 weeks old) an in. creased sympathetic tone was observed by direct nerve recordings $(21)$, increased activity of synthetizing enzymes (13) and turnover of noradrenall. ne $(15,25)$, which does not seem to be in agreement with our study.

Before dicussing this dicrepancy the plasma noradrenaline concentration needs a further evaluation.

Plasma levels of noradrenaline appear to reflect adequately the level of sympathetic nerve activity. In pithed rats, in which the rate of sympathetic outflow from the spinal cord can be accurately controlled, plasma levels of noradrenalline attained during stimulation are directly proportional to the rates of stimulation (10). In this study the total sympathetic nerve system was stimulated and no conclusions can be made on the contribution of individual organs to the plasma noradrenaline concentration. In a recent study Wallin et al. (24) demonstrated a direct correlation between plasma noradrenaline and sympathetic muscle nerve activity in normotensive man. These authors suggested that overflow of transmitter from sympathetic terminals in muscles contributes significantly to the plasma noradrenaline concentration at rest. It seems therefore likely that not all organs contribute to the plasma noradrenaline concentration in the same way both in man and experimental animals. Although no increase of overall sympathetic activity could be demonstrated in the 5 weeks old SHR on the basis of noradrenaline concentrations, an increased sympathetic nerve activity may still be present in individual organs, which do not significantly contribute to the plasma noradrenaline concentration.

Since several studies have indicated an increased activity of sympathetic nerve activity to the kidney in the 4-6 weeks old SHR this organ may be an example (3).

The major weakness of most studies in which techniques such as direct nerve recordings and turnover studies of noradrenaline were applied to estimate sympathetic nerve activity is that anaesthetics are used and the need of killing the animals, which may clearly interfere with the sympathetic activity. Therefore the observations of Judy et al. (9) on direct nerve recordings in the SHR are of great value. These authors demonstrated that the sympathetic nerve activity to visceral organs increased raplidly with increasing ages up to 24 weeks and slowly thereafter. Another very important observation in this study is an increased sympathetic nerve activity to the kidney in the 5 weeks old SHR and an increase of this activity during aging and development of hypertension, whereas the renal sympathetic nerve activity in the SHR remained constant in the normotensive animals. These findings of an increasing sympathetic nerve activity in several of gans during aging is in agreement with our results and it may be conclu. ded from our data that an increased overall activity of the sympathetic nervous system is not present in the 5 weeks old SHR, whereas an Increased sympathetic nerve activity to individual organs (e.g. the kidney) cannot be 
excluded from this study. In the adult SHR an increased sympathetic actvity can be demonstrated more explicitly on the basis of increased plasma noradrenaline concentrations. 


\section{References}

1. Axelrod, J. and Tomchick, R.: J. Biol. Chem. 233, 702 (1958).

2. Chiueh, C.C. and Kopin, I.J.: Am. J. Physiol. 234, H690 (1978).

3. Collis, M.G., DeMey, C. and van Houtte, P.M.: Clin. Sci. 57, suppl.5 $233(1979)$.

4. Depocas, F. and Behrens, W.A.: Can; J. Physiol. Pharmacol. 55, 212 (1977).

5. Goldstein, D.S.: Hypertension 3, 48 (1981).

6. Grobecker, H., Roizen, M.F., Welse, V., Saavedra, J.M. and Kopin, I.J.: Nature 258, 267 (1975).

7. Grobecker, H., Saavedra, J.M., McCarty, R., Chiweh, C.C. and Kopin, I.J.: Postgrad. Med. J. 53, suppl. 3, 43 (1977).

8. Henquet, J.W. Kho, T.L., Schols, M., Thijssen, H. and Rahn, K.H.: Clin. Sci. 60, 25 (1981).

9. Judy, W.V., Watenabe, A.M., Henry, D.P., Besch, H.R., Murphy, W.R. and Hockel, G.M.: Circ. Res. 38, suppl.2, 21 (1976).

10. Kopin, I.d., McCarty, R., Yamaguchi, I.: Clin. Exp. Hypert. 2, 379 (1980).

11. MoCarty, R. and Kopin, I.J.: Life Scl. 22, 997 (1978).

12. Miura, $Y$., Kobayaski, K., Sakuma, H., Tomioka, M., Adachi, M. and Yoshinaga, K.: Clin. Sci. Mol. Med. 55, suppl. 4, 69 (1978).

13. Nagaoki, A. and Lovenberg, W.: Life Sci 19, 29 1976».

14. Nakamura, K. and Nakamura, K.: Naunyn Schmiedeberg's Archives of Pharmacol. 299, 143 (1977).

15. Patel, $P$, Kline, R.L. and Mercer, P.F.: Hypertension 3, 682 (1981).

16. Peuler, J.D. and Johnson, G.A.: Life Sci. 21, 635 (1977).

17. Popper, C.W., Chuang, C., Chiueh, C.C. and Kopin, ll.J.: J. Pharmacol. Ther. 202, 144 (1977).

18. Roizen, M.F., Moss, J., Henry, D.P., Weise, V. and Kopin, I.J.: J. Pharmacol. Exp. Ther. 204, 11 (1978).

19. Roizen, M.F., Weise, V., Grobecker, H. and Kopin, I.J.: Life Sci. 17, 283 (1975).

20. Schömig, A. Dietz, R., Rascher, W., Lüth, J.B., Mann. J.F.E., Schmidt, M. and Weber, J.: Klin. Wochenschr. 56, suppl.1, 131 (1978).

21. Schramm, L.P., Barton, G.N.: Am. J. Physlol. 236, R147 (1979).

22. Thoren, P. and Ricksten, S. E.: Clin. Sci. 57, 197 (1979).

23. Wallin, B.G. and Sundiof, G.: Hypertension 1, 67 (1979).

24. Wallin, B.G., Sundlof, G. Eriksson, B.M., Dominiak, P., Grobecker, H. and Lindblad, L.E.: Acta Physiol. Scand. 111, 69 (1981).

25. Yamori, Y., Ooshima, A., Okamoto, K.: Jap. Circ. J. 37, 1235 (1973). 


\section{Chapter IX}

\section{Adaptations of the sympathetic nervous system and cardiovascular system to physi- cal exercise during the development of spontaneous hypertension in rats.}

\section{Introduction}

The increase in work capacity that results from regularly performed physical exercise (physical training) is an example of biologicall long-term adaptations. These adaptations manifest themselves $a_{n} 0$. in changes of the cardiovascular system, blochemical adaptations in skeletal muscle and adaptations of the nervous system. The cardiovascular adaptation to prolonged dynamic exercise has been extensively reviewed. Both in man and in experimental animals a decrease in resting heart rate and an increase in heart weight have been reported in response to this type of exercise $(13,25,32)$.

In recent years it has become evident that in addition to the changes in the cardiovascular system major biochemical adaptations occur in skeletal muscle in response to dynamic exercise $(14,15)$. As a part of these biochemical adaptations cytochrome oxidase and succinate oxidase activity, both reflecting the functional capacity of the respiratory chain in skeletal muscle cells, can increase in animals subjected to regularly performed vigorous endurance exercise $(14,15)$.

Another system which has drawn the attention with respect to prolonged dynamic exercise is the sympathetic nervous system. In man a reduction of plasma noradrenaline concentrations (as an indicator of sympathetic nerve activity) has been demonstrated in response to training programs lasting from $7-20$ weeks $(3,8,38)$. In rats a decrease in sympathetic nerve activity was demonstrated by a decrease in turnover of noradrenaline in the heart and spleen (24). Although adaptations to prolonged physical exercise have been studied extensively in healthy individuals and in experimental animals, less is known about possible beneficial adaptations due to physical exercise in patients with cardiovascular diseases. The benefits of physical exercise by a blood pressure lowering effect have been reported in borderline and essential hypertensive patients $(4,6,12,31)$. In contrast, several other authors were unable to show a blood pressure lowering effect of physical training in borderline and essential hypertensives $(7,17,29)$. In addition to these changes in blood pressure a decrease in heart rate has been reported in borderline and in essential hypertensives (31). Interpretation of data on the effects of physical training in hypertensive patients is hampered by the variability of blood pressure values in these patients. Moreover, so far only relatively small groups of patients were observed and training periods extended over a maximum of 7 months. The 
benefits of physical exercise on hypertension have been recently demonstrated by Roman et al. (28). After a training period of 12 months they observed a significant drop in both diastolic and systolic blood pressure in 30 hypertensive female patients. These periods are short in relation to the several years that it may take before borderline hypertension develops into hypertension (18). Moreover studies in which physical exercise was started in the borderline phase of human hypertension and continued until the stabilization of the hypertension was reached are not avallable. Since the onset, development and stabilization of spontaneous hypertension in rats takes weeks rather than years in comparison to the development of human essential hypertension and moreover since it is a useful model for essential hypertension, the SHR provides an excellent animal model for the performance of such a study (23).

In young SHR (7 weeks old) Tipton et al. (34) reported a decrease in resting systolic blood pressure in combination with a decrease in heart rate when rats were submitted to treadmill exercise. A possible explanation for the observed decrease in heart rate is a decrease in sympathetic drive to the heart $(24,25,33)$. On the other hand, a major disadvantage of the treadmill exercise used by Tipton et al. is that footshocks were needed as an avoidance stimulus, which results in aggresive animals and therefore interpretation of effects of training on the sympathetic nervous system is doubtful (25). A decrease in sympathetic activity may also explain the blood pressure lowering effect of physical exercise in the SHR. Moreover, since sympathetic activity has been reported to be elevated both in SHR and in essential hypertensive patients $(5,11)$, and sympathetic activity has been reported to be reduced in response to training, the development of the sympathetic nervous system during physical exercise in spontaneous hypertension needs to be further investigated.

In this chapter we present the cardlovascular adaptions of SHR and WKY to swim training during the development of spontaneous hypertension. In a second study, separate groups of SHR and WKY were submitted to the same swim training protocol, to investigate the adaptation of the sympathetic nervous system - assessed by measuring plasma noradrenaline concentration - to physical training in the SHR and WKY during the development of spontaneous hypertension.

\section{Materials and methods}

\section{Animals}

Male pneumonia-free spontaneously hypertensive rats (SHR) and genetically related Wistar-Kyoto rats (WKY) were used in this study. These animals were born in our laboratory facilities from pregnant SHR and WKY temales obtained from the Centraal Proefdieren Bedrijf (T.N.O., Zeist). At an age of 21-24 days after birth rats were separated from thell mothers and housed at a temperature of $24 \pm 1^{\circ} \mathrm{C}$ in cages with $4-6$ animals per cage. They were given standard laboratory diet and tap water ad libitum. 
During the fourth week after birth each rat was handled daily to facilitate indirect systolic blood pressure measurements according to the technique described below. At the end of this week rats were weighed and systollc blood pressure and heart rate were measured. From each cage some ariimals were then assigned to a group to be trained or to a control group in such a way that these groups were matched for systolic blood pressure and body weight (Table 9.1).

\section{Training protocol}

The training protocol consisted of a swimming program according to Dawson and Horvath (10). Rats swam in glass tanks $30 \times 30 \times 50 \mathrm{~cm}$ with water temperature maintained at $36 \pm 1{ }^{\circ} \mathrm{C}$. Training was started when animals were 4-5 weeks old. Rats swam 4 days a week for a total period of 11 weeks. During the first week training time was raised from 20 min on the first day to $1 \mathrm{hr}$ on the fourth. During the second and later weeks a weight of $3 \%$ of the body weight was attached to the talls (cf. Dawson and Horvath, 10). To avoid a bias in the trained groups on the basis of factors related to handiling procedures rather than training, the non-trained animals were held in the swimming tanks for a few minutes before each swimming program of exercising groups. At the end of the experiments rats were killed by decapitation; heart and kidneys were rapidly taken out and weig. hed. Moreover, in a number of animals the medial head of the gastocnemius muscle was taken out to determine cytochrome oxidase activity.

\section{Cytochrome oxidase activity}

Cytochrome oxidase activity was determined in gastrocnemius muscle according to Schaitman et al. (32) with a Clark electrode at $23^{\circ} \mathrm{C}$, using TMPD and sodium ascorbate as reducing agents. Cytochrome oxidase activity is expressed as $\mu \mathrm{l} \mathrm{O}_{2}$ uptake/min/gram wet tissue.

Water content of gastrocnemius musle was measured by placing a piece of muscle in an oven at $80^{\circ} \mathrm{C}$ until weight was constant.

\section{Plasma noradrenaline}

At the end of the training period plasma noradrenaline concentrations were measured by a radioenzymatic method (see chapter VIII). To ensure that the rats are not stressed during the blood sampling procedure we developed a relatively unstressfull method in our laboratory. After the last training day catheters were inserted into the right carotid artery under ether anaesthesia and the animals were taken to a quiet room for recovery. One day later the conscious animals were trained for the blood sampling procedure in their home cages in the same room. On the next day $1 \mathrm{ml}$ blood was taken from the undisturbed animals for the determination of plasma noradrenaline. 
During the training period systolic blood pressure, heart rate and weight of each animal were measured at regular times between $9.00-12.00$ a.m. The final measurement was made 1 day after the last swimming exercise. Systolic blood pressure was measured indirectly by the sphygmomanometric tail-cuff method. A programmed electrosphygmomanometer (NARCO Biosystems PE-300) equipped with a piezo-electric pulse pick-up (UgoBasil) was used. A band-pass filter (Technical Department, Rilksuniversiteit Limburg) was used to narrow signal sensitivity from $3-10 \mathrm{~Hz}$. The addi. tion of this band-pass filter greatly enhanced the sensitivity of the method. Rats were placed in special recording cages for the blood pressure measurement. Temperature in the cages was malntained at $38^{\circ}-39^{\circ} \mathrm{C}$ to obtain adequate vasodilation of the caudal artery. The electrosphygmomanometer was inflated and deflated at a rate of $12.5 \mathrm{mmHg} / \mathrm{sec}$. The systolic blood pressure was determined on the basis of a minimum of 4 measurements. Heart rate was calculated from the pulsatile blood pressure signal.

\section{Statistics}

Values indicated represent mean \pm S.E.M., unless stated otherwise. Student's t-test was used for statistical comparison of cytochrome oxidase activity, water content of the muscle and organ weights and plasma noradrenaline of the different groups of animals at the end of the training periad. The classic experimental analysis of variance was used for the statistical evaluation of curves for changes in body weight, systolic blood pressure and heart rate in time (22). For a difference to be statistically significant, the 0.05 level of probability had to be reached.

\section{Results}

Body weights

Figures $1 A$ en $B$ summarize the change in body weight during the training period of 11 weeks. Both in trained WKY and SHR there is a significant delay in increase in body weight ( $F$ values of 46.4, $P<0.001$ and 28.0, $P<0.001$ for SHR resp. WKY for the total period).

The difference was significant $(P<0.05)$ first at an age of $7-8$ weeks for SHR (F $=8.3)$ and $8-9$ weeks for WKY $(F=4.1)$. At the end of the training period body weights were almost equal for the SHR and WKY: $273 \pm 11$ and $261 \pm 8 \mathrm{~g}$ for the trained animals and $302 \pm 9$ and $294 \pm 10 \mathrm{~g}$ for the nontrained animals (Table 1 ).

\section{Systolic blood pressure}

Already at the beginning of the training period systolic blood pressure was slightly higher for SHR $(129 \pm 5 \mathrm{mmHg}$ and $128 \pm 5 \mathrm{mmHg}$ for the 


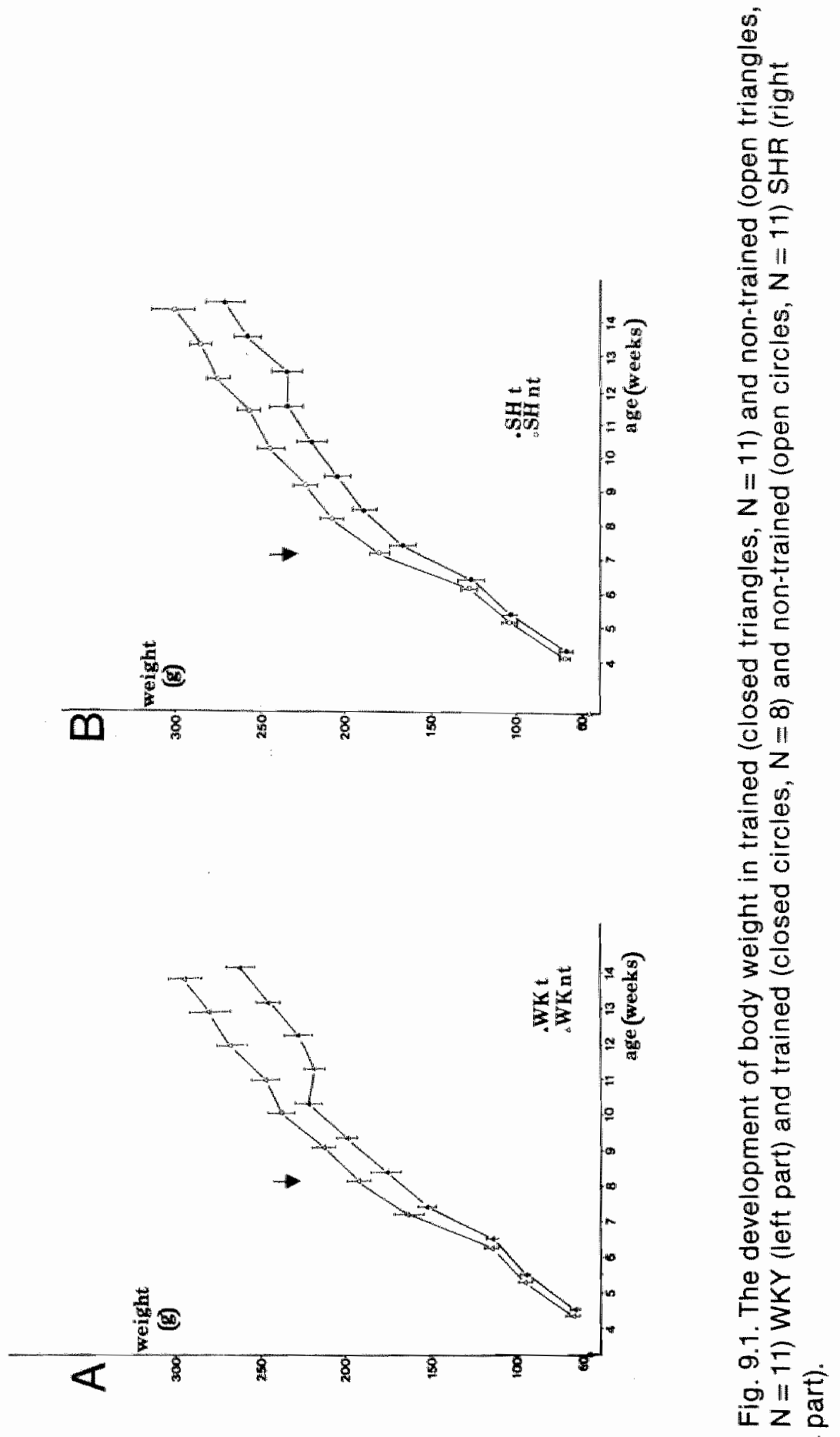




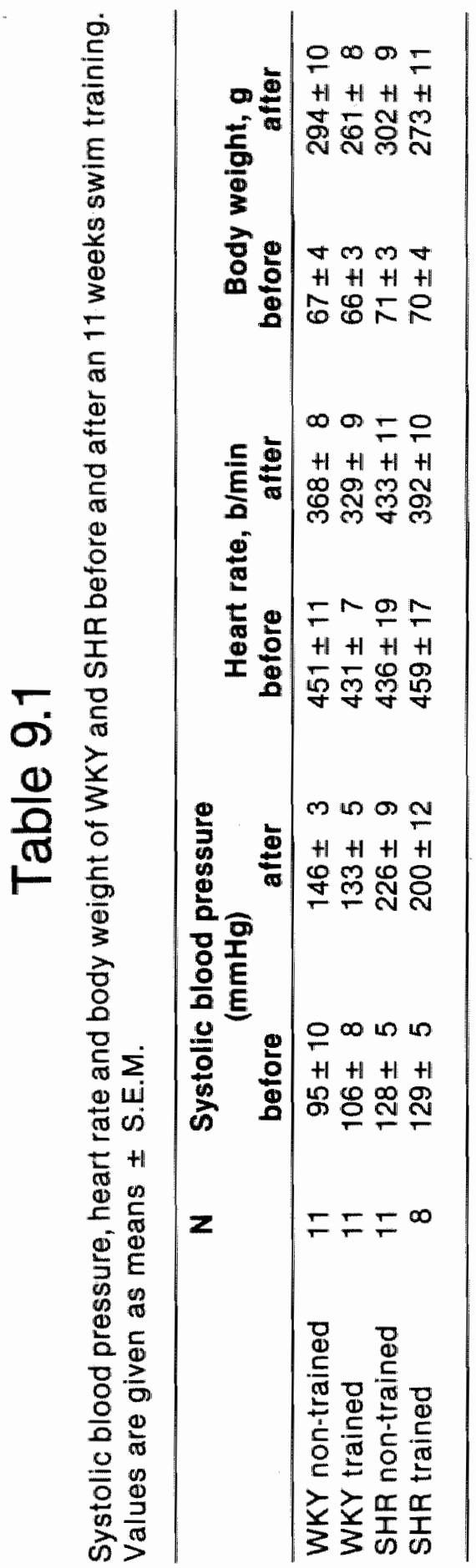




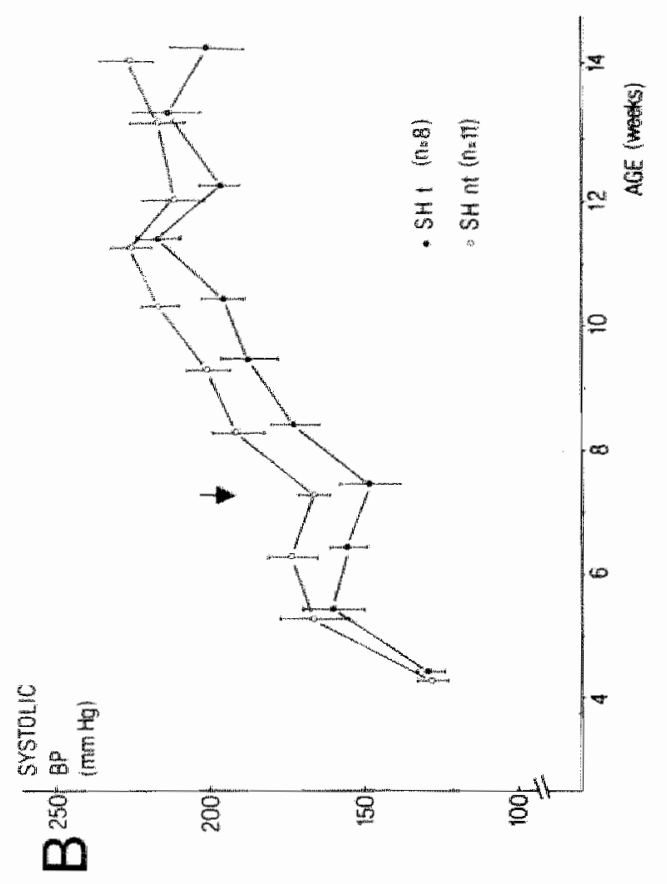

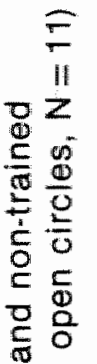

용

II

$z$

is

$\frac{0}{0}$

동

$\pm \frac{0}{2}$

过 11

02

엉

万ิ응

d.

뭉

$\therefore 0$

(1)

जิ

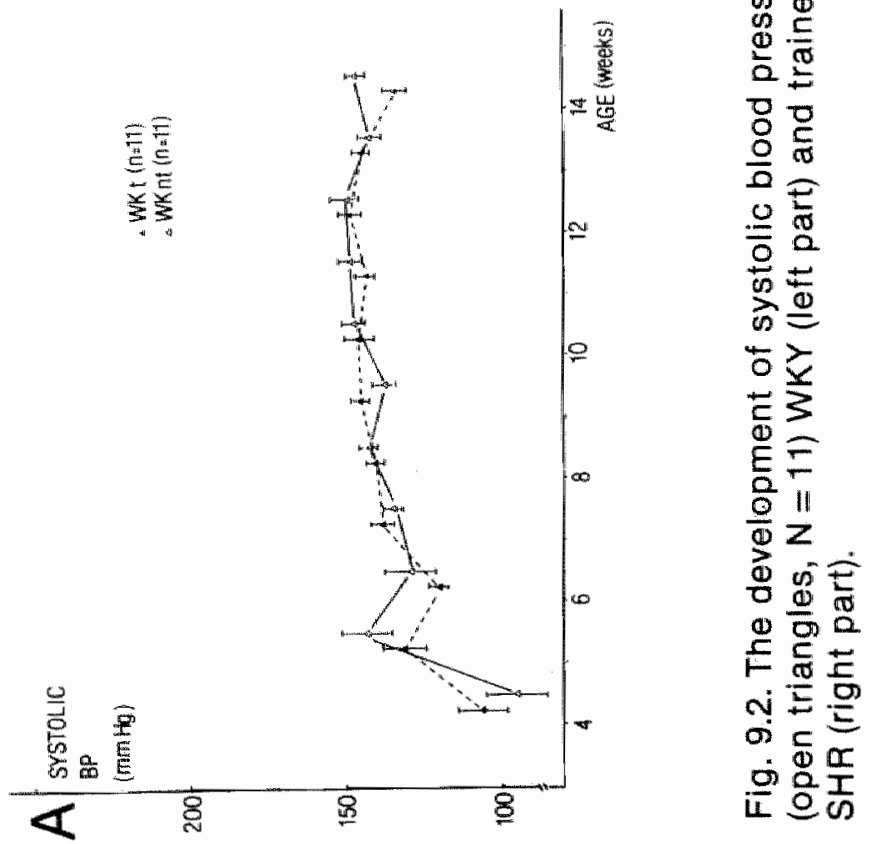


group to be trained respectively controls) when compared with the WKY groups $(106 \pm 8$ and $95 \pm 10 \mathrm{mmHg}$ ). In both the trained and non-trained WKY systolic blood pressure increased rapidly to reach a plateau around $143 \mathrm{mmHg}$ (Fig. 9.2a). There was no significant difference in the blood pressures for trained or non-trained WKY $(F=0.67 ; P>0.1$ for the total period). Systolic blood pressure increased gradually in both trained and nontrained SHR (Fig.9.2b). In the trained animals blood pressure remained slightly below that of non-trained animals. Although this difference never exceeded $26 \mathrm{mmHg}$ it was highly significant $(F=13.9 ; P<0.001$ for the to. tal period). The difference was significant $(P<0.05)$ first at an age of $7-8$ weeks $(F=6.2)$. At the end of the total period systlic blood pressure was $200 \pm 12 \mathrm{~mm} \mathrm{Hg}$ for trained SHR and $226 \pm 9 \mathrm{mmHg}$ for non-trained animals (Table 1).

\section{Heart rate}

The initial heart rate values for SHR's to be trained $(459 \pm 17 \mathrm{~b} / \mathrm{min})$ and of control SHR's ( $436 \pm 19 \mathrm{~b} / \mathrm{min}$ ) did not differ significantly from those of the 2 WKY groups $(431 \pm 7$ and $451 \pm 11 \mathrm{~b} / \mathrm{min})$.

In both groups of WKY heart rate decreased during the experimental period (Fig.9.3a). The decrease was significantly larger for the trained WKY $(F=59.0 ; P<0.001$ for the total period). This difference was significant $(P<0.05)$ first at an age of 6.7 weeks $(F=7.2)$.

For the SHR's a slightly different effect was obtained (Fig.9.3b). Heart rate remained high in control SHR's, whereas it decreased for trained animals. The difference in the two groups was statistically significant $(F=32.9$; $P<0.001$ for the total period). The first significant $(P<0.05)$ difference was observed at an age of $9-10$ weeks $(F=4.2)$. At the end of the training period heart rate was $329 \pm 9$ and $368 \pm 8 \mathrm{~b} / \mathrm{min}$ for trained resp. control WKY and $392 \pm 10$ and $433 \pm 11 \mathrm{~b} / \mathrm{min}$ for trained and control SHR (Table 9.1).

\section{Organ weights}

Table 9.2 summarizes the absolute and relative heart and kidney weights for the 4 groups of rats. Both absolute and relative heart weights are significantly higher in SHR. Training did not increase the absolute or relative heart weight in SHR, whereas it caused a significant $(P<0.01)$ increase in the relative heart weight of WKY.

The relative and absolute kidney weights of SHR were significantly smaller than those of WKY. Training caused a small, but significant $(P<0.01)$ reduction in the absolute kidney weight of WKY whereas it had no significant effect on kidney weights of SHR. 

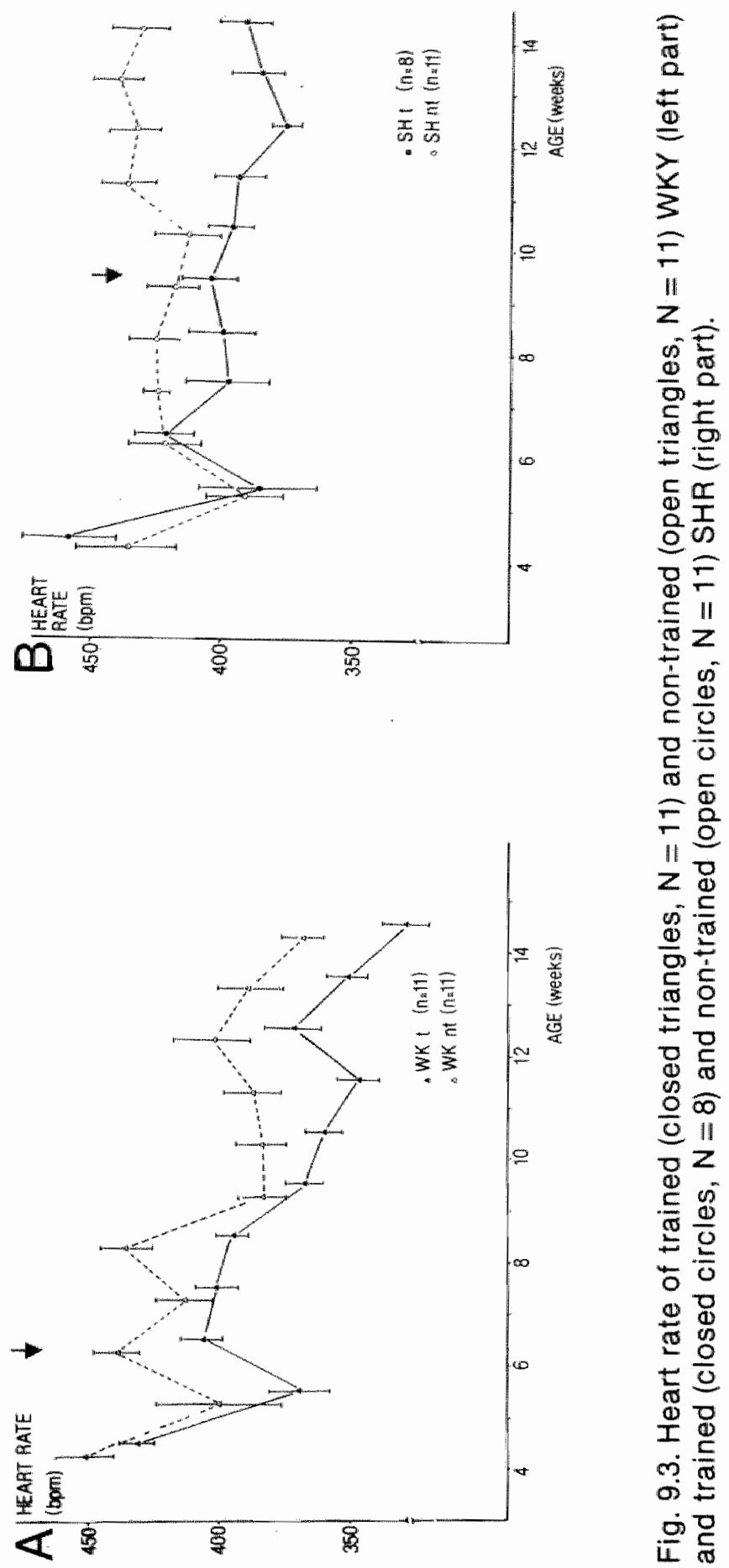


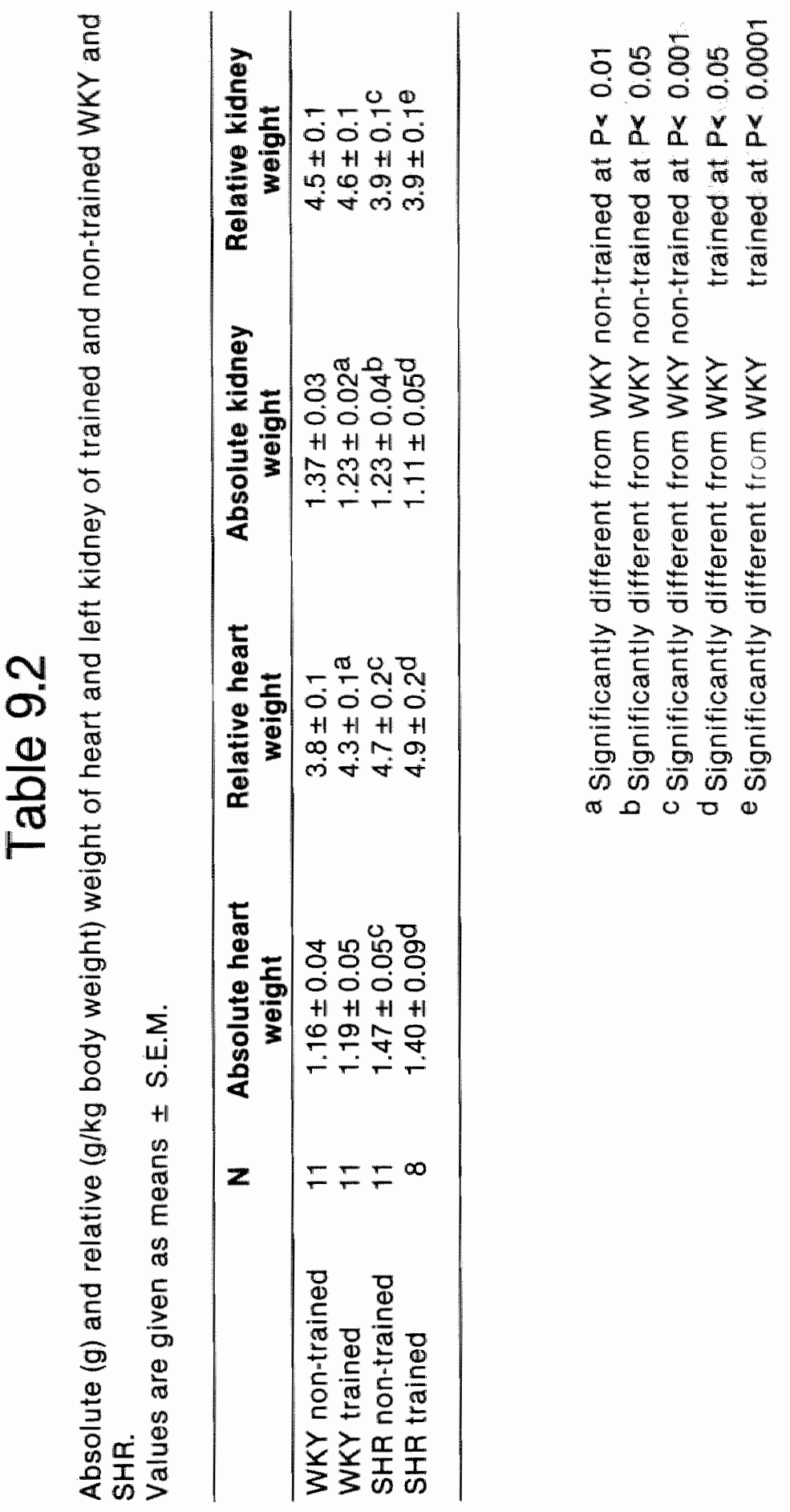




\section{Cytochrome oxidase activity}

Cytochrome oxidase activity in the gastrocnemius was higher in trained than in control animals (Table 9.3). However, the difference is statistically only signiflcant for the WKY $(P<0.05)$. Cytochrome oxidase activity in the non-trained SHR was higher than that in control WKY. Cytochrome oxidase activity can be expressed per gram wet tissue since the relative water content of gastrocnemius muscle was the same for all groups of animals (Table 9.3).

\section{Table 9.3}

Cytochrome oxidase activity $\left(\mu \mathrm{l} \mathrm{O}_{2} / \mathrm{min} / \mathrm{g}\right.$ wet tissue) and relative water content $(\%)$ of the medial head of the gastrocnemius muscle of trained and non-trained WKY and SHR. Values are given as means \pm S.E.M.

\begin{tabular}{lccc}
\hline & N & $\begin{array}{c}\text { cytochrome oxidase } \\
\text { activity }\end{array}$ & $\begin{array}{c}\text { relative water } \\
\text { content }\end{array}$ \\
\hline WKY non-trained & 6 & $215 \pm 20$ & $74 \pm 0.4$ \\
WKY trained & 5 & $274 \pm 12^{\mathrm{a}}$ & $73 \pm 0.2$ \\
SHR non-trained & 6 & $244 \pm 24$ & $74 \pm 0.4$ \\
SHR trained & 4 & $278 \pm 13$ & $74 \pm 0.5$ \\
\hline
\end{tabular}

a Significantly different from non-trained WKY at

$P<0.05$

\section{Plasma noradrenaline concentration}

Plasma noradrenaline concentrations were measured in separate groups of trained and non-trained SHR and WKY (Table 4 and 5). Similar data as in the first groups were obtained. In an analysis of variance a significant $(F=5, P<0.05)$ reduction of systolic blood pressure was obtained when SHR were submitted to a swim training, while in the WKY no signifivant reduction was observed $(F=0.67 ; P>0.05)$.

At the end of the swim training period the heart rates were $317 \pm 6$ and $353 \pm 8 \mathrm{~b} / \mathrm{min}$ for trained resp. control WKY and $348 \pm 7$ and $405 \pm 7 \mathrm{~b} / \mathrm{min}$ for trained and controls SHR; for the whole period of training the heart rates were significantly lower in trained SHR and WKY (resp. P< 0.001 and $P<0.05$ ).

Before presenting plasma noradrenaline data of trained SHR and WKY information about plasma noradrenaline must be repeated from chapter VIII 
of this thesis from animals at the age at which the training was started. In 5 weeks old WKY $(\mathrm{N}=10)$ and SHR $(\mathrm{N}=8)$ plasma noradrenaline was $556 \pm 114$ and $593 \pm 146 \mathrm{pg} / \mathrm{ml}$ resp., which means that there was no difference at the age at which swim training was started. The plasma noradrenaline concentrations response to training are illustrated in Table 9.5.

After the training period when rats were 15 weeks old, a significant reduction ( $P<0.05$ ) of plasma noradrenaline was found in the SHR: $469 \pm 58$ vs $291 \pm 63 \mathrm{pg} / \mathrm{ml}$ (non-trained va trained) but not in WKY: $309 \pm 28$ vs $365 \pm 31$ $\mathrm{pg} / \mathrm{ml}$ (non-trained vs trained). 


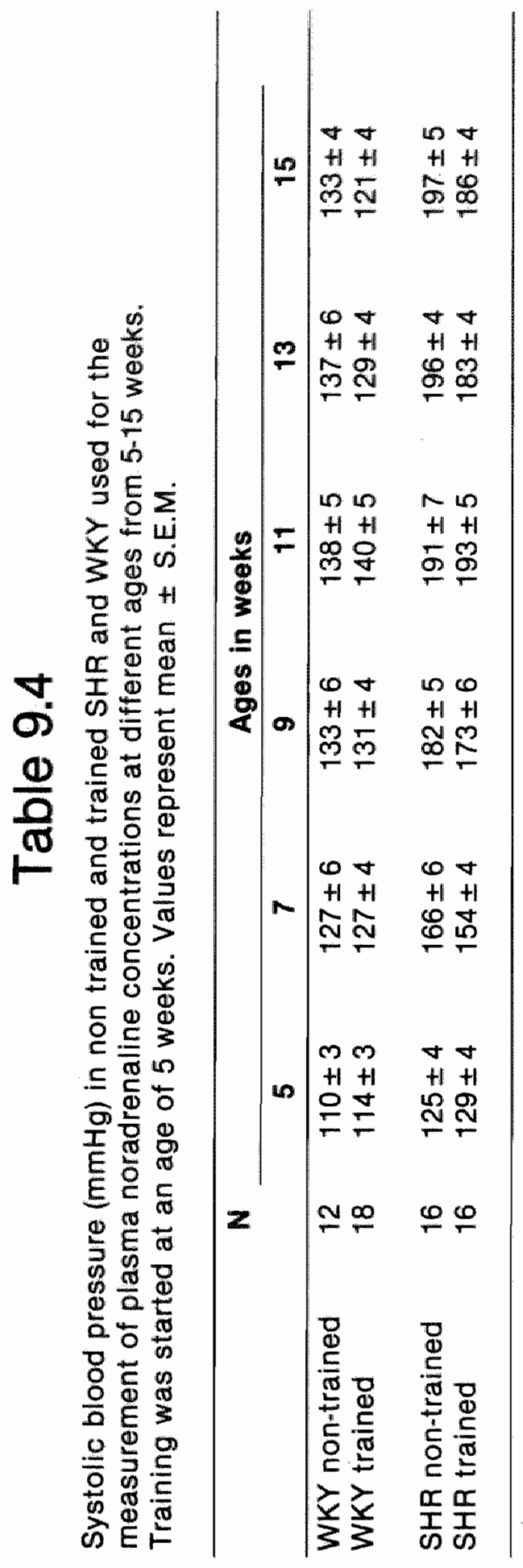




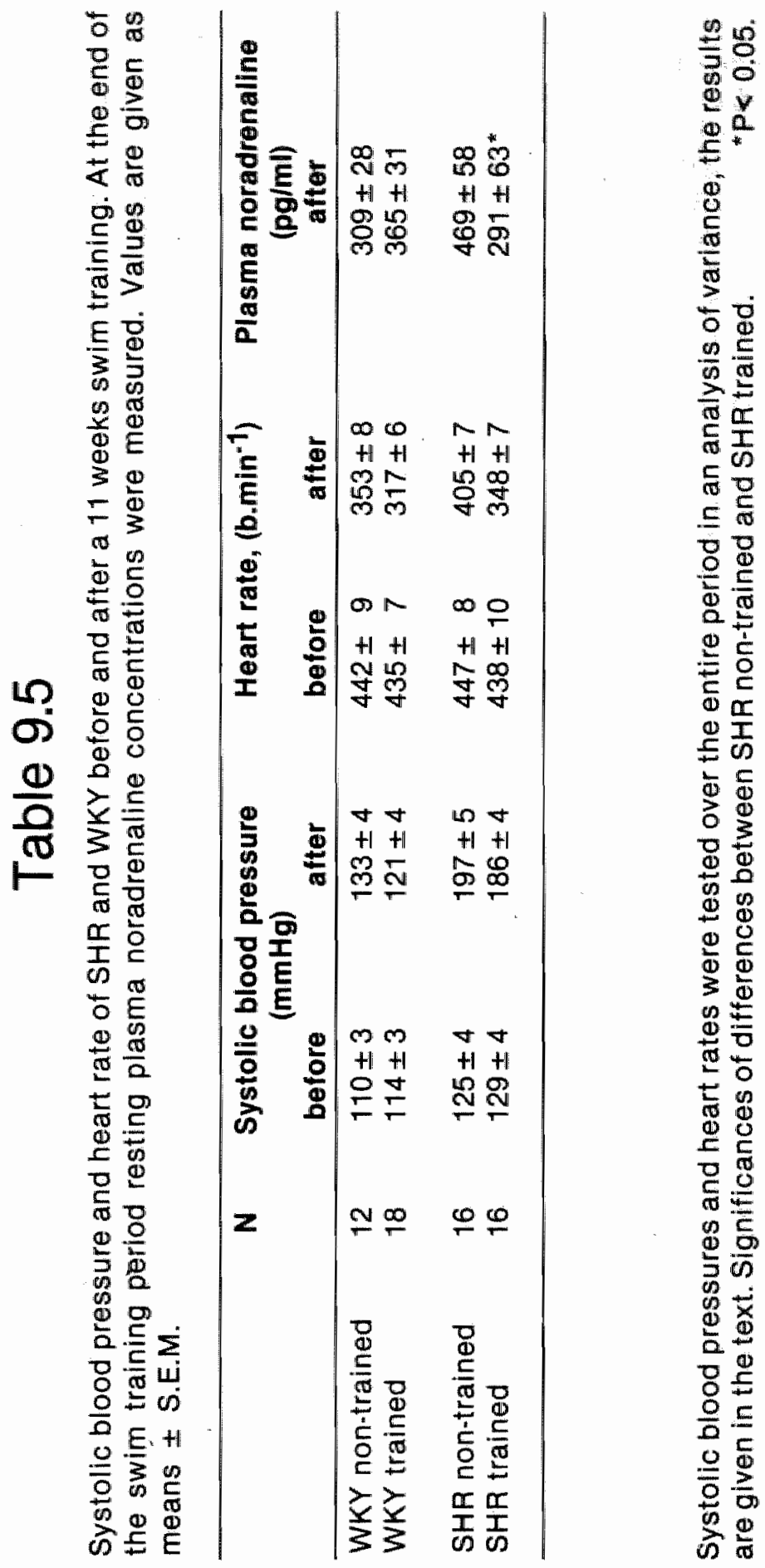




\section{Discussion}

In this study we investigated cardiovascular adaptations and the role of the sympathetic nervous system in the SHR and WKY submitted to chronic physical exercise. We used swimming exercise as a method for physical training. In an extensive review Dawson and Horvath (10) have compared swimming to other forms of exerclse especially treadmill running. No tralning is required for swimming exercise since laboratory rodents such as mice and rats have natural swimming ability, whereas in case of treadmill exercise footshocks have to be used as an unconditioned avoidance stimulans (10).

Dawson and Horvath (10) concluded that swimming exercise is a reliable method for chronic physical training in rats if proper attention is given to the absence of pneumonia in the experimental animals, if water temperature is kept constant just below thermoneutrality and if the training program is gradually built up over the course of several weeks.

A major problem in swimming as well as treadmill exercise is to avoid unneccesary stress and fear to the animals. We therefore handled the animals dally for one week before starting the training program.

Furthermore, animals were slowly adapted to the training situation and control animals were also held in the swimming tanks daily for a few minutes. We noticed during the course of this study that especially the use of animals without pneumonia-like symptoms is of vital importance. Many laboratory rats suffer from pneumonia-like conditions and the ability of such animals to exercise is limited.

The investigation of effects of chronic physical exercise in SHR on parameters such as blood pressure, heart rate, heart and kidney weight may be complicated by the hypertensive process occuring simultaneously. We therefore investigated the effects of training in the progenitor normotensive WKY strain under indentical conditions. The degree of training can be assessed by measuring a number of adaptations in the organism. One of the most sensitive methods in this respect is measurement of muscle cytochrome oxidase activity, one of the enzymes of the electron transport chain $(14,15,35)$. We found a significant increase in the cytochrome oxidase activity of gastrocnemius muscle of trained WKY. In trained SHR cytochrome oxidase activity was also increased, but the difference was not statistically significant. The lack of statistical significance in SHR may be related to the small number of animals measured and the relatively high values ils not-trained animals. SHR have a higher locomotor activity when compared to WKY, which may contribute to an elevated muscle cytochrome oxidase activity (23).

Moreover, swimming exercise may cause a smaller elevation in gastrocnemius cytochrome oxidase activity than observed after running, since the contribution of the hindlegs to swimming is not as large as that to treadmill running (33).

Another method of assessing the trained state is the study of cardiac adaptations to chronic physical exercise (31). An increase of the ratio of 
heart weight to body weight has been produced by various training regi: mens in normotensive rats $(10,32)$. In our experiments an increase in this ratio was observed for trained WKY, indlcating the appropriateness of the training program. However, hearts of SHR are already hypertrophied wi. thout physical training. In fact, in our studies the relative heart weight of non-trained SHR was $24 \%$ higher that that of non-trained WKY.

This degree of cardiac hypertrophy agrees with previous observations $(26,27)$. The already existing cardiac hyperthrophy in SHR as a consequence of high arterial blood pressure or a myocardial abnormality preceding the hypertensive phase (9) may explain the lack of additional increase in the ratio of heart weight to body weight after physical training in these animals. Our present data do not allow firm conclusions on the mechanisms involved in cardiac hypertrophy. Another cardiac adaptation frequently associated with chronic physical exercise is a decrease in heart rate $(13,25,32)$. Bradycardia in physically trained rats was shown to be related to a decrease in sympathetic activity rather than an increase in vagal tone $(24,25,33)$. In this view the reduction in heart rate can be seen as an adaptation of the sympathetic nervous system to training. Another indicator of reduced sympathetic activity in response to training is the decrease in plasma noradrenaline level (8). In our study only the SHA responded with a significant reduction in plasma noradrenaline, while the WKY failed to do so. The mechanism by which a reduction in sympathetic activity occurs in response to physical training remains a subject of speculations. With respect to the decrease in resting heart rate the type of physical exercise is important. A relative bradycardia is seen in the dynamic forms of physical training (e.g. distance running) and not in more static forms of exercise (e.g. weight lifting). Since dynamic exercise results in a larger ventricle volume and stroke volume (20), we speculate that a larger stroke volume provokes a decrease in heart rate due to a decreased sympathetic activity.

Another mechanism by which a decrease of sympathetic activity in response to training can occur is exhaustion due to over-stimulation of the sympathetic nerves (2). In this regard the difference in response to training between SHR and WKY can be explained by the hyperactive sympathetic nervous system of the SHR $(5,21)$ under different conditions. Additional data for an over-active sympathetic system in adult SHR was discussed in chapter VII. Fifteen weeks old SHR have significantly higher plasma noradrenaline concentration in comparison to age-matched WKY (resp. $469 \pm 58$ vs $309 \pm 28 \mathrm{pg} / \mathrm{ml}$ ).

The major goal of our study was to investigate whether the sympathetic nervous system plays a role in the blood pressure lowering effect of training in the SHR. Since a reduction of both systolic blood pressure and sympathetic activity was observed in the SHR and not in the WKY, we conclude that a reduction of sympathetic activity may play a role in the small blood pressure lowering effect of training in spontaneous hypertension. It must be noted that training causes a reduction of plasma noradrenaline 
concentration to control but not a normalization of systolic blood pressure in the SHR. In this respect the training-induced reduction of sympathetic nerve activity does not affect blood pressure as strongly as substances that destroy the sympathetic nerve system (e.g. nerve growth factor antiserum or 6-hydroxydopamine) which prevent the rise in blood pressure in the SHR $(9,36)$.

The mechanism by which reduced sympathetic activity lowers systolic blood pressure in the SHR in response to training remains unknown. A decrease in flow resistance has been reported in the isolated hind quarters of the trained SHR suggesting a decrease in peripheral resistance (36). Another interesting observation in this regard is an increase of the number of microvessels in muscle tissue of the trained rat $(1,16)$ whilch can also contribute to a decrease in resistance and blood pressure. However, a reduction in cardiac output can not be excluded as a mechanism involved in the decrease in systolic blood pressure and needs to be further investigated. Finally, our study shows that physical training causes a normalization of plasma noradrenaline levels in the SHR but no normalization of systolic blood pressure, suggesting that the remaining high systolic blood pressure in trained rats is due to other factors (e.g. structural changes of the blood vessels) than to an increased sympathetic tone. Since training gives a normalization of plasma noradrenaline in the SHR it may provide an alternative tool in the investigation of the role of the sympathetic system in hypertension to agents which destroy the sympathetic nerves such as nerve growth factor antiserum and 6-hydroxydopamine $(9,36)$. 


\section{References}

1. Adolfsson, J., Ljungqvist, A., Tornling, G. and Unge, G.: J. Physiol. 310, 529 (1981).

2. Benedict, C.R., Fillenz, M. and Stanford, C.: Brit. J. Pharmacol. 66, $521(1979)$.

3. Bloom, S.R., Johnson, R.H., Park, D.M., Rennie, M.J. and Sulaiman, W.R.: J. Physiol. 258, 1 (1976).

4. Boyer, J.L., Kasch, F.W.: J. Am. Med. Assoc. 211, 1668 (1970).

5. Chiveh, C.C. and Kopin, I.J.: Am. J. Physiol. 234, H690 (1978).

6. Choquette, G. and Ferguson, R.J.: Can. Med. Ass. J. 108, 699 (1973).

7. Clausen, J.P.: Physiol. Rev. 57, 779 (1977).

8. Cleroux, J., Péronnet, F., Perrault, M., Cousineau, D., de Champlain, $J$. and Nadeau, R.; International series on sport sciences vol. 11B, (Poortmans, J. and Niset, G. Eds.) University Parkpress, Baltimore 1981, p.118.

9. Cutilletta, A.F., Benjamin, M., Culpepper, W.S., Oparil, S.: J. Mol. Cell. Cardiol. 10, 689 (1978).

10. Dawson, C.A., and Horvath, S.M.: Med. Sci. Sport 2, 51 (1970).

11. Goldstein, D.S.: Hypertension 3, 48 (1981).

12. Hanson, J.S., Nedde, W.H.: Circ. Res. 27, suppl.I, 149 (1970).

13. Harpur, R.P.: Comp. Biochem, Physiol. 66, 553 (1980).

14. Holloszy, J.O.: J. Biol. Chem. 242, 2278 (1967).

15. Holloszy, J.O., Booth, F.W.: Ann. Rev. Physiol. 38, 273 (1976).

16. Hudličká, O.: Exercise and sport sciences reviews (Hutton R.S. and Miller D.I. Eds.) vol.5 Franklin institute press Washington (1977).

17. Johnson, W.P., Grover, J.A.: Can. Med. Ass. 96, 842 (1967).

18. Julius, S., Schork, M.A.: J. Chron. Dis. 23, 723 (1971).

19. Lin, Y.C., Horvath, S.M.: J. Appl. Physiol. 33, 796 (1972).

20. Longhurst, J.C., Kelly, A.R., Gonyea, W.J. and Mitchell, J.H.: J. Appl. Physiol. 49, 676 (1980).

21. McCarty, R. and Kopin, I.J.: Life Scl. 22, 997 (1978).

22. Nie, N.H., Hull, C.H., Jenkins, J.S., Steinbrenner, K., Bent, D.H.: Statistical package for the social sciences. McGraw-Hill, New York, (1975).

23. Okamoto, K.: Spontaneous hypertension: its pathogenesis and complications. Springer Berlin, Heidelberg, New York: (1972).

24. Östman, I. and Nybäck, H.: Neuroscience I, 41 (1976).

25. Östman-Smith, I.: Acta Physiol. Scand. 477, 1 (1979).

26. Pfeffer, M.A., Pfeffer, J.M., Frohlich, E.D.: Circ. Res. 38, 423 (1976).

27. Pfeffer, M.A., Ferrell, B.A., Pfeffer, J.M., Weiss, A.K., Fishbein, M.C., Frohlich, E.D.: Am. J. Physiol. 235, H193 (1978).

28. Román, O, Camuzzi, A.L., Villalón, E. and Klenner, C.A.: Cardiology $67,230(1981)$.

29. Rost, R., Hollman, W., Liesen, H.: Herz Kreislauf 12, 680 (1976).

30. Sannerstedt, R.: Adv. Cardiol. 24, 164 (1978). 
31. Sannerstedt, R., Wasir, H., Henning, R., Werkö, L.: Clin. Sci. Mol. Med. 45, 145 (1973).

32. Scheuer, J. and Tripton, C.M.: Ann. Rev. Physiol. 39, 2210 (1977).

33. Schnaitman, C., Erwin, V.G., Greenawalt, J.W.: J. Cell. Biol. 32, 719 (1967).

34. Sigvardsson, K., Svanfeldt, E. and Kilbom, A.: Acta Physiol. Scand. 101, 481 (1977).

35. Tipton, C.M. Matthes, R.D., Callahan, A., Tcheng, T.K. and Lais, L.T. Med. Sci. Sport 9, 168 (1977).

36. Vappatalo, H., Hackmann, R., Anttila, P., Vainiopää, V. and Neuvonen, P.J.: Naunyn Schmiedeberg's Arch. Pharmacol. 284, 1 (1974).

37. Weiss, L.: Cardiovasc. Res. 12, 329 (1978).

38. Winder, W.W., Hickson, C., Hagberg, J.M., Ehsani, A.A. and McLane, J.A.: J. Appl. Physiol. 46, 766 (1979). 


\section{Chapter X}

\section{General discussion and summary}

This thesis presents a series of studies on the development and stabillzation of spontaneous hypertension in rats as well as an analysis of several factors involved in the disturbed blood pressure regulation in this animal model of hypertension.

After a general introduction, chapter ll described the minute to minute variabillty of the blood pressure in relation to the development of hypertension in the SHR. A resp. normal and decreased variability was observed in 5 and 7.8 weeks old SHR, whereas a significant increase in variability of blood pressure was observed in the 15 weeks old SHR in comparison to WKY. Since the baroreflex is a powerful buffer against acute changes in blood pressure, It was speculated that a decreased sensitivity of this system was responsible for the increased variabllity of blood pressure in the adult SHR.

In chapter III the role of the baroreflex sensitivity (BRS) was evaluated in SHR of different ages.

The BRS did not change during the development of hypertension in the SHR $(0.37 \pm 0.04$ vs $0.40 \pm 0.03 \mathrm{msec} / \mathrm{mmHg}$ in resp. 4.5 weeks and 12.20 weeks old SHR), whereas an 2-3 fold increase was observed in the WKY $(0.38 \pm 0.05 \mathrm{msec} / \mathrm{mmHg}$ vs $0.93 \pm 0.08 \mathrm{msec} / \mathrm{mmHg}$ in resp. 4.6 weeks old and 12-20 weeks old WKY). From these experiments it was concluded that an increase in baroreflex sensitivity is part of the development of a normotensive cardiovascular system, whereas in the SHR it remains depressed during the development and stabilization of the hypertension.

In chapter IV peripheral and systemic hemodynamics were evaluated during and shortly after the hyperkinetic phase of the hypertension in respectively 5 weeks and 7 weeks old animals. In the 5 weeks old SHA an increased cardiac output was accompanied by an increased heart rate and blood pressure whereas a normal total peripheral resistance compared to WKY was observed. The increased total blood flow (cardiac output) in the 5 weeks old SHR was predominantly transmitted to skin ( $44 \%$ in. crease) and skeletal muscle (gastrocnemius and plantarls, 106\% increa. se), whereas the kidney flow was decreased, $(31 \%)$ at this age as a result of an increased resistance in the kidney $(84 \%)$. In the 7 weeks old SHR the cardiac output and the abnormal flow distribution returned to control values of WKY. At this age the hypertension is characterized by an increased total peripheral resistance to which all organs studied contributed. A significant increase was observed in : liver $(117 \%)$, spleen $(106 \%)$, heart $(34 \%)$, gastrocnemius $(109 \%)$, kidneys $(113 \%)$, testis $(47 \%)$ and brain $(89 \%)$. From these data it was concluded that:

1. The increase in peripheral resistance in several organs during the development of spontaneous hypertension starts with an increase in resistance in the kidney, which points to a primary role of the kidney in 
the Iriduction of spontaneous hypertension.

2. Autoregulation in response to hyperperfusion is not adominant mechanism in skin and skeletal-muscle, whereas the remaining tissues (e.g. brain, gut, testis etc.) are relatively quickly auroregulated organs, in the 5 weeks old SHR.

In chapter $V$ total plasma volume and regional plasma volumes in a num. ber of tilssues were measured in the SHR.

In the very young group ( 5 weeks) total plasma volume in the SHR was sig. nificantly higher than in WKY $(11 \% 7$. In the other 3 groups $(7-9$ weeks, $9-12$ weeks, 12-16 weeks) total plasma volume was lower in SHR than in WKY (resp. $7 \%, 7 \%$ and $14 \%$ ). This difference reached statistical significance only in the oldest age group. These differences were associated with an impairment of increase in total plasma volume during aging in the SHR. A signiflcantly lower regional plasma volume was seen in several tissues In the 5 weeks old SHR (gut: 16\%, gastrocnemius and plantaris muscle: 19\% and testes: $50 \%$ ) and the 12.16 weeks old SHR (gut: $29 \%$; skeletal muscle: $21 \%$; testes: $46 \%$ and skin: $34 \%$. In the $7-9$ weeks and the $9-12$ weeks old groups a significant decrease was observed only in the testes of SHR $(48 \%$ and $36 \%)$.

It is concluded from these data that:

1. Centralization of plasma to the cardiopulmonary region occurs in the 5 weeks old SHR, since an increase of total plasma vollume was observed together with a decreased plasma volume in individual regional tissues.

2. Since most blood is on the venous side of the circulation (18), decreases of plasma volumes in the SHR may be related to functional or structural adaptations of veins and venules.

3. The impairment of increase in plasma volume in the SHR during aging, points to an impairment of blood vessel growth during aging.

In chapter VI the total plasma disappearance of albumin (TER) and regional extravasation of albumin in several tissues were measured with a double label technique in three groups of SHR and compared to age-matched WKY.

In the very young group (5 weeks) the TER was significantly increased $(32 \%)$, whereas in the $6-9$ weeks old SHR the TER reached the same level as In the WKY. In the oldest group the increase in TER reappeared $(14 \%, P<0.05)$. The tissue clearance of albumin increased significantly in the 5 weeks old SHR in the gastrocnemius and plantaris muscle $(47 \%)$ and In the skin (42\%). In the adult group of SHR an increase in tissue clearance was observed in gut ( $46 \%$ ), gastrocnemius and plantaris muscle $(42 \%)$ and $\operatorname{skin}(43 \%)$. In the middle group of SHR a significant increase in tissue clearance was only observed in gastrocnemius and plantaris muscle $(52 \%)$.

Chapter IV and VI lead to the following suggestions:

1. An increased capillary pressure as a consequence of an increased flow, causes an increased albumin clearance in skeletal muscle and 
skin in the 5 weeks old SHR.

2. An increased capillary pressure as a consequence of a decreased number of microvessels (arterioles, capillaries and venules) and an overflow in the remaining microvessels causes an increased albumin clea. rance in the gastrocnemius of the middle aged group of SHR and an increased albumin clearance in gut, skin and skeletal muscle of the adult group of SHR.

In chapter VIl extracellular fluid volumes (ECFV) were measured in 5 weeks old and 15 weeks old SHR and WKY.

As a parameter of extracellular fluid volume the ${ }^{51} \mathrm{Cr}$ EDTA distribution space was chosen. In the 5 weeks old and 15 weeks old SHR no signiflcant difference in extracellular fluid volume was observed, although in young animals a $10 \%$ larger volume was found.

From these data it is concluded that:

1. Accumulation of extracellular fluid as a consequence of a deficient re. nal sodium output as was postulated by Borst and Borst de Geus (8) as an induction mechanism for hypertension cannot be demonstrated in the 5 weeks old SHR, in contrast to other forms of hypertension (20).

2. The normal extracellular fluid volume observed in chapter VII and the increased plasma volume observed in chapter $V$ may point to a shift in starling equilibrium of capillary exchange in the 5 weeks old SHR (0.g. an increased plasma oncotic pressure).

In chapter VIII the sympathetic nervous system was investigated in two groups of SHR different ages and compared to age-matched WKY. As a parameter of sympathetic nerve activity the plasma noradrenaline concentration was chosen. In the very young group of SHR (5 weeks old) no difference in plasma noradrenaline was observed when compared to WKY whereas in the 15 weeks old SHR a significantly higher plasma noradrenaline level was observed in comparison to WKY. It may be concluded from these data that the overall sympathetic activity is not increased in the 5 weeks old SHR and has no obvious function in the induction of spontaneous hypertension. The increased sympathetic acitivity observed in the adult SHR may reflect an adaptation to the increased blood pressure.

In chapter $I X$ the role of the sympathetic nervous system was further evaluated by physical exercise (swim training) during the development of spontaneous hypertension in the SHR (from 4 to 15 weeks old). At the end of the swimming period the plasma noradrenaline levels were unchanged In the WKY, whereas a normalization of the enhanced plasma noradrenaline levels in the SHR was observed to normotensive WKY levels. This "normalization" of plasma noradrenaline levels was accompanied by a small reduction in resting systolic blood pressure.

From these data it is concluded that sympathetic nerve activity plays a role in the blood pressure lowering effect of training in the SHA. However, normalization of plasma noradrenaline does not cause normotension, which suggests that the remaining high systollc blood pressure in the trained SHR is caused by other factors than an increased sympathetic activi- 
ty (e.g. structural adaptations of the resistance vessels).

The preceding separate conclusions allow us to propose the following hypotheses for mechanisms Involved in the induction and stabilization of spontaneous hypertension in rats:

1. Spontaneous hypertension in rats results directly from a primary increase in afferent resistance (preglomerular resistance) in the kidney, resulting in an increase in intravascular fluid volume, an increased atrial pressure and an increased cardiac output, which is succeeded by autoregulation and/or structural adaptations in local tissues and an increase in peripheral resistance (fig. 10.1).

2. Spontaneous hypertension results directly from a nervous mechanism which is responsible for the increased cardlac output, independent of an increased retenion of fluid by the kidney (cardiogenic hypertension). Simillary as in possibility I the hyperperfusion of different tissues is opposed by lokal autoregulatory mechanisms and/or structural adaptations, which results in a normal cardiac output and an increased peripheral resistance.

3. A neural mechanism is responsible for both an increased renal vascular resistance and a increased cardiac output. The flluid retention by the kidney further enhances the cardiac output and autoregulation of different tissues and/or structural adaptations increases the peripheral resistance.

4. Spontaneous hypertension is a consequence of a primary rise in peripheral resistance, independent of cardiac or renal factors.

In the first hypothesis the hypertension is starts with an increased resistance in the kidney (preglomerular resistance). Before further discussing the function of the preglomerular resistance in spontaneous hypertension it is appropriate to consider a few generally accepted mechanisms of the kidney, which might be responsible for the induction of hypertension (fig. 10.1). The extracellular fluid volume and the renin angiotensin system are not primarily involved in the induction of spontaneous hypertension as may be concluded from this thesis and several other studies $(5,7,32)$. An increased plasma volume as was presented in chapter $V$ of this thesis is the only obvious mechanism by which the kidney can produce hypertension in the 5 weeks ald SHA. The increased plasma volume may cause an increase in main circulatory filling pressure (which is the pressure inside the vascular system when the circulation stops) and an increased atrial pressure is responsible for an increased cardiac output. Both an increased mean clrculatory filling pressure and an increase in atrial pressure have been described in the adult SHR $(26,29,33)$. Unfortunatelly such measurements are lacking for the very young SHR. Local autoregulation mechanisms of several tissues may be responsible for an increased peripheral resistance and a rise in blood pressure in the established phase of the hypertension.

Let us go back to the increased resistance in the kidney observed in chapter IV. 

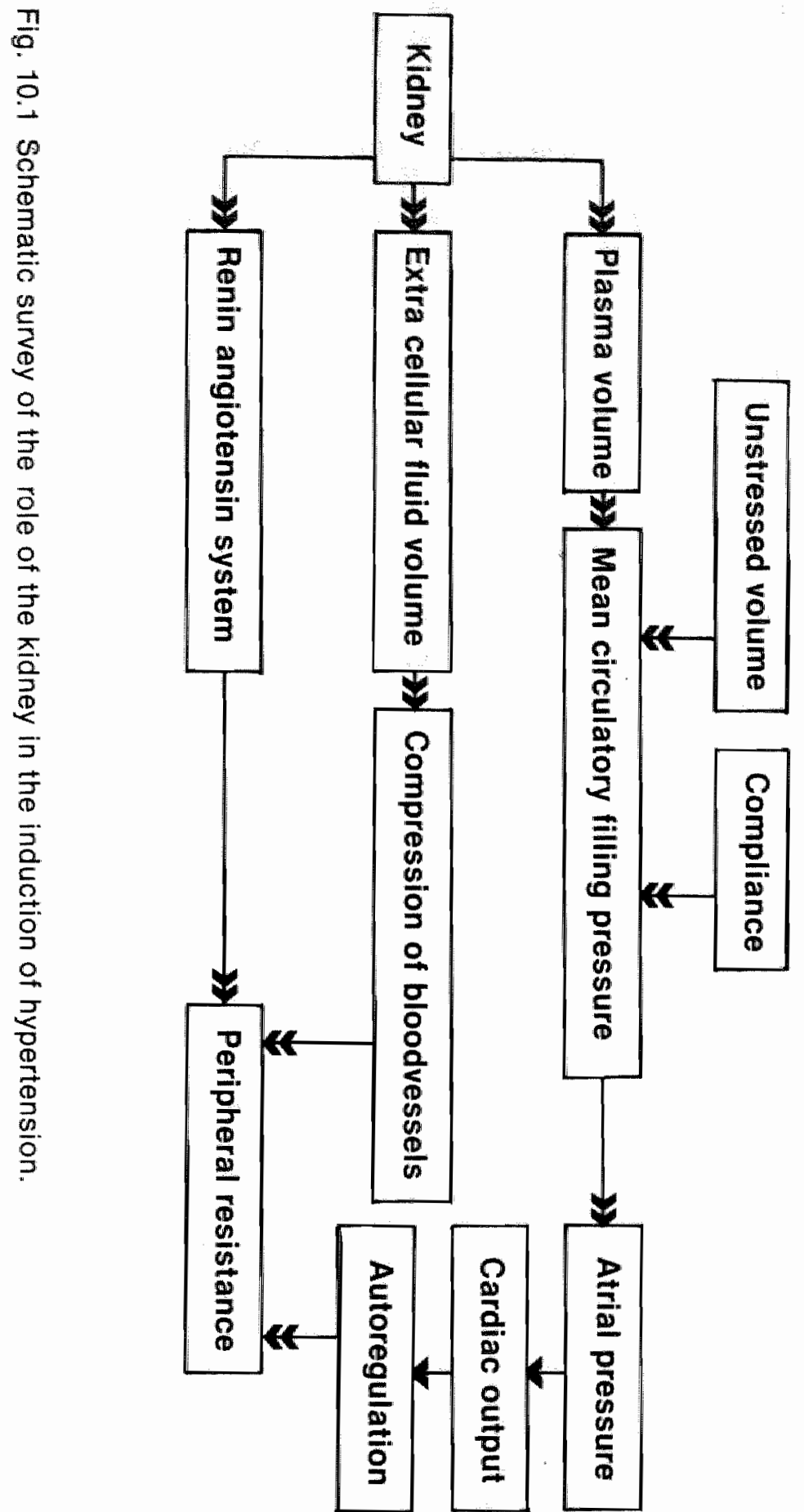
The kidney in spontaneous hypertension has been the subject of many recent studies. Ferrone et al (13) reported an increased resistance to flow in the kidney of adult SHR (4-6 month old) with established hypertension. Arendshorst and co-workers (1,2) and Azar et al. (3) reported that the increased resistance to flow in the kidney is mainly due to constriction of afferent arterioles in resp. 12 weeks and 15 weeks old SHR. In very young SHR (5m6 weeks old) stimulation of the renal sympathetic nerve supply to the kidney causes a greater increase in resistance and release of noradrenalline than in age matched WKY $(9,10)$. Furthermore an increased sympathetic activity was demonstrated on the basis of an increased turnover of noradrenaline in the 5 weeks old SHR (25). The role of the sympathetic nervous activity to the kidney in relation to the hypertension was further evaluated by denervation studies. In 6-8 weeks old SHA this resulted in a delay in blood pressure rise during further development of the spontaneous hypertension $(19,22)$. It may be concluded from these studies that an increase in renal sympathetic activity is present in the 5 weeks old SHR age. The SHR also resembles other models of kidney induced hypertension, such as a new model of genetic hypertension (the Millan hypertensive rat strain) and the renovascular hypertensive rat.

In both models a dysregullation of the kidney leads to an increased plasma volume $(6,20)$.

In the second hypothesis an increased autonomic drive to the heart was held responsible for an increased cardiac output in an early phase of the hypertension and an increased peripheral resistance in a later phase in spite of, or without retention of fluid by the kidney (cardiogenic hypertension).

Recently it was reported by Liard (23) that retention of water and salt is not a necessary first step in the autoregulation concept of hypertension and an increased resistance as a result of an increased cardiac output can also occur after a volume-independent increase in cardiac output e.g. by chronic intracoronary infusion of the $\beta$ adrenergic receptor stimulant dobutamine. In these experiments the initial increase in cardiac output was succeeded by an increase in peripheral resistance and normalization of the cardiac output. Lundin et al. (24) suggested that the increased cardiac output in the SHR is caused by an increased drive of the autonomic nervous system to the heart, since pharmacological blockade of the autonomic nervous driveto the heart (atropine and $B$-blockade) resulted in a normal cardiac output in the SHR.

In chapter IV of this thesis an increased cardiac output was accompanied by an increased heart rate and a normal stroke volume, which is also suggestive for an increased autonomic drive to the heart. On the other hand the increased plasma volume and centralization of plasma volume presented in chapter $V$ may prevent a decrease in stroke volume in the 5 weeks old SHR. (The latter is probably too high in the light of the increased heart rate). Therefore fluld retention by the kidney resulting in an increased plasma volume cannot be excluded as at least an additional mechanism 
in maintaining the increased cardlac output in the 5 weeks old SHR. In the third hypothesis a nervous mechanism caused both an increase in heart rate, cardiac output and increased renal vascular resistance. Two important concepts are of interest in the light of this hypothesis, which will be discussed below.

In a recent publication Folkow (14) attributed a function in spontaneous hypertension to a mechanism which occurs normally during mental arousal (the defence reaction). This defence reaction suppresses vagal tone, increases the heart rate, constricts capacitance and most systemic resistance vessels, except those in skeletal muscle, heart and brain. This defence reaction can be produced by electral stimulation of several sites in the brain (e.g. the hypothalamus and midbrain). The response includes: increase in arterial pressure, hind limb vasodilatation, renal vasoconstriction and tachycardia (4). Another interesting mechanism involved in stimulation of the sites associated with a defence reaction is inhibition of the baroreflex (11). Since most of the phenomena described in this thesis can be explained by the so called defence reaction $(1,3)$ (e.g. an increased heart rate, an increased muscle blood flow, a decreased kidney flow), this seems an attractive explanation for the induction of spontaneous hypertension. On the other hand an increased flow through myocardium and brain was not observed in our study (cf. chapter IV) and moreover an increased muscle blood flow observed in the 5 weeks old SHR can also be considered to be the result of slow autoregulation. Recent investigations in relation to spontaneous hypertension, revealed a second important group of nervous control mechanisms: that of the cardiopulmonary baroreceptors. Both in the pulmonary arteries and the atrium stretch-sensitive receptors are located. Because of the prevailing low blood pressure in these parts of the circulatory system these receptors have been referred to as low pressure receptors. The afferent information of these receptors travels with vagal $C$ fibers as well as sympathetic medullated $A$ and nonmedullated C fibers $(12,30,34)$. Since these receptors are located in the "Iow pressure" capacitance part of the circulatory system, it has been suggested that these receptors sense the degree of filling of the circulation $(15,17)$.

The efferent mechanisms affect renal function, both by a change in renal sympathetic nerve activity and antidiuretic hormone release $(16,30)$. It has been suggested that these reflexes contribute to volume homeostatis $(15,16)$. Also their role in long-term blood pressure control and hypertension is virtually unexplored. In an interesting series of studies Thorén en Ricksten recently showed resetting of cardiac $\mathrm{C}$ fiber endings to a higher threshold left arterial pressure in spontaneously hypertensive rats (SHR) when compared to normotensive controls $(27,28,34)$. It is likely that resetting of this system results in an increased resistance in the kidney, a fluid retention and an increased atrial pressure, which might be responsibie for the increased cardiac output in the SHR. Furthermore it is of interest that stimulation of the hypothalamic defence area inhibits the low pressure 
baroreflex $(36)$, which indicates an interrelation between the two mechanisms. On the basils of an increased heart rate, venoconstriction in several organs, a decreased kidney flow (which may be the result of an increased sympathetic tone to the kidney) and an increased plasma volume, we prefer the third hypothesis as the most likely explanation for the induction of spontaneous hypertension.

Finally the increased resistance in the adult SHR needs further evaluation. In a recent extensive review Webb et al. (35) summarized all mechanisms which may contribute to an increased peripheral resistance in several forms of hypertension. The mechanisms include: structural adaptations (e.g. a decreased number and a decreased lumen of resistance vessels) as well as functional adaptations (e.g. an increased response to pressor substance). Increasing evidence suggests that a decreased number of microvessels might be responsible for the increase in peripheral resistance in the SHR. A reduction of all microvessels (arterioles, capillaries and venules) may not only explain the increased peripheral resistance in established spontaneous hypertension, but also the decreased plasma volume and increased TER.

Therefore the plasma volume distribution and the album in clearance are of interest, especially in those organs in which a decrease in microvessels has been reported in the SHR.

In 5 weeks old SHR a increased albumin clearance was observed in skin and skeletal muscle. These tissues are also those which are hyperperfused at that age.

Structural or functional adaptations of the microvessels are therefore not needed to explain the increased albumin clearance at that age. In the adult SHR (12-20 weeks) an increased albumin clearance was observed in gut, skin and skeletal muscle. At that age a normal blood flow has been reported in those organs by others (13). Hyperperfusion cannot be a possible mechanism involved in the incresed albumin clearance at that age and therefore structural or functional adaptations provide a likely explanations for the increase in albumin clearance at that age. In the 12-16 weeks old SHR a decrease in plasma volume was observed in almost the same tissues which exhibit an increased albumin clearance. This observation suggests that a venoconstriction (structural or functional) or a reduced number of venules are responsible for the increased clearance in those organs by increasing the capillary pressure at that age. A pressure induced escape through arteriolles seems not likely since the increase in albumin clearance is restricted to specific tissues in the middle and adult group of SHR.

From this thesis it must be concluded that stabilization of spontaneous hypertension in rats is not restricted to changes in resistance vessels, but that changes on the postarteriolar site of the circulation are also involved. Future direct microcirculatory studies should define these changes in more detall. 


\section{References}

1. Arendshorst, W.J.: Circ. Res. 44, 344 (1979).

2. Arendshorst, W.J. and Beierwaltes, W.H.: Am. J. Physiol. 263, F 246 (1979).

3. Azar, S., Johnson, M.A., Scheinman, J., Bruno, L. and Tobian, L.: Clin. Sci. 56, 203 (1979).

4. Azevedo, A.D., Hilton, S.M. and Timms, R.J.: Proc. Physiol. Soc. 301, 56P (1979).

5. Bagby, S.P., McDonald, W.J. and Mass, R.D.: Hypertension 1, 347 (1979).

6. Bianchi, G., Baer, P.G., Fox, U., Duzzi, L., Caravaggi, A.M., Mohring, $J$. and Cusi, D.: In: The kidney in arterial hypertension (G. Bianchi and G. Bazzato eds.) Bunge Scientific Publishers, Utrecht, 1979.

7. Bianchi, M., Bellini, G., Hessan, H., Kim, K.E., Swartz, G. and Fernandez, M.: Clin. Sci. 61, 635 (1981).

8. Borst, J.G.G. and Borst de Geus, A.: Lancet I, 677 (1963).

9. Collis, M.G. and van Houtte, P.M.: Clin. Sci. Mol. Med. 55, suppl. 4 233 (1978).

10. Collis, M.G., De Mey, C. and van Houtte, P.M.: Clin. Sci. 57, 233 (1979).

11. Coote, J.H., Hilton, S:M. and Perez Gonzalez J.F.: J. Physiol. 288, $549(1979)$.

12. Donald, D.E. and Shepherd, J.T.: Ann. Rev. Physiol. 42, 429 (1980).

13. Ferrone, R.A., Walsh, G.M. and Tsuchiya, M. and Frohlich, E.D.: Am. J. Physiol. 236, H403 (1979).

14. Folkow, B.: Clin. Sci. 57, suppl. 5, 83 (1979).

15. Gauer, O.H., Henry, J.P. and Behn, C.: Ann. Rev. Physiol. 32, 547 (1970).

16. Goetz, K.L., Bond, G.C. and Boxham, D.D.: Physiol. Rev. 55, 157 (1975).

17. Gupta, P.D., Henry, J.P., Sinclair, R. and Baumgarten, R. von: Am. J. Physiol. 211, 1429 (1966).

18. Guyton, A.C.: Textbook of medical Physiology; W.B. Saunders Company, Philadelphia, (1976). p.237.

19. Kline, R.L., Kelton, P.M. and Mercer, P.F.: Can. J. Physiol. Pharmacol. 56, 818 (1978).

20. Kunes, J. and Jelinek, J.: Clin. Exp. Pharmacol. Physiol. 6, 507 (1979).

21. Ledingham, J.M. and Cohen, R.D.: Lancet II, 887 (1963).

22. Liard, J.F.: Experientia 33, 339 (1977).

23. Liard, J.F.: Clin. Sci. Mol. Med.: 54, suppl. 6, 153 (1978).

24. Lundin, S.A. and Hallbäck-Nordlander, M.G.: Cardiovasc. Res. 14, 561 (1980).

25. Patel, K.P., Kline, R.L. and Mercer, P.F.: Hypertension 3, 682 (1981). 
26. Ricksten, S.E.: Function of cardiac mechano receptors in primary hypertension, Ph.D. Thesis Goteborg (1980).

27. Picksten, S.E., Noresson, E. and Thorén, P.C.: Acta Physiol. Scand. $106,17(1979)$.

28. Ricksten, S.E., Yao, T., Dibona, G.F. and Thorén, P.: Acta Physiol. Scand. 112, 161 (1981).

29. Samar, R.E. and Coleman, T.G.: Am. J. Physiol. 237, H584 (1979),

30. Shepherd, J.T.: Circulation 63, 1 (1981).

31. Smith, T.L. and Hutchins, P.M.: Hypertension 1, 508 (1979).

32. Trippodo, N.C., Walsh, G.M. and Frohlich, E.D.: Am. J. Physiol. 235, 52 (1978).

33. Trippodo, N.C., Yamamoto, Y. and Frohlich, E.D.: Hypertension 3, 104 (1981).

34. Thoren, P., Noresson, E. and Ricksten, S.E.: Acta Physiol. Scand. $107,13(1979)$.

35. Webb, R.C. and Bohr, D.F.: Am. Heart, J. 102, 251 (1981).

36. Wennergren, G., Thoren, P. and Lisander, B.: Acta Physiol. Scand. 101, 241 (1977). 


\section{Samenvatting (Summary)}

In 1963 rapporteerde Okamoto voor het eerst dat hil door het selectlef kruilsen van ratten met een lets hogere bloeddruk een nieuwe vorm van experimentele hypertensle had ontdekt, namelijk de spontaan hypertensieve rat (SHR). Sinds de ontdekking van deze rattenstam zljn er vele overeenkomsten gevonden tussen de spontane hypertensie bij de rat en de essentiële hypertensie zoals die bij de mens voorkomt. Het grote voordeel van deze experimentele worm van hypertensie is de korte periode waarin de hypertensie zich ontwikkelt en stabiliseert. Studies omtrent de ontwikkeling van essentiële hypertensie bij de mens vergen jaren, terwill bij de rat deze periode slechts enkele weken duurt. In dit proefschrlft wordt een studie beschreven naar verschillende belangrijke mechanismen die van invloed kunnen zijn op zowel de ontwikkeling als het in stand houden van de spontane hypertensie. In hoofdstuk I wordt ingegaan op de plaats die de spon. taan hypertensive rat inneemt temidden van andere vormen van experimentele hypertensie; vervolgens wordt in een literatuuroverzlcht uitgebreid ingegaan op de overeenkomsten tussen de mogelijke mechanismen die van invloed zijn op de spontane hypertensie bij de rat en de essentiële hypertensie zoals die bij de mens voorkomt. In hoofdstuk II wordt het verloop in de tijd van de ontwikkeling en stabilisatie van de hypertensie bij de SHR, alsmede de variabiliteit van de bloeddruk beschreven. In een fase van de spontane hypertensie ( 5 weken oude dieren), die hemodynamisch overeenkomt met de borderline fase van de essentiële hypertensie bij de mens, wordt geen verschil in variabiliteit gevonden tussen SHR en normotensieve, genetisch verwante Wistar Kyoto ratten (WKY). Bij volwassen SHR (14 weken oud) met een gestabiliseerde hypertensie wordt een verhoogde variabiliteit gevonden in vergelijking met WKY van dezelfde leef: tijd. Aangezien de baroreflex een krachtige buffer lis tegen acute schommelingen in de bloeddruk, is het waarschijnlijk dat een verminderde gevoeligheid van deze reflex -zoals die in hoofdstuk III gevonden wordt-verantwoordelijk is voor een verhoogde variabiliteit van de bloeddruk bil de volwassen SHR.

In hoofdstuk III wordt de baroreflex bestudeerd gedurende de ontwikkeling en stabillisatie van de hypertensie bij de SHR en vergeleken met WKY van dezelfde leeftijd. De baroreflex gevoeligheld (BRS) verandert nlet tijdens de ontwikkeling en stabilisatie van de hypertensie blj de SHR. In de WKY daarentegen neemt de baroreflex gevoeligheid met een factor 2 tot 3 toe tijdens de groel. Uit deze experimenten wordt de conclusie getrokken dat een toenemende baroreflex gevoeligheid onderdeel uitmaakt van een zich normaal ontwikkelend normotensief cardlovasculair systeem, terwijl de baroreflex gevoeligheid niet verandert gedurende de ontwikkeling en de stabllisatie van de hypertensle blj de SHR.

In hoofdstuk IV wordt de perifere en centrale hemodynamica bestudeerd gedurende en kort na de hyperkinetisch circulatie in de SHR (resp. 5 en 7 weken oude dieren). Bij de 5 weken oude SHR wordt een verhoogd hartmi- 
nuutvolume en hartfrequentie gevonden, terwili het slagvolume op deze leeftijd normaal is in vergeliking met WKY. Het verhoogd hartminuutvolume bij de SHR in vergelliking met de WKY wordt bil de 5 weken oude dieren hoofdzakellik door huid en spier opgevangen, terwijl op deze leeftijd dr bloeddoorstroming door de nieren van de SHR verlaagd is als gevolg van een verhoogde vaatweerstand in dat orgaan. In de 7 weken oude SHR is het hartminuutvolume genormaliseerd tot de waarde die bil de 7 weken oude WKY gevonden wordt. Op deze leeftijd gaat de hypertensie gepaard aan een verhoogde perifere weerstand waaraan alle organen die bestudeerd worden deelnemen.

Uit deze studie worden twee conclusies getrokken:

1. De stllging in weerstand in verschillende organen van de SHR gedurende de ontwikkeling van de hypertensie begint met een stijging van de weerstand in de nier, helgeen wijst op een induktie van deze vorm van hypertensie door de nier.

2. Huid en skeletspier zijn organen met een langzame relatieve autoregulatie, terwijl de overige bestudeerde organen een snelle relatieve autoregulatle hebben.

In hoofdstuk $V$ worden zowel de totale plasma volumina als de regionale plasma volumina in een aantal weefsels bestudeerd gedurende de ontwikkeling en stabilisatie van de hypertensie bij de SHR. Bij 5 weken oude SHR wordt een significante verhoging van het plasma volume gevonden. In latere fases van de hypertensie is het plasma volume verlaagd. Dit verschil is alleen significant in de groep van 12 weken en ouder. Deze laatste verschillen gaan gepaard met een geringere toename van het totale plasma volume gedurende het ouder worden van de SHR. De regionale plasma volumina zi] in een aantal vaatgebieden significant verlaagd bij de SHR in vergelijking met de WKY, vooral in de jongste ( 5 weken) en de oudste groep (12 weken en ouder). In de 5 weken oude SHR wordt een significante verlaging gevonden in de darm, skeletspier en de testes. In de 12 weken en oudere SHR zijn de plasma volumina in de darm, de skeletspier, de testes en de huis verlaagd. In de 2 midden groepen (7-9 weken oude dieren en 9-12 weken oude dieren) werd alleen een significante daling in het plasma volume van de testes van de SHR gevonden.

Uit deze studies worden de volgende conclusies getrokken:

1. Een toename van het totale plasma volume in combinatie met een verlaging van regionale plasma volumina in de 5 weken oude SHR wijst op een centralisatie van het plasma naar het hart en de longen.

2. Aangezlen het meeste bloed zich aan de veneuze zijde van de circulatie bevindt, is het waarschilnlijk dat afnames in plasma volumina in de SHR veroorzaakt worden door functionele of structurele veranderingen In de venen, en venulae.

3. De vertraging van de toename in plasma volume gedurende het ouder worden van de SHR wijst op een vertraging in de groei van bloedvaten gedurende het ouder worden.

In hoofdstuk VI wordt de overall plasma verdwijning van albumine (trans- 
capillary escape, TER) in combinatie met de regionale extravasatie van albumine in verschillende weefsels bestudeerd in drie groepen SHR van verschillende leeftijden en vergeleken met WKY van dezelfde leeftijd. In de jongste groep (5 weken oud) wordt een significant verhoogde TER gevonden terwijl in de 6.9 weken oude SHR geen verschil in TER optreedt in vergelijking met WKY. In de oudste groep (12 tot 20 weken) wordt weer een verhoogde TER gevonden. Een verhoogde weefselklaring voor albumine wordt m.n. in de jongste en oudste groep SHR gevonden. In de 5 weken oude SHR is de weefselklaring van albumine verhoogd in de skeletspier en in de huid. In de volwassen groep SHR wordt een significante toename in albumine weefselklaring gevonden in de darm, skeletspier en in de huid. In de midden groep is uitsluitend de weefselklaring van albumine in de skeletspier verhoogd.

De hoofdstukken IV en VI geven aanleiding tot de volgende suggesties:

1. Een verhoogde capillair druk ten gevolge van een verhoogde doorstroming veroorzaakt een verhoogde klaring van albumine in skeletspier en huid in de 5 weken oude SHR.

2. Een verhoogde capillair druk ten gevolge van een afgenomen aantal vaten (capillairen en venulae) en een verhoogde doorstroming van de overgebleven vaten veroorzaakt een toegenomen albumine klaring in de skeletspier van de midden groep en een toegenomen albumine klaring in darm, huid en skeletspier van de volwassen groep SHR.

In hoofdstuk VII wordt het extracellulaire vloeistofvolume als $51 \mathrm{Cr}$-EDTA verdelingsruimte gemeten. In 5 weken en 15 weken oude SHR treden geen significante verschillen op in het extracellulaire vloeistofvolume gemeten in vergelijking met de WKY van dezelfde leeftijd, hoewel in de jongste graep een $10 \%$ hoger volume wordt gemeten.

Uit deze gegevens worden twee conclusies getrokken:

1. Een toename van het extracellulaire vioeistofvolume ten gevolge van een verminderde natriumuitscheiding door de nier - zoals waargenomen bịj verschillende andere vormen van hypertensie - kan in de SHR niet met zekerheid worden aangetoond.

2. Het niet significant verhoogde extracellulair vloeistofvolume in combinatie met het verhoogde plasma volume wijst mogelijk op een veranderend Starling evenwicht in de capillairen van de 5 weken oude SHR (b.v. een verhoogde plasma oncotische druk).

In hoofdstuk VIII wordt de activiteit van het sympatische zenuwstelsel onderzocht in twee verschillende groepen van SHR van verschillende leeftijden en vergeleken met WKY van dezelfde leeftijd. Als parameter voor de activiteiten van de sympatische zenuwactiviteit wordt de plasma noradre. naline concentratie gekozen. In de jongste groep (5 weken oud) worden . geen verschillen in plasma noradrenaline concentratie tussen SHR en WKY gevonden, terwijl in de 15 weken oude SHR de plasma noradrenalime concentratie significant is verhoogd.

Hieruit wordt geconcludeerd dat de overall activiteiten van het sympathi. sche zenuwstelsel niet is verhoogd in de 5 weken oude SHR in vergelijking 
mel de WKY. De verhoogde sympathische activitelt in de volwassen SHR zou een adapatie kunnen ziln aan de verhoogde bloeddruk.

in het hoofdstuk IX wordt de betrokkenheid van het sympathische ze. nuwstelsell bil spontane hypertensie van de rat verder bestudeerd mell behulp van een zwemtraining gedurende de ontwikkeling van de hypertensie (van 4 tot 15 weken na de geboorte). Aan het einde wan deze trainingsperiode wordt geen verschil in plasma noradrenaline concentratie gevonden tussen getrainde en ongetrainde WKY,terwill in de getrainde SHR de verhoogde noradrenaline concentraties gedaald zijn tot waardes die bij de WKY gevonden worden. Deze normalisatie van plasma noradrenaline concentraties gaat gepaard met een kleine, doch significante daling van de systolische bloeddruk bij de getrainde SHR.

Uit deze gegevens wordt geconcludeerd dat een reductie in sympathische activitelten een rol speelt bil het bloeddruk-verlagend effect van training bij de SHA. Een normalisatie van plasma noradrenaline concentratie geeft echter geen normalisatie van de bloeddruk, zodat de resterende verhoogde systolische bloeddruk van de getrainde SHR waarschijnlijk berust op andere factoren dan een sympatische hyperactiviteit (b.v. structurele adaptaties van de weerstandsvaten).

De verschillende bevindingen in de individuele hoofdstukken geven aanleiding tot de volgende hypothese, die in hoofdstuk $X$ uitvoerig wordt besproken.

De spontane hypertensie begint met een verhoogde vaatweerstand in de nier, mogelljk als gevolg van een verhoogde sympathicus activiteit naar de preglomerulaire weerstandsvaten. Dit geeft aanleiding tot een retentie van water en zout, waardoor een verhoogd plasma volume ontstaat. Dit verhoogde plasma volume veroorzaakt -eventueel in combinatie met een veranderde activiteit van het autonome zenuwstelsel naar het hart- een verhoogd hartminuutvolume, waarna in een latere fase autoregulatie en/of structurele adaptaties van de vaatwand voor een verhoogde perifere weerstand zorgen. Blj dit laatste mechanisme moet niet alleen gedacht worden aan een vernauwing van weerstandsvaten, maar ook aan een vermindering van het aantal doorstroomde vaten. Tenslotte dient nog opgemerkt te worden dat spontane hypertensie bij ratten zich niet beperkt tot de weerstandsvaten maar dat ook caplllairen en venulae bij het proces betrokken zijn. In de toekomst zullen microcirculatie studies uitermate belangrijk zijn voor het verkrijgen van meer inzicht in de pathofysiologile van deze aandoening. 


\section{Curriculum vitae.}

Op 1 juli 1948 werd R.T. Evenwel geboren te Rotterdam. Het eindexamen HBS-B werd in 1968 behaald aan het Libanon Lyceum te Rotterdam. Na wegens plaatsgebrek een jaar als toehoorder te zljn ingeschreven aan de Medische Faculteit te Rotterdam werd in 1969 begonnen met de medische studie aan deze faculteit. In 1972 werd het Kandidaatsexamen behald met als keuzevak radiobialogie (TNO, Rijswijk). In 1976 werd het artsexamen met goed gevolg afgelegd, waarna een aanstelling volgde als assistent Interne Geneeskunde aan het Instituut voor Tropengeneeskunde (Havenziekenhuis) te Rotterdam. In 1977 volgde een aanstelling als wetenschappelijk medewerker aan de afdeling Farmacologie van de Rijksuniversiteit Limburg te Maastricht waar onder leiding van Prof. Dr. H.A.J. Struyker Boudier het in dit proefschrift beschreven onderzoek werd verricht.

Publicaties en samenvattingen waaraan werd medegewerkt:

1. Evenwel, R.T. en van Putten, L.M.:

Bescherming van beenmerg tegen halothaan;

Abstract 14e Federatieve Vergadering van Medisch Biologische Verenigingen, Groningen, 26 april (1973), p.26.

2. Evenwel, R.T. en van Putten, L.M.:

Effect of anaesthesia on bone marrow proliferation;

Proceeding of the 2nd meeting of the European Association for Cancer Research, Heidelberg 2-5 oktober (1973).

3. Evenwel, R.T., Keizer, H.J. en van Putten L.M.:

Preferential inhibition of DNA synthesis in mouse hemopoletic cells by Halothane. Cancer Research 36, 3156-3159 (1976).

4. Putten van, L.M., Keizer, H.J. and Evenwel, R.T.:

Resting cells and Cancer Biology

In: Growth kinetics and biochemical regulation of normal and malignant cells (Eds. B. Drewinko and R.W. Humphrey Williams and Wilkins, Baltimore, (1977), pp. 91-98.

5. Evenwell, R.T. and Struyker Boudier, H.A.J.:

Effect of physical training on the development of hypertension in the spontaneously hypertensive rat. Pflüg. Arch. 381, 19-24 (1979).

6. Evenwel, R.T. and Struyker Boudier, H.A.J.:

Effect of physical training on the development of hypertension in the SHR: Proceedings of the 20th Dutch Federation Meeting, Groningen, abstract 115, (1979).

7. Evenwel, R.T. and Struyker Boudier, H.A.J::

Effect of physical training on the development of hypertension in the SHR. Therapiewoche 29, $7722-7725$ (1979). 
8. Struyker Boudier, H.A.J., Evenwel, R.T., Smits, J.F.M. en Min, R.: Antihypertensleve geneesmiddelem: interacties met de regulatie van de bloeddruk.

In: Regulatie van de bloeddruk, (Ed. H.A.J. Struyker Boudier), Bunge, Utrecht, (1979), pp. 90-102.

9. Struyker Boudler, H.A.J., van Essen, H., Smits, J.F.M. and Evenwel, R.T.:

Exaggerated diuresis and natriuresis in conscious spontaneously hypertensive rats, Therapiewoche 29, $7740-7743$ (1979).

10. Struyker Boudier, H.A.J., Van Essen, H., Smits, J.F.M. and Evenwel, R.T.:

Baroreceptor reflex sensitivity in unrestrained conscious SHR and WKY. Proceedings of the 7th Meeting of the International Soclety of Hypertension, New Orleans, abstract 659 (1980).

11. Struyker Boudier, H.A.J., Smits, J.F.M. and Evenwel, R.T.: Exaggerated diuresis ans natriuresis in conscious SHR. Proceedings of the 7 th Meeting of the International Society of Hypertension, New Orleans, abstract 665 (1980).

12. Evenwel, R.T., Kasbergen, C. and Struyker Boudier H.A.J.: Abnormal distribution of plasma volume in the SHR.

Proceedings of the 4th International Symposium on SHR, Heidelberg (1981), p.18.

13. Evenwell, R.T., Smits, J.F.M. and Struyker Boudier, H.A.J.: Reduction of plasma norepinephrine in the SHR by physical training; Proceedings of the 4th International Symposium on SHR, Heldelberg, (1981), p.53.

14. Struyker Boudier, H.A.J., Smits, J.F.M., Evenwel, R.T. und Kleinjans, J.:

Alpha-methyldopa und das Sympathische Nervensystem bei der Hypertonie.

In: Alpha-Methyldopa (Eds. W. Kaufmann and G. Kronenberg). George Thieme Verlag, Stuttgard, (1981) pp. 35-45.

15. Struyker Boudier, H.A.d., Evenwel, R.T., Smits, J.F.M. and Essen, H. van:

Baroreflex sensitivity during the development of spontaneous hypertension in rats: Clin. Sci. in press (1982).

16. Evenwel, R.T., Verwoort-Peters, L., Smits, J.F.M. and Struyker Boudier, H.A.J.:

Reduction of plasma noradrenaline in the SHR by physical training In: International Symposilum on SHR and related studies (Ed. D. Ganten). Thieme Verslag, in press (1982). 